\title{
EINLEITUNG
}

\section{Forschungszusammenhang und analytischer Ansatz}

Im »Akkulturations«-Sog der Französischen Revolution ${ }^{1}$ begann der symbolische Siegeszug des öffentlichen Personendenkmals in Frankreich und von da aus bald in ganz Europa. Das plastische erhielt nicht nur neben dem architektonischen Denkmal einen eigenständigen Status im öffentlichen Stadtareal, es egalisierte zugleich die Berechtigung zum öffentlichen Monument zugunsten nicht-fürstlicher und nicht-dynastischer Figuren und lud deren Exponierung kultisch auf. Der Kult des großen Individuums, des Helden und grand homme, bezog sich zunehmend auf die Nation und das "Volk« als ihren neuen Souverän. Denkmalsturz und politisch-kultisches Fest mit neuen, eigenen Monumenten waren die destruktiven und innovativ-konstruktiven Kollektivakte, die die Thematisierung der Nation im öffentlichen Personendenkmal vorbereiteten $^{2}$.

Doch vorerst erlahmte der emanzipatorische Eifer rasch wieder. Die meisten der in der revolutionären Epoche projektierten Denkmäler für die grands hommes de la Nation blieben auch in Paris im Planungsstadium stecken. Zur revolutionären Symbolpolitik suchte Napoleon I. Distanz und ließ die Idee nationalen Ruhms bevorzugt im Selbstbild propagieren. Auf der Place Vendôme (Place des Piques) veranlaßte er die Errichtung einer mit seinem Standbild gekrönten Säule. Nicht nur hier, sondern auch mit weiteren Denkmälern für verdiente Militärs ${ }^{3}$ erschien der nationale Held nun als erfolgreicher Feldherr, der, gelegentlich auf hohem Sockel entrückt, die kriegsbewährte Nation personifizierte $^{4}$. Die 1814/15 restaurierte Bourbonenmonarchie trat an, den revolutionären Ikonoklasmus zu kompensieren. In dieser Absicht plazierte sie erneut die Reiterdenkmäler für Louis XIII. auf der Place Royale (heute Place des Vos-

1 Rolf REICHARDT, Für eine integrierte soziale Kulturgeschichte der Französischen Revolution durch Kommunikationssoziologie und historische Anthropologie, in: Reinhart KOSELLECK, DERS. (Hg.), Die Französische Revolution als Bruch des gesellschaftichen Bewußtseins, München 1988 (Ancien Régime. Aufklärung und Revolution, 15), S. 673684, hier S. 674.

2 Vgl. Annie Jourdan, Les Monuments de la Révolution 1770-1804: une histoire de représentation, Paris 1997.

3 Vgl. [An.,] Description de la Colonne de la Grande Armée et de la statue du Général Desaix, o. O. o. J. [1810].

4 Vgl. Maurice AGULHON, La »statuomanie« et l'histoire, in: Éthnologie française 8 (1978) S. $145-172$, hier S. 147. 
ges $)^{5}$, Louis XIV. auf der Place des Victoires ${ }^{6}$, und die Reiterstatue von Henri IV. auf dem Pont Neuf ${ }^{7}$. Während der Julimonarchie und der Zweiten Republik schließlich begann die Zahl öffentlicher, nun längst auch zivilen Personen gewidmeter Denkmäler, stetig zu steigen, bevor sie während der Dritten Republik nach 1871 zum ebenso ubiquitären wie vielbeklagten Ausdruck demokratisierter Nationalsymbolik avancierte.

In Deutschland offenbarten nach ersten Individualdenkmälern im Rahmen einer patriotischen Gartenkunst ${ }^{8}$ die öffentlichen Standbilder und Denkmalprojekte für Luther ${ }^{9}$ nach der Jahrhundertwende eine »Nazionaldenkmal«Ambition für nichtfürstliches Personendenkmal. Städtische Personendenkmäler häuften sich ab Ende der 1830er Jahre in den verschiedenen deutschen Einzelstaaten und beförderten die Verbürgerlichung bzw. Popularisierung des genialen Menschen ${ }^{10}$ als Inbegriff eines kulturzentrierten nationalen Selbstbildentwurfs. In Berlin vollzog sich anders als in Paris eine erste Demokratisierung der öffentlichen Denkmalidee nicht als revolutionärer Akt, sie wurde vielmehr als Versatzstück eines aufgeklärten Absolutismus monarchisch initiiert und gestiftet: Eine ganze Standbildgruppe von Generalen des Siebenjährigen Krieges auf dem Berliner Wilhelmplatz unterlief als nicht-fürstliches Denkmalensemble noch vor der Wende zum 19. Jahrhundert im städtischen Zentrum

5 Vgl. Anatole DE MONTAGLION, Notice sur l'ancienne statue équestre. Ouvrage de D. Ricciarelli et de Biard le Fils, élevée à Louis XIIl en 1639 au milieu de la Place Royale à Paris, Paris 1874.

6 Vgl. N.-L. MOREL, Description des nouvelle et ancienne statues de Louis XIV, inaugurée l'une le 28 mars 1686, et l'autre le 25 août 1822, Place des Victoires, o. O. o. J. [Paris 1822]; [An.,] Notice sur la Nouvelle statue équestre de Louis XIV, fondue d'après le modèle de M. Bosio, Paris 1822; Paul MarmotTan, Les statues de Paris, Paris o. J. [1886], S. 76-82.

7 Vgl. Ph. CHÉRY, Notes analytiques sur la statue équestre de Henri IV, érigée en bronze, sur la terre du Pont-Neuf, à Paris, Paris 1819; [An.,] Description de la nouvelle statue de Henri IV avec un fac-simile de l'écriture de ce bon roi, Paris 1819; [An.,] La statue de Henri IV. Nouveau Pont-Neuf. Sur le rétablissement et l'inauguration de la statue de Henri IV chanté et distribué le 15 août 1818 en l'honneur de la fête de S.M. Louis XVIII, o. O. o. J.

8 Vgl. dazu Gert MATTENKLOTT, ,Denk ich an Deutschland .... Deutsche Denkmäler 1790 1990, in: DERS. (Red.), Deutsche Nationaldenkmale 1790-1990, Bielefeld 1993, S. 17-48, hier S. 22.

9 Vgl Wilhelm WEBER, Luther-Denkmäler - Frühe Projekte und Verwirklichungen, in: Hans-Ernst MITTIG, Volker PlagemanN (Hg.), Denkmäler im 19. Jahrhundert. Deutung und Kritik (Studien zur Kunst des 19. Jahrhunderts, 20), München 1972, S. 183-215.

${ }^{10} \mathrm{Vgl}$. etwa während der 1830er Jahre die Denkmäler für Gutenberg in Mainz, Dürer in Nümberg, Schiller in Stuttgart, in den 1840er Jahren für Goethe in Frankfurt und für Beethoven in Bonn. Dazu bereits Franz SCHNABEL, Die Denkmalkunst und der Geist des 19. Jahrhunderts, in: Die Neue Rundschau 50 (1939) S. 415-436 und wieder in: Heinrich LUTZ (Hg.), Franz Schnabel: Abhandlungen und Vorträge 1914-1965, Freiburg, Basel, Wien 1970, S. 134-150. 
erstmals das Monopol des öffentlichen Herrscherdenkmals, dessen Erscheinungsform als Reiterdenkmal freilich weiter konkurrenzlos blieb ${ }^{11}$.

Pläne zur Ehrung der "Großen« der Nation kursierten schließlich in England nicht anders als in Frankreich und Deutschland bereits im ausgehenden 18. Jahrhundert, konzentrierten sich hier aber auf architektonische Bauvorhaben: Mit dem Temple of British Worthies in Stowe als einer Art Gallerie von WhigHeroen ${ }^{12}$ und dem Temple of Liberty in Woburn als Zentrum des frühen FoxKults ${ }^{13}$ entstanden nicht-dynastische, private $\gg$ Freundschaftsdenkmäler«, die stärker auf elitär-private Rezipientenzirkel beschränkt blieben. Bis mit der Plazierung der Duke of York-Column 1834 in London $^{14}$ neben den bereits zahlreichen Monarchenstatuen ${ }^{15}$ auch hier der Kriegsheros die Nation verkörperte, waren mit Fox, Pitt und Canning längst auch zivile Personen in der Kapitale zu "nationaler« Denkmalehre gekommen ${ }^{16}$. An der Manie monumentaler Symbolpolitik in nationaler Absicht hatte schließlich London nicht anders als Paris und Berlin vor allem nach der Jahrhundertmitte teil.

Die vorliegende Untersuchung faßt öffentliche Denkmalerrichtungen als Reflex einer an Intensität und argumentativer Differenzierung gewinnenden nationalen Debatte während der zweiten Hälfte des 19. Jahrhunderts auf. Sie konzentriert sich nicht auf die architektonischen Großprojekte der Epoche, sondern meidet die monumentale Gipfelwanderung zugunsten einer Synopse und symbolischen Topographie hauptstädtischer Personendenkmäler. Thr Gegenstand sind nicht die zeitgenössischen Ikonographien der Denkmäler, sondern zum einen eine einschlägige rituelle Praxis, zum anderen die dezidiert "nationale« Semantik im Wirkungsumfeld des monumentalen Personals. Unter diesen Vorgaben fragt sie aus vergleichender Perspektive nach Verfahren na-

"Vgl. Hans MACKOWSKY, Die vorbereitenden Entwürfe Schinkels und Rauchs zum Denkmale Friedrichs des Großen in Berlin, Inaugural-Dissertation, Berlin 1894, S. 13; Peter BLOCH, Denkmäler in Berlin. Rehabilitierung und Restaurierung, in: Jahrbuch Preußischer Kulturbesitz JbPK 13 (1976) S. 45-70, hier S. 47.

12 Vgl. Meinhold LuRZ, Kriegerdenkmäler in Deutschland, Bd. 1: Befreiungskriege, Heidelberg 1985, S. $56 f$.

13 Zur Anlage in Woburn von Henry Holland vgl. N.B. PENNY, The Whig cult of Fox in early nineteenth-century sculpture, in: Past and Present (P\&P) 70 (1976) S. 94-105, hier S. $96 \mathrm{f}$.

14 Vgl. die umfangreiche Dokumentation in PRO Work 20/39 Duke of York's Column. 1849 und 1910 und PRO Work 20/6/1 Duke of York Memorial. 1827-1850. Committee; und [An.,] A tribute of high respect and gratitude to His Royal Highness the Duke of York, London o. J.

15 Etwa zum 1836 an Cockspur Street nahe des Trafalgar Square eingeweihten Denkmal für George III. vgl. Correspondence and documents respecting the proposed monument to the memory of His Late Majesty King George III. Printed form the Committee Books. For the use of the Committee alone, London 1822.

$16 \mathrm{Vgl}$. Thomas HARRAL, The Apotheosis of Pitt, or, The crowning of the statue. A Masque, London, Bury St. Edmund's 1822. Vgl. allgemein John BLACKWOOD, London's immortals. The complete outdoor commemorative statues, London 1989, S. 173,174 und 178. 
tionaler Sinnstiftung und Konditionen öffentlicher Sinnaneignung und identifiziert thematische Konjunkturen und kultische Dissoziierungen im zeitgenössischen Denkmalkult als wesentliche Teile eines symbolischen Diskurses über die Nation.

\section{Verortungen}

\subsection{Nationalismustheorien und Nationalsymbolik}

Bevor öffentliche Monumente und ihre Inszenierung untersucht werden, ist zu klären, welche zentralen Thesen und Vorannahmen die Nationalismusforschung ${ }^{17}$ zum Phänomen nationaler Symbole im allgemeinen und öffentlicher Denkmäler im besonderen bereithält. So kann eingeschätzt werden, welchen Erkenntniszugewinn die Denkmalanalyse für die drei Nationalismen erwarten läßt.

An einige Theoriebildungen zum Nationalismus läßt sich nicht anknüpfen. Dies gilt erstens für den modernisierungstheoretischen Ansatz Ernest Gellners, wonach die Nationsbildung eine Funktion der Industrialisierung darstellt und primär den Bedarf an einer homogenen »high culture $«$ deckt ${ }^{18}$. Motivation und Logik der Bildung von Nationen liegen so außerhalb ihrer selbst. Überhaupt erschöpft sich hier die Bedeutung von Nationen darin, Reflexionsflächen für auf anderen Strukturebenen ablaufende Prozesse darzustellen ${ }^{19}$. Der Frage, ob und wie Homogenitätserfordernisse ausreichen, um der Nationsidee weithin Akzeptanz zu verschaffen, geht Gellner nicht nach ${ }^{20}$.

Dies gilt zweitens auch für politikwissenschaftliche Ansätze $\mathrm{e}^{21}$ wie denjenigen John Breuillys ${ }^{22}$, der die Frage nach Kollektividentitäten in nationalen Bewegungen als "misleading idea« ausdrücklich aus dem unmittelbaren Ziel-

17 Vgl. grundlegend Anthony D. SMTTH, Nationalism and modernism. A critical survey of recent theories of nations and nationalism, London und New York 1999; Dieter LANGEWIESCHE, Nation, Nationalismus, Nationalstaat: Forschungsstand und Forschungsperspektiven, in: NPL 40 (1995) S. 190-236.

Ernest GELLNER, Nations and Nationalism, Oxford 1983, ND 1990, S. 46.

19 Vgl. ibid. S. 55: „It is nationalism which engenders nations, and not the other way round."

${ }^{20}$ Vgl. zur Kritik an dieser Leerstelle der Theorie auch Anthony D. SMITH, State-Making and Nation-Building, in: John A. HALL (Hg.), States in History, Oxford u. a. 1986, S. 228 263, hier S. 232 und Helmut KUZMICS, Einleitung. Nationalismus, Nationalstaat und Nationalcharakter in zivilisationstheoretischer Sicht, in: DERS., Reinhard BLOMERT, Anette TREBEL (Hg.), Transformationen des Wir-Gefühls. Studien zum nationalen Habitus, Frankfurt a. M. 1993, S. 7-41, hier S. 26.

21 Vgl. etwa Rogers BRUBAKER, Citizenship and Nationhood in France and Germany, Cambridge, Mass., London 1992, hier S. 10-17.

22 Vgl. John BREUILLY, Nationalism and the state, Manchester 1982, S. 1-11 und S. 359. 
horizont seiner Untersuchung ausgeklammert ${ }^{23}$. Gegen sie wird der Vorwurf erhoben, nur zum Spekulieren über soziale Psychologien zu verleiten ${ }^{24}$. Für Breuilly verweist statt dessen nationale Symbolik niemals auf eine eigenrationale "Nation $\aleph^{25}$. Eine (Denkmal)Symbolanalyse ließe sich beiden Theorien zufolge kaum als substantieller Beitrag zur Nationalismusforschung begründen.

Zentral für die vorliegende Fragestellung ist demgegenüber zum einen das »Invention of tradition «-Konzept von Eric Hobsbawm und Terence Ranger ${ }^{26}$, wonach Nationen als Phänomene mit einem hohen Anteil an sartefact, invention and social engineering « aufgefaßt werden ${ }^{27}$. Daher wird die Analyse der winvented traditions « empfohlen und also jener symbolischen Praxis, die nationalen Sinn postuliert und eine nationale Vergangenheit beschwört ${ }^{28}$. Folglich hat Hobsbawm nicht nur Symbole wie Flaggen, Hymnen, Personifikationen und Stereotypen als Vehikel nationaler $»$ Erfindung ${ }^{29}$ sondern auch Dispute über Denkmalsetzungen als Indizien für Kämpfe um Deutungshoheiten über die nationale Geschichte ausgemacht ${ }^{30}$. Ähnliche Aspekte unterstreicht zum anderen Benedict Anderson, demzufolge die Nation als simagined community ${ }^{31}{ }^{2} \mathrm{zu}$ bezeichnen ist, da sie - eigentlich eine inkommensurable Größe - überhaupt nur als begrenztes, souveränes und egalitäres Kollektiv imaginiert werden kann und $m u \beta^{32}$. Der in beiden Modellen zentrale Hinweis auf den Artefaktcharakter von Nationen läßt eine Untersuchung öffentlicher Denkmal-

23 Vgl. ibid. S. 1-2.

24 Vgl. ibid. S. 32-34.

25 Vgl. ibid. S. 382-384.

${ }^{26}$ Als Beispiel für ihre weitreichende, zum Teil allerdings eher implizite Rezeption auch in der deutschen Historiographie vgl. u. a. Hagen SCHULZE, Staat und Nation in der europäischen Geschichte, München 1994, ND 1999, S. 111.

27 Eric John HoBSBAWM, Nations and Nationalism since 1780. Programme, myth, reality, Cambridge $1990,{ }^{2} 1997$, S. $8-11$ und 130.

28 Vgl. DERS., Introduction: Inventing traditions, in: DERS., Terence RANGER (Hg.), The invention of tradition, Cambridge 1983, ND 2000, S. 1

29 Ibid. S. 7 und 11.

30 Vgl. DERS., Mass-producing Traditions: Europe, 1870-1914, in: DERS., RANGER (Hg.), The invention of tradition, S. 263-307, hier zu Denkmälern in Deutschland, S. 264, 275278, zu Frankreich S. 270-273; englische Denkmäler werden nicht erwähnt. Die erfundenen Traditionen der europäischen Nationalismen werden vorläufig jenseits institutionellen Oktrois zum einen oder unwillkürlicher Spontaneität zum anderen in einem historischanalytisch erst noch auszulotenden Bereich populärer Bedürfnisse (felt needs) und kollektiver Dispositionen zur Aneignung nationaler Deutungsmuster verortet; vgl. ibid. S. 307.

31 Vgl. zum Begriff der »gedachten Ordnung « in Anlehnung an Etienne FRANÇOIS, M. Rainer LEPSIUS, Nation und Nationalismus in Deutschland, in: Heinrich A. WNKLER (Hg.), Nationalismus in der Welt von heute, Göttingen 1982 (Geschichte und Gesellschaft [GG] Sonderheft 8), S. 12-27, hier S. 13.

$32 \mathrm{Vgl}$. Benedict ANDERSON, Imagined communities. Reflections on the origin and spread of nationality, London ${ }^{2}$ 1991, S. 7 [dt.: Die Erfindung der Nation. Zur Karriere eines folgenreichen Konzepts, Frankfurt, New York 1996]. 
figuren als vorgestellten Repräsentanten des Nationalen gut begründbar erscheinen. Allerdings belassen beide Ansätze einen durchaus weiten Deutungsraum für die vorgestellte Nation, der für nahezu kontextlose Erfindung, Revitalisierung oder Transformierung traditional verankerter Bezugsgrößen offen is $^{33}$. In welchem Maße und mit welchem Erfolg bestimmte Figuren und Denkmalinszenierungen die Nation erfunden haben, bleibt noch zu sehen.

Solcher Bestimmungslücken wegen ist zum dritten die Weiterführung hilfreich, die Andersons Ansatz bei Alon Confino gefunden hat: Confino verzahnt die These von der simagined community « mit Halbwachs' Theorie zum Kollektivgedächtnis ${ }^{34}$ und interpretiert im Sinne einer theoretischen Engführung beider Erklärungsmodelle die Nationsbildung im Deutschen Reich nach 1871 - anhand eines ubiquitären, apolitischen Heimatbildes - als einen ikonographischen Prozeß. Daß visuelle Konkretion, wie sie auch in den öffentlichen Personendenkmälern erfolgt ist, für die Aneignung eines gesamtstaatlichen Nationsbewußtseins (»sense of national belonging $\left(\right.$ ) von zentraler Bedeutung ist ${ }^{35}$, wird so plausibel. Ebenso wird hier plausibel, daß Nationswerdung nicht nur als programmatisch-rationaler, sondern auch wesentlich ästhetisch-affektiv geprägter Prozeß zu beschreiben ist, auch wenn die tatsächliche Aneignung nationaler Sinnstiftungsangebote im Rahmen öffentlicher Denkmäler damit noch nicht abschließend erfaßt ist.

Der hier vorgelegte transnationale Vergleich von Denkmalsymboliken orientiert sich daher besonders an politik- und kulturzentrierten Forschungsansät-

33 Der von Smith, Nationalism and Modernism, S. 130, erhobene Vorwurf, im Extremfall lasse Hobsbawms Modell auch den Fall der winvention《 als "fabrication and/or creation e $x$ n i h i l o« [H. i. O.] zu, scheint aber überzogen. Vgl. kritisch auch Hans-Ulrich WEHLER, Nationalismus. Geschichte, Formen, Folgen, München 2001, S. 37. In der Tat sieht HOBSBAWM, The invention, S. 11, das Spezifikum der emotional und symbolisch aufgeladenen nationalen Zeichen darin, eine »undefined universality « aufzuweisen. Damit werden aber nicht die Zeichen als beliebig, sondern die Reichweite zuerkannter Bedeutungen als universal bestimmt. Geglückt scheint demgegenüber die Diagnose einer "synkretistischen Flexibilität" nationalistischer Deutungsmuster; vgl. Peter WALKENHORST, Der »Daseinskampf des Deutschen Volkes«: Nationalismus, Sozialdarwinismus und Imperialismus im wilhelminischen Deutschland, in: Jörg ECHTERNKAMP, Sven Oliver MÜller (Hg.), Die Politik der Nation. Deutscher Nationalismus in Krieg und Krisen, 1760-1960, München 2002 (Beiträge zur Militärgeschichte, 56), S. 131-148, hier S. 131. Vgl. auch James J. SHEEHAN, The problem of the Nation in German History, in: DERS., Otto BƯSCH (Hg.), Die Rolle der Nation in der deutschen Geschichte und Gegenwart, Berlin 1985, S. 3-20, hier S. 4. Vgl. dazu weiter unten.

35 Vgl. Alon CONFINO, The Nation as a local metaphor. Württemberg, Imperial Germany, and national memory, 1871-1918, Chapel Hill und London 1997, S. 3-15, hier besonders S. 3f. und 10. Vgl. auch DERS., The Nation as a local metaphor: Heimat, National memory and the German Empire, 1871-1918, in: History and Memory 5 (1993) S. 42-86, hier S. 42-47 und DERS., Die Nation als lokale Metapher: Heimat, nationale Zugehörigkeit und das Deutsche Reich 1871-1918, in: ZGW 44 (1996) S. 421-435. 
zen. Die von der politischen Nationalismustheorie dringlich gemachte politische und institutionelle Einordnung wird als unerläßliche Ergänzung für den Invention of tradition-Ansatz erachtet, der umgekehrt den Vorteil bietet, auf die zentrale Indikatorfunktion von Symbolen, Mythen und rituellen Erinnerungsakten als Zeichen und Verfahren kollektiver Selbstbildschöpfung zu verweisen. Zugleich soll unter Nation als analytischer Begriff ein zeitgenössisch gedachtes, aber nicht willkürlich erfundenes, gesellschaftlich und politisch verankertes Phänomen verstanden werden, das unter anderem in der Inszenierung und programmatischen Aufladung von Denkmalfiguren zum Ausdruck gekommen ist.

\subsection{Nationale Denkmalkultur als Gegenstand einer kulturgeschichtlichen Nationalismusforschung}

Lehnt sich die vorliegende Untersuchung thematisch an die Nationalismusforschung an, so greift sie konzeptionell gleichermaßen auf kultur- wie mentalitätsgeschichtliche Grundannahmen zurück. Zunächst wird die Wirkungsweise öffentlicher Denkmäler im Bereich der »Kultur« als einem »subjektiven« Verfahren der Bedeutungszuweisung durch historische Akteure veranschlagt ${ }^{36}$. Zugleich werden "symbolische Manifestationen « im allgemeinen und das "politische Denkmal« im besonderen als Niederschlag von sozial konstituierten, handlungsrelevanten und strukturbedingt veränderlichen Wahrnehmungsmustern aufgefaß $\mathrm{t}^{37}$. Entsprechend sind die Denkmalsymboliken auf implizite Werthaltungen und Deutungsmuster hin transparent zu machen ${ }^{38}$.

Damit bleiben die für die Kulturgeschichte generell zentralen Ansätze auch für den Denkmalvergleich wichtig. Erstens ist im Rückgriff auf die hermeneutische Ethnologie nach Clifford Geertz beabsichtigt, soziale Praktiken im Umfeld von Denkmalerrichtungen vor dem Hintergrund möglichst präziser Detail-

36 Vgl. als Überblick Ute DANIEL, »Kultur« und »Gesellschaft«, Überlegungen zum Gegenstandsbereich der Sozialgeschichte, in: GG 19 (1993) S. 69-99.

37 Vgl. Volker SELLIN, Mentalitäten in der Sozialgeschichte, in: Wolfgang SCHIEDER, DERS. (Hg.), Sozialgeschichte in Deutschland. Entwicklungen und Perspektiven im internationalen Zusammenhang, Bd. 3, Göttingen 1987, S. 101-122, hier S. 101-105 und 116; DERS., Mentalität und Mentalitätsgeschichte, in: Historische Zeitschrift (HZ) 241 (1985) S. 555598. Vgl. weiter Frank-Michael KUHLEMANN, Mentalitätsgeschichte. Theoretische und methodische Überlegungen am Beispiel der Religion im 19. und 20. Jahrhundert, in: HARDTWIG, WEHLER (Hg.), Kulturgeschichte Heute, S. 182-211, hier S. 183f. und Olaf BLASCHKE, Frank-Michael KUHLEMANN, Religion in Geschichte und Gesellschaft. Sozialhistorische Perspektiven für die vergleichende Erforschung religiöser Mentalitäten und Milieus, in: DIES. (Hg.), Religion im Kaiserreich. Milieus - Mentalitäten - Krisen, Gütersloh 1996 (Religiöse Kulturen der Moderne, 2), S. 7-56, hier S. 12-21.

38 Vgl. v.a. Charles DuBY, L'histoire culturelle, in: Révue de l'enseignement supérieur $n^{\circ} 44$ 45 (1969); jetzt neu in Jean-Pierre RIOUX, Jean-François SIRINELLI (Hg.), Pour une historie culturelle, Paris 1997, S. 427-432, hier S. 429f. 
beobachtung als Selbstaussagen der Akteure zu lesen ${ }^{39}$. Zweitens wird im Sinne der kultursoziologischen Sichtweise Pierre Bourdieus darauf geachtet, wie soziale Gruppen sich im permanent stattfindenden symbolischen Kampf um die legitime Weltsicht durchzusetzen und also Deutungsmacht zu erlangen versuchen $^{40}$, die zwar nicht einfach sozioökonomische Machtbeziehungen abbildet, aber auch nicht gänzlich unabhängig von ihnen gewonnen werden kann ${ }^{41}$. Von daher werden den Denkmalfesten als Akten der "Definition von [nationalen] Werten, Symbolen, Bedeutungen« analysierbare Bedeutungen unterstellt und das Rivalisieren um den öffentlichen Raum und um anerkannte nationale »Legitimationsmuster« als einer ihrer Grundzüge ausgemacht ${ }^{42}$.

${ }^{39} \mathrm{Vgl}$. Clifford GEERTZ, Thick description: towards an interpretative theory of culture, in: DERS., The Interpretation of cultures, selected essays, New York 1973, ${ }^{27} 1994$, S. 3-30, hier S. 14f., 17, 20, 24-27. Vgl. zur Geertz-Rezeption Richard VAN DULMEN, Historische Anthropologie in der deutschen Sozialgeschichtsschreibung, in: Geschichte in Wissenschaft und Unterricht (GWU) 42 (1991) S. 692-709, hier S. 695f. und kritisch Hans-Ulrich WEHLER, Alltagsgeschichte. Königsweg zu neuen Ufern oder Irrgarten der Illusionen?, in: Aus der Geschichte lernen, München 1988, S. 130-151, hier S. 141; William H. SEWELL $\mathrm{J}_{\mathrm{r}}$., Geertz, Cultural systems, and history: from synchrony to transformation, in: Representations 59 (1997) S. 35-55, hier S. 36f. und 46. Die moderne Kulturgeschichte rekurriert inzwischen auf eine Art "modifizierten Geertz", indem sie seinen überdehnten Kulturbegriff und seine Abstraktion vom Sozialhandeln meidet.

${ }^{40}$ Vgl. Pierre BOURDIEU, Sozialer Raum und »Klassen«, Leçon sur la leçon, zwei Vorlesungen, Frankfurt a. M. ${ }^{2} 1991$, S. 9-46, hier S. 11 und 16-19.

41 Vgl. DERS., Social space and symbolic power, in: DERS., In other words. Essays towards a reflexive sociology, Cambridge 1990, S. 123-139, hier S. 135. Vgl. kritisch Roger CHARTIER, Die Welt als Repräsentation, in: Matthias MIDDELL (Hg.), Alles Gewordene hat Geschichte, Leipzig 1994, S. 320-355; Ian MACLEAN, Bourdieu's field of cultural production, in: French Cultural Studies 4 (1993) S. 283-289, hier S. 285f.; Ingrid GILCHER-HOLTEY, Kulturelle und symbolische Praktiken: das Unternehmen Pierre Bourdieu, in: HARDTWIG, WEHLER (Hg.), Kulturgeschichte Heute, S. 111-130, hier S. 122; Sven REICHARDT, Bourdieu für Historiker? Ein kultursoziologisches Angebot an die Sozialgeschichte, in: Thomas MERGEL, Thomas WELSKOPP (Hg.), Geschichte zwischen Kultur und Gesellschaft. Beiträge zur Theoriedebatte, München 1997, S. 71-93, hier S. 86-88

42 Vgl. Wolfgang KASCHUBA, Kulturalismus: Kultur statt Gesellschaft?, in: GG 21 (1995) S. 80-95, hier S. 87; Reinhard SIEDER, Sozialgeschichte auf dem Weg zu einer historischen Kulturwissenschaft, in: GG 20 (1994) S. 445-468, hier S. 449, 466; Jürgen KOCKA, Sozialgeschichte der neunziger Jahre, in: Die neue Gesellschaft/Frankfurter Hefte 40 (1993) S. 1125-1129, hier S. 1129; Lothar GALL, Das Argument der Geschichte. Überlegungen zum gegenwärtigen Stand der Geschichtswissenschaft, in: HZ 264 (1997), S. 1-20, hier S. 13-19; Hans Ulrich WEHLER, Rückblick und Ausblick - oder: arbeiten, um überholt zu werden?, in: Paul NOLTE, Manfred HeTTLNG (Hg.), Perspektiven der Gesellschaftsgeschichte, München 2000, S. 159-168, hier S. 164f.; Carola LIPP, Kulturgeschichte und Gesellschaftsgeschichte - Mißverhältnis oder glückliche Verbindung?, in: Ibid. S. 25-35, hier S. 28 und 32f,; Antoine PROST, Sociale et culturelle, indissociablement, in: Jean-Pierre RIOUX, Jean-François SIRINELli (Hg.), Pour une histoire culturelle, Paris 1997, S. 131-146, hier S. 138f. und 143. 
Diesen Aspekt von Dynamik und Dissens unterstreicht auch die Zuordnung von Denkmälern, ihren Feiern und Deutungen zur "politischen Kultur ${ }^{43}$, in deren Rahmen mitunter eine konkurrierende - etwa ikonographische ${ }^{44}$ "Gegenkultur« geprägt oder Teilen der Gesellschaft die Zugehörigkeit zur geltenden (nationalen) Kultur bestritten wird ${ }^{45}$. Für Frankreich hat Robert Gildea bereits nicht nur kollidierende Ansprüche auf die verbindliche Definition nationaler Vergangenheit als Kennzeichen der politischen Kultur ausgemacht, sondem auch öffentliche Denkmalsetzungen für Kultfiguren (»cult figures«) als zentrales zeitgenössisches Phänomen dieser Deutungsrivalität zwischen verschiedenen Gruppen der französischen Gesellschaft im 19. Jahrhundert identifiziert ${ }^{46}$.

Zuletzt wird davon ausgegangen, daß die Denkmalsetzer in allen drei Fällen eine spezifische nationale $» I d e n t i t a ̈ t{ }^{47} \mathrm{zu}$ generieren versuchten oder ein

43 Vgl. Karl RoHE, Politische Kultur und ihre Analyse. Probleme und Perspektiven der politischen Kulturforschung, in: HZ 250 (1990) S. 321-346, hier S. 326, 333, 336f. und 343 und Jean-François SIRINELLI, Politische Kultur und nationale Emotionen, in: FrançoIS (Hg.), Nation und Emotion, S. 393-395. Vgl. ähnlich Lynn HuNT, Politics, culture, and class in the French Revolution, Berkeley 1984, S. 12f. [dt.: Symbole der Macht, Macht der Symbole. Die Französische Revolution und der Entwurf einer politischen Kultur, Frankfurt 1989].

44 Vgl. z.B. Beatrix W. BoUVIER, Es wird kommen der Mai ... Zur Ikonographie des Arbeitermai im Kaiserreich, in: Archiv für Sozialgeschichte (AfS) 33 (1993) S. 570-585, hier S. 571; Monika WAGNER, Lebende Denkmäler in den Maifeiem der Sozialdemokratie um 1900, in: Michael DIERs (Hg.), Mo(nu)mente, Berlin 1993, S. 93-112, hier S. 105, 109; Manuel FREY, Tugendspiele. Zur Bedeutung der »Tableaux vivants « in der bürgerlichen Gesellschaft des 19. Jahrhunderts, in: Historische Anthropologie 6 (1998) S. 401-430, hier S. 425 .

${ }^{45}$ Vgl. Roland POSNER, Kultur als Zeichensystem. Zur semiotischen Explikation kulturwissenschaftlicher Grundbegriffe, in: Aleida ASSMANN, Dietrich HARTH $(\mathrm{Hg}$.), Kultur als Lebenswelt und Monument, Frankfurt a. M. 1991, S. 37-74; Markus REISENLEITNER, Kulturgeschichte auf der Suche nach dem Sinn. Überlegungen zum Einfluß poststrukturalistischer Theoriebildung auf moderne Kulturgeschichtsschreibung, in: Österreichische Zeitschrift für Geschichtswissenschaft 3 (1992) S. 7-30, hier S. 9, 12 und 19.

46 Vgl. Robert GLDEA, The Past in French History, New Haven und London, 1994, S. 9-12; kritisch dazu Alon CONFINO, Collective Memory and Cultural history: Problems of method, in: The American Historical Review (AHR) 102 (1997) S. 1386-1403, hier S. 1400. Vgl. zum Begriff des Gegenkults auch Maurice AGULHON, Die nationale Frage in Frankreich: Geschichte und Anthropologie, in: Etienne FRANÇOIS, Hannes SIEGRIST, Jakob VOGEL (Hg.), Nation und Emotion. Deutschland und Frankreich im Vergleich. 19. und 20. Jahrhundert, Göttingen 1995, S. 56-65, hier S. 60.

47 Vgl. Rudolf VON THADDEN, Aufbau nationaler Identität. Deutschland und Frankreich im Vergleich, in: Bernhard GIESEN (Hg.), Nationale und kulturelle Identität: Studien zur Entwicklung des kollektiven Bewußtseins in der Neuzeit, Frankfurt a. M. 1991, S. 493-512, hier S. 496-498; Shmuel Noah EISENSTADT, Die Konstruktion nationaler Identitäten in vergleichender Perspektive, in: ibid. S. 21-38, hier S. 21-24; Aleida ASSMANN, Zum Problem der Identität aus kulturwissenschaftlicher Sicht, in: Rolf LINDNER (Hg.), Die Wiederkehr des Regionalen. Über neue Formen kultureller Identität, Frankfurt, New York 1994, S. 13-35, v.a. S. 16, 22-26; Linda COLLEY, Britishness and Otherness: an argument, in: 
Selbstbild ${ }^{48}$, das sich allerdings aus sehr unterschiedlichen regionalen oder lokalen, religiösen, klassen-, geschlechts- und altersspezifischen Loyalitäten zusammensetzte. Mithin blieben die propagierte nationale Kollektividentität und die erheblich disparateren individuellen Dispositionen gesellschaftlicher Gruppen in doppelter Weise in einem Spannungsverhältnis: indem beide in Wechselwirkung mit sozialen und politischen Strukturen veränderbar blieben ${ }^{49}$ und indem die reklamierte nationale durchaus mit anderen Parallelloyalitäten konkurrierte. Die kulturgeschichtlichen Thesen legen bereits nahe, daß zeitgenössische Denkmal- und Kultstifter eine ebenso heterogene wie flexible nationale Loyalität zu provozieren oder zu kanalisieren versuchten ${ }^{50}$.

\subsection{Denkmal, Fest und Nation. Historische Denkmal- und Festforschung in drei Historiographien}

\subsubsection{Zum Forschungsstand in Deutschland}

Die historische Denkmalforschung hat sich in den Historiographien der berücksichtigten Länder unter höchst unterschiedlichen Prämissen entwickelt. Forschungsstand und Forschungsinteresse befinden sich in einer bemerkenswerten Schieflage. Die historisch-kritische Analyse öffentlicher Denkmäler im Sinne einer spezifischen nationalen Symbolik beginnt in der deutschen Historiographie mit Theodor Schieder. Seine These vom kaiserzeitlichen National-

Ronald G. ASCH (Hg.), Three nations - a common history?: England, Ireland and British History c. 1600-1920, Bochum 1993, S. 273-296, hier S. 279, Ralph GIBSON, The intensification of national consciousness in modern Europe, in: Claus BJøRN, Alexander GRANT, Keith J. STRINGER (Hg.), Nations, nationalism and patriotism in the European Past, Kopenhagen 1994, S. 177-188; Heinz-Gerhard HAUPT, Die Konstruktion der Regionen und die Vielfalt der Loyalitäten im Frankreich des 19. und 20. Jahrhunderts, in: Günther LOTTES (Hg.), Region, Nation, Europa. Historische Determinanten der Neugliederung eines Kontinents, Heidelberg, Regensburg 1992, S. 121-126.

$48 \mathrm{Vgl}$. Michael JEISMANN, Was bedeuten Stereotypen für nationale Identität und politisches Handeln?, in: Jürgen LNN, Wulf WULFING (Hg.), Nationale Mythen und Symbole in der zweiten Hälfte des 19. Jahrhunderts. Strukturen und Funktionen von Konzepten nationaler Identität, Stuttgart 1991, S. 84-93, hier S. 88, 90f.

49 Vgl. so in Anlehnung an Heinz-Gerhard HAUPT, Charlotte TACKE: Die Kultur des Nationalen. Sozial- und kulturgeschichtliche Ansätze bei der Erforschung des europäischen $\mathrm{Na}$ tionalismus im 19. und 20. Jahrhundert, in: HARDTWIG, WEHLER (Hg.), Kulturgeschichte heute, S. 255-283, hier S. 266.

50 Vgl. FrançOIS, SIEGRIST, VoGEL, Die Nation. Vorstellungen, Inszenierungen, Emotionen, in: DIES. (Hg.), Nation und Emotion, S. 13-35, hier S. 15-19. Eine rigorose Demontage des Begriffs der Kollektividentität, der normativ aufgeladen und auf zu Kollektivsubjekten stilisierte soziale Entitäten übertragen worden sei, unternimmt Lutz NIETHAMMER, Kollektive Identität. Heimliche Quellen einer unheimlichen Konjunktur, Reinbeck b.Hamburg 2000. Dem Einwand wird durch die oben entwickelte Begriffsdefinition Rechnung getragen werden, die den Aspekt von Inhomogenität und Subjektivität der individuellen wie Gruppen-Wahrnehmung berücksichtigt. 


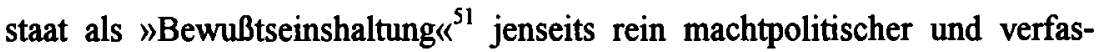
sungsrechtlicher Erscheinungsformen antizipierte ebenso kulturhistorische Fragestellungen wie seine an die Interpretation mittelalterlicher Herrschaftszeichen angelehnte Betrachtung öffentlicher Denkmäler neben der Untersuchung von Reichs- und Kaisertitel, Hymnen, Feiertagen, Fahnen und Kokarden wesentliche Ansatzpunkte für die später intensivierte historische Fest- und Symbolforschung geliefert hat. Dabei wirken Schieder zufolge nationale Symbole im Gegensatz zu den traditionalen Herrschaftszeichen der monarchischen Fürstenstaaten als "ständige Stimulantia« zugunsten eines »Nationalbewußtseins" und nationaler "Gefühlswerte ${ }^{52}$. Elisabeth Fehrenbach weitete den Blick auf die Nationalsymbolik international vergleichend aus ${ }^{53}$. Noch in den 1960er Jahren hat Thomas Nippperdey die methodische Reflexion zugunsten einer ausschließlichen Verhandlung deutscher Monumente im 19. Jahrhundert verdichtet ${ }^{54}$, während interdisziplinäre Forschungsunternehmungen von Historikern und Kunsthistorikern methodisch heterogene Ansätze im Rahmen empirischer Fallstudien ausgearbeitet haben ${ }^{55}$. Darüber hinaus sind auch Aspekte der organisatorisch-institutionellen Rahmenbedingungen der Kunstverwaltung in Deutschland als Kontext für den öffentlichen Denkmalbau behandelt worden ${ }^{56}$. Die Geschichtswissenschaft hat von der auf Stilentwicklungen und ikonographische Analysen konzentrierten, insbesondere Berlin gewichtenden kunsthistorischen Forschung zu öffentlichen Denkmälern profitieren können ${ }^{57}$.

Ganz aus dem Bereich der Kunstgeschichte stammen schließlich auch diejenigen Beiträge zu einer dezidiert politischen Ikonographie, die auf dem Wege

51 Theodor SCHEDER, Das deutsche Kaiserreich von 1871 als Nationalstaat, hg. von HansUlrich WEHLER, Göttingen ${ }^{2} 1992$ [erstmals 1961], S. 17.

52 Ibid. S. 82.

53 Vgl. Elisabeth FEHRENBACH, Über die Bedeutung der politischen Symbole im Nationalstaat, in: HZ 213 (1971) S. 296-357 insbesondere zur Rolle von Hymnen und Flaggen in den europäischen Nationalismen.

$54 \mathrm{Vgl}$. dazu unten.

s5 Vgl. MITTIG, PLAGEMANN (Hg.), Denkmäler im 19. Jahrhundert.

${ }^{36}$ Vgl. Ulrich SCHEUNER, Die Kunst als Staatsaufgabe im 19. Jahrhundert, in: Ekkehard MAI, Stephan WAETZOLDT (Hg.), Kunstverwaltung, Bau- und Denkmalpolitik im Kaiserreich (Kunst, Kultur und Politik im deutschen Kaiserreich, 1), Berlin 1981, S. 13-46; Wolfgang BRUCKNER, Zugänge zum Denkmalwesen des 19. Jahrhunderts. Kollektive Trägerschaften und populäre Formen des Gedenkens, in: Ekkehard MAL, Gisela SCHMIRBER (Hg.), Denkmal - Zeichen - Monument: Skulptur und öffentlicher Raum heute, München 1989, S. 13-18.

57 Vgl. Peter BLOCH, Waldemar GRZMMEK, Die Berliner Bildhauerschule im 19. Jahrhundert. Das klassische Berlin, Frankfurt a. M., Berlin, Wien 1978, Berlin ${ }^{2} 1994$ sowie zahlreiche Beiträge in Peter BLOCH, Sibylle EINHOLz, Jutta vON SIMSON (Hg.), Ethos und Pathos. Die Berliner Bildhauerschule 1786-1914. Beiträge, Berlin 1990 (AK). Vgl. auch Ries ROOWAAN, Nationaldenkmäler zwischen Geschichte und Kunstgeschichte, in: Archiv für Kulturgeschichte (AKG) 78 (1996) S. 453-466, hier v.a. S. 454-457. 
einer »kritischen Denkmaltopographie« Beziehungen zwischen öffentlichen Denkmälern im Sinne eines flächendeckenden Monumentalprogramms herzustellen versuchten ${ }^{58}$. Schließlich sind aus soziologischer Perspektive öffentliche (Landschafts-)Denkmäler als Symptome einer bürgerlichen »Kulturidee« vom Nationaldenkmal verhandelt worden, deren Formung allerdings überwiegend im 18. Jahrhundert und ohne Hinweis auf soziale Praktiken in ihrem Umfeld verfolgt wird ${ }^{59}$.

Generell ist für die deutsche Forschung die sozialhistorische wie ikonographische Aspekte berücksichtigende Studie von Nipperdey ${ }^{60}$ grundlegend geblieben, die erstmals eine freilich auf den deutschen Betrachtungsrahmen fixierte und nicht europäisch kompatible Denkmaltypologie enthält ${ }^{61}$. Auch andere Typologien bieten keine analytische Vergleichsbasis für die europäische Perspektive $^{62}$. Nipperdeys These allerdings, daß die Opposition keine Denkmäler errichtet habe ${ }^{63}$, bleibt eine zentrale Testfrage nach Reichweite und Grenzen der Deutungs- und Symbolmacht im öffentlichen Raum, die für Berlin neu zu stellen und auch im Blick auf London und Paris aufzugreifen ist.

58 Vgl. grundlegend Karl ARNDT, Denkmaltopographie als Programm und Politik. Skizze einer Forschungsaufgabe, in: MAI, WAETZOLDT (Hg.), Kunstverwaltung, S. 165-190.

59 Vgl. Wilfried LIPP, Natur - Geschichte - Denkmal. Zur Entstehung des Denkmalbewußtseins der bürgerlichen Gesellschaft, Frankfurt a. M., New York 1987, S. 18-24. Vgl. hier S. 243-283 auch zur Entstehung öffentlicher Personendenkmäler, allerdings fast ausschließlich im Rahmen einer quellenfernen Diskussion der Forschungsliteratur.

$60 \mathrm{Vgl}$. Thomas NIPPERDEY, Nationalidee und Nationaldenkmal in Deutschland im 19. Jahrhundert, in: HZ 206 (1968) S. 529-585.

${ }_{61}$ Die Typologie hat allerdings eine problematisch normative Tendenz, indem Nipperdey in den Bismarckdenkmälern als Zeichen snationaler Sammlung` die eigentlich 'geglückten Nationaldenkmäler` verwirklicht sieht. Dies, weil sie ein optimales Ausmaß an integrativen Inhalten mit dem Nationsbegriff verbänden und in sspontanen Bewegungen( wurzelten; vgl. ibid. S. 577, 585. Wenn die Kombination aus integrativem Nationsbegriff, spontaner Initiierung und Kohärenz zwischen Intention und Symbolsprache das sgeglückte Nationaldenkmal ausmacht, wird fraglich, welche Nation über ein solchermaßen normativ definiertes Nationaldenkmal verfügt(e). Auch die französischen Pantheonisierungen verliefen oft genug nicht konsensual; vgl. Martin PAPENHEIM, Erinnerung und Unsterblichkeit. Semantische Studien zum Totenkult in Frankreich (1715-1794), Stuttgart 1992 (Sprache und Geschichte, 18), S. 294-301; Jean-François CHANET, ,Les invalides de la Liberté،. Les débats sur le Panthéon et le choix des grands hommes de la troisième à la cinquième République, in: Christophe CHARLE u. a. (Hg.), La France démocratique (combats, mentalités, symboles). Mélanges offerts à Maurice Agulhon, Paris 1998 (Histoire de la France au XI$\mathrm{X}^{\mathfrak{e}}$ et $\mathrm{XX}^{\mathrm{e}}$ siècle, 45), S. 267-276. Ebenso war die symbolische Zulassung von mationalem« Personal zur Westminster Abbey nicht konfliktfrei, vgl. COLLINI, French Contrasts, S. 58-66. Verteilungsdichte und absolute Häufigkeit der Denkmäler für eine Person sind kaum hinreichende Kriterien für eine nationale Symbolwirkung. Die öffentliche Rezeption hat Nipperdey ohnedies nicht ausdrücklich untersucht.

${ }^{62}$ Vgl. F. J. BAUER, Gehalt und Gestalt in der Monumentalsymbolik. Zur Ikonologie des Nationalstaates in Deutschland und Italien 1860-1914 (Schriften des Historischen Kollegs, Vorträge 30), München 1992.

${ }^{63}$ Vgl. NIPPERDEY, Nationalidee und Nationaldenkmal, S. 531. 
Zur immensen Fülle von Detailstudien, die für Deutschland vorliegen, zählen zunächst solche zu architektonischen Baudenkmälem, die entfernt von den urbanen Zentren entstanden sind. Anders als die in der vorliegenden Untersuchung thematisierten metropolitanen Personendenkmäler beziehen sie eine weiträumig mitästhetisierte Naturlandschaft mit ein, auf die sie ihrerseits an exponierter Stelle Panoramablicke bieten. Vor allem entwickeln sie eine politische Symbolik, die auf einen national inspirierten Tourismus und ein säkularisiertes Pilgerfahrtswesen zu den Kultstätten der großen Toten zielt ${ }^{64}$. Daneben kann die Entstehungs- und zum Teil auch Wirkungsgeschichte der wilhelminischen Monumentaldenkmäler unter Berücksichtigung struktureller wie sozialer Faktoren in weiten Teilen als erforscht gelten ${ }^{65}$. Für den urbanen Raum liegen mit Einzeldarstellungen zum Berliner Dom sowie zum Stadtschloß als dynastischem Herrschersymbol, zu Berliner Rathaus und Reichstag als politischen Repräsentationsbauten Beiträge vor, in denen untersucht wird, wie sich die preußisch-dynastische Legitimationssymbolik gegen einzelstaatlich-regionale bzw. kommunal-autonome Traditionslinien städtischer Institutionen zum einen und gegen ein dezidiert demokratischeres Symbolverständnis des Parlaments zum anderen durchgesetzt hat ${ }^{66}$.

${ }^{64}$ Vgl. Jörg TRÄGER, Der Weg nach Walhalla. Denkmallandschaft und Bildungsreise im 19. Jahrhundert, Regensburg 1987, hier S. 9-36; Hans WLDEROTTER, Nationaldenkmäler. „Fern vom alltäglichen Gewühl ...", in: Bodo Michael BAUMUNK, G. BRUNN (Hg.), Hauptstadt: Zentren, Residenzen, Metropolen in der deutschen Geschichte, Köln 1989 (AK Bonn), S. 297-305. Einen kursorischen Vergleich der Walhalla mit dem Pariser Panthéon und der Londoner Westminster Abbey liefert Lars VÖLCKER, Tempel für die Großen der Nation. Das kollektive Nationaldenkmal in Deutschland, Frankreich und Großbritannien im 18. und 19. Jahrhundert, Frankfurt a. M. 2000 (Europäische Hochschulschriften Reihe III, 877).

${ }^{65}$ Vgl. immer noch Lutz TTTTEL, Monumentaldenkmäler von 1871 bis 1918 in Deutschland. Ein Beitrag zum Thema Denkmal und Landschaft, in: MAI, WAETZOLDT (Hg.), Kunstverwaltung, S. 215-275; DERS., Das Niederwalddenkmal 1871-1883, Hildesheim 1979 als Pionierstudie für eine detaillierte exemplarische Denkmalanalyse einschließlich der Erstellung von Sozialprofilen und Erörterung von Finanzierungswegen, Ikonologie, Fest und rezeptiven zeitgenössischen Voten. Vgl. auch Helmut SCHARF, Zum Stolze der Nation. Deutsche Denkmäler des 19. Jahrhunderts, Dortmund 1983; Thomas NIPPERDEY, Der Kölner Dom als Nationaldenkmal, in: HZ 283 (1981) S. 595-613. Eine populärwissenschaftliche Zusammenfassung der Sekundärliteratur bietet Ulrich SCHLIE, Die Nation erinnert sich. Die Denkmäler der Deutschen, München 2002.

${ }_{66} \mathrm{Vgl}$. Helmut ENGEL, Der Berliner Dom im 19. Jahrhundert, in: Detlef PLOSE (Red.), Der Berliner Dom. Geschichte und Gegenwart der Oberpfarr- und Domkirche zu Berlin, Berlin 2001, S. 22-35; Laurenz DEMPS, Der Berliner Dom in der zeitgenössischen Architektur und der politischen Kritik, in: ibid. S. 70-79; Albert GEYER, Geschichte des Schlosses zu Berlin. Bd. 2: Vom Königsschloß zum Schloß des Kaisers (1698-1918), bearb. v. SeppGustav GRÖSCHEL, Berlin ${ }^{2} 1993$; Michael S. CULLEN, Uwe KIELING, Der deutsche Reichstag. Geschichte eines Parlaments, Berlin 1992; Christa SCHREIBER, Das Berlinische Rathaus - Versuch einer Entstehungs- und Ideengeschichte, in: Ekkehard MAI, Jürgen PAUL, Stephan WAETZOLDT (Hg.), Das Rathaus im Kaiserreich. Kunstpolitische Aspekte 
An der Schnittstelle zwischen kunstgeschichtlicher und geschichtswissenschaftlicher Perspektive hat die Erforschung von Personendenkmälern seit den 1960 er Jahren stattgefunden ${ }^{67}$. Das Interesse ist von jeher stark auf die Kaiser $^{68}$ und Bismarckdenkmäler ${ }^{69}$ im ländlichen wie städtischen Umfeld fixiert gewesen. Nur britische Historiker haben dabei öffentliche Denkmalerrichtungen besonders für die Monarchen der Invention of tradition-These zugeordnet $^{70}$. Beiträge, die demgegenüber die Kaiser- oder Kanzlerdenkmäler gerade ausgeblendet haben, sind verstärkt der Frage nach einer spezifischen stadtneben der nationalpolitischen Motivierung von Denkmalerrichtungen nachge-

einer Bauaufgabe des 19. Jahrhunderts, Berlin 1982 (Kunst, Kultur und Politik im deutschen Kaiserreich, 4), S. 91-149, hier S. 133-137; Monika ARNDT, Die »Ruhmeshalle» im Berliner Zeughaus. Eine Selbstdarstellung Preußens nach der Reichsgründung, Berlin 1985 (Die Bauwerke und Kunstdenkmäler von Berlin, Beiheft 12).

${ }^{67} \mathrm{Vgl}$. neben den bereits genannten, enzyklopädisch nutzbaren Sammelbänden von Mai und Waetzoldt zuletzt v.a. Peter BLOCH, Denkmal und Denkmalkult, in: DERS., EINHOLZ, vON SIMSON (Hg.), Ethos und Pathos, S. 191-205. Ältere Themengrundrisse liegen gleichwohl vor, vgl. v.a. SCHNABEL, Die Denkmalskunst, S. 134-150.

${ }^{68}$ Vgl. u. a. Gunther MAI (Hg.), Das Kyffhäuser-Denkmal 1896-1996. Ein nationales Monument im europäischen Kontext, Köln, Weimar, Wien 1997.

69 Vgl. Hans-Walter HEDINGER, Bismarck-Denkmäler und Bismarck-Verehrung, in: MAI, WAETZOLDT (Hg.), Kunstverwaltung, S. 277-314; Ekkehard MAI, Die Denkmäler im Kaiserreich, in: Winfried NERDNNGER, DERS. (Hg.), Wilhelm Kreis. Architekt zwischen Kaiserreich und Demokratie 1873-1955, Berlin 1994, S. 29-43; DERS., Vom Bismarckturm zum Ehrenmal. Denkmalformen bei Wilhelm Kreis, in: DERS., SCHMIRBER (Hg.), Denkmal - Zeichen - Monument, S. 50-57; aus kunsthistorischer Perspektive vgl. Felix REUSSE, Das Denkmal an der Grenze seiner Sprachfähigkeit, Stuttgart 1995 (Sprache und Geschichte, 23), S. 100-105. Zum Bismarckkult vgl. Michael MCGUIRE, Bismarck in Walhalla: Der Bismarckkult und die Politik der Nationalen Identität vom Kaiserreich bis zum Dritten Reich, in: Hermann REUTER, Heide REUTER, DERS. (Hg.), Otto von Bismarck. Spuren und Wirkungen, Lingen o. J. [1996], S. 139-163, hier S. 139-158; Lothar MACHTAN, Bismarck-Kult und deutscher National-Mythos 1890-1914, in: DERS. (Hg.), Bismarck und der deutsche Nationalmythos, Bremen 1994, S. 15-67; HEDINGER, HansWalter, Der Bismarck-Kult, in: Gunther STEPHENSON (Hg.), Der Religionswandel unserer Zeit im Spiegel der Religionswissenschaft, Darmstadt 1976, S. 201-215; Rolf PARR, Zwei Seelen wohnen, ach! in meiner Brust. Strukturen und Funktionen der Mythisierung Bismarcks 1860-1918, München 1992; Lothar GALL, Die Deutschen und Bismarck, in: Ralph MELVILLE u. a. (Hg.), Deutschland und Europa in der Neuzeit, FS für Karl Otmar von Aretin zum 65. Geburtstag, Wiesbaden, Stuttgart 1988 (Veröffentlichungen des Instituts für Europäische Geschichte Mainz. Abt. Universalgeschichte, 134/2), S. 525-536 sowie Werner PÖLS, Bismarckverehrung und Bismarcklegende als innenpolitisches Problem der Wilhelminischen Zeit, in: Jahrbuch für die Geschichte Mittel- und Ostdeutschlands 20 (1971) S. 183-201. Vgl. zu den deutschen Kaiser- und Kanzlerdenkmälern auch HOBSBAWM, Mass-producing traditions, S. 264 in Anlehnung an Mosse und Nipperdey. Das Berliner Bismarckdenkmal wird dabei höchstens kursorisch erwähnt.

70 Vgl. neben dem Beitrag von Hobsbawm weiter für die erste Jahrhunderthälfte David E. BARCLAY, Ritual, ceremonial and the "Invention « of Monarchical Tradition in nineteenth century Prussia, in: Heinz DUCHHARDT, Richard A. JACKSON, David STURDY (Hg.), European Monarchy. Its evolution and practice from Roman Antiquity to Modern Times, Stuttgart 1992, S. 207-220. Zum minvention«-Konzept vgl. Kapitel 1.3.3. 
gangen $^{71}$. Andere Personendenkmäler ${ }^{72}$ sind eher exemplarisch anhand eines einzelnen städtischen oder landschaftlich plazierten Monuments berücksichtigt worden. Seltener hat die Denkmalpolitik partikularstaatlich im Vergleich zur gesamtstaatlichen Nationsbildung vor und nach 1871 Beachtung gefunden ${ }^{73}$. Wo der binnennationale, regionale Denkmalvergleich durchgeführt worden ist, hat man ihn aus arbeitspragmatischen Gründen auf Einzelfälle beschränkt und wiederum bevorzugt auf Kaiser-, Kanzler- und figürlich-architektonische Kriegerdenkmäler nach 1871 bezogen ${ }^{74}$. Demgegenüber bleibt Charlotte Takkes transnationaler Vergleich deutscher Hermann- und französischer Vercingetorix-Denkmäler nach wie vor konkurrenzlos ${ }^{75}$.

Studien zu den Berliner Denkmälern liegen entweder als enzyklopädische Gesamtbetrachtungen oder dezidiert kunst- und stilgeschichtliche Analysen $\operatorname{vor}^{76}$. Städtische Denkmaltopographien sind sowohl für München im Span-

"1 Vgl. kursorisch Jürgen MƠLLER, Die Stadt, die Bürger und das Denkmal im 19. Jahrhundert, in: Dieter HEIN, Andreas ScHULZ (Hg.), Bürgerkultur im 19. Jahrhundert. Bildung, Kunst und Lebenswelt, München 1996, S. 269-288, hier S. 280-286.

72 Vgl. MATTENKLOTT, Denk ich an Deutschland; Rolf SELBMANN, Versteinerte Poesie oder Verkehrhindernis? Zur Geschichte der Dichterdenkmäler in Deutschland, in: AKG 76 (1994) S. 365-388; u. a. zum Walther-Denkmal in Bozen von 1889 André SCHNYDER, Der Dichter als Monument. Ein Kapitel aus der Geschichte der Rezeption Walthers von der Vogelweide, in: AKG 71 (1989) S. 395-429; zur Weimarer Republik u. a. Heike FISCHER, Tannenberg-Denkmal und Hindenburgkult. Hintergründe eines Mythos, in: Michael HƯTT u. a. (Hg.), Unglücklich das Land, das Helden nötig hat. Leiden und Sterben in den Kriegsdenkmälern des Ersten und Zweiten Weltkrieges, Marburg 1990 (Studien zur Kunst- und Kulturgeschichte, 8), S. 28-49.

B Vgl. so die Rekonstruktion einer einzelstaatlichen Erinnerungslandschaft am Beispiel von Württemberg für den Zeitraum von nach 1800 bis 1918 Friedemann SCHMOLL, Verewigte Nation. Studien zur Erinnerungskultur von Reich und Einzelstaat im württembergischen Denkmalkult des 19. Jahrhunderts, Tübingen und Stuttgart 1995 (Stuttgarter Studien, 8). Als kunsthistorische Regionalstudie vgl. Wolfgang VoMM, Denkmäler für Herrscher, in: Eduard TRIER, Willy WEYRES (Hg.), Kunst des 19. Jahrhunderts im Rheinland, 4: Plastik, Düsseldorf 1980, S. 213-247; Henning MƯLLER, Krieg und Tod als Mittel der PolitikDenkmäler für Politiker, Feldherrn, Gefallene, in: ibid. S. 249-279, und Peter BLOCH, Heroen der Kunst, Wissenschaft und Wirtschaft. Zierbrunnen und »freie Kunst«, in: ibid. S. 281-348, hier S. 281-317.

74 Vgl. so vor allem Reinhard ALINGS, Monument und Nation. Das Bild vom Nationalstaat im Medium Denkmal - zum Verhältnis von Nation und Staat im deutschen Kaiserreich 1871-1918, Berlin, New York 1996 (Beiträge zur Kommunikationsgeschichte, 4); Rudy KOSHAR, From monuments to traces. Artifacts of German memory, 1870-1990, Berkely, Los Angeles, London 2000, S. 15-79.

75 Vgl. Charlotte TACKE, Denkmal im sozialen Raum. Nationale Symbole in Deutschland und Frankreich im 19. Jahrhundert, Göttingen 1995 (Kritische Studien zur Geschichtswissenschaft, 108).

76 Vgl. Stefanie ENDLICH, Bernd WURLITZER, Skulpturen und Denkmäler in Berlin, Berlin 1990; Peter BLOCH, Anmerkungen zu Berliner Skulpturen des 19. Jahrhunderts, in: JbPK 8 (1970) S. 162-190; Sibylle ScHULZ, Denkmäler im Stadtbild Berlins. Geschichte und Erhaltung, in: Institut für Denkmalpflege, Arbeitsstelle Berlin (Hg.), Denkmale in Berlin und in der Mark Brandenburg, Weimar 1987, S. 88-105; Peter BLOCH, Die Berliner Bild- 
nungsverhältnis zwischen einzelstaatlich-dynastischer Zielrichtung und reichsnationaler Rhetorik ${ }^{77}$, wie auch für den Berliner Raum rekonstruiert worden, für den man Topographien des Machtzentrums seit seinen stadtplanerischen Anfängen im 18. Jahrhundert nachgezeichnet hat ${ }^{78}$.

Schließlich ist der Aspekt einer personifizierenden Nationsdarstellung auch wiederholt anhand der Germania-Allegorie ${ }^{79}$ verfolgt und bereits mit der Allegorie der französischen Marianne in Beziehung gesetzt worden ${ }^{80}$. Mit der wichtigen Ausnahme des Niederwalddenkmals trat dabei der Aspekt denkmalförmiger Konkretion der allegorischen Figur eher in den Hintergrund. Statt

hauerei des 19. Jahrhunderts und die Antike, in: Willmuth ARENHOVEL, Christa SCHREIBER (Hg.), Berlin und die Antike. Ergänzungsband zum Katalog der Ausstellung, Berlin 1979, S. 395-429. Vgl. den wohl frühesten Versuch einer politikgeschichtlichen Synopse bei Eberhard FADEN, Zur politischen Geschichte der Berliner Denkmäler, in: Zeitschrift des Vereins für die Geschichte Berlins 54 (1937) S. 91-96. Kursorisch zu den architektonischen Bauten Berlins Hans KAUFFMANN, Berliner Baukunst von Schlüter bis Schinkel, in: JbPK 13 (1976) S. 25-43

77 Vgl. Wolfgang HARDTWIG, Soziale Räume und politische Herrschaft. Leistungsverwaltung, Stadterweiterung und Architektur in München 1871 bis 1914, in: DERS., Klaus TENFELDE (Hg.), Soziale Räume in der Urbanisierung. Studien zur Geschichte Münchens im Vergleich 1850-1933, S. 59-153.

78 Vgl. Laurenz DEMPS, Berlin - Wilhelmstraße. Eine Topographie preußisch-deutscher Macht, Berlin 1994; DERS., Der Pariser Platz. Der Empfangssalon Berlins, Berlin 1995; Wolfgang SCHÄCHE, Platz für die Macht. Der Spreebogen in Berlin-Tiergarten, in: Romana SCHNEDER, Wilfried WANG (Hg.), Modeme Architektur in Deutschland, 1900-1950. Macht und Monument, Ostfildern-Ruit 1998, S. 33-51; Helmut ENGEL, "Durch sie ist die Gestalt der Dinge verändert und die Hoffnung auf eine bessere Zukunft begründet worden/ - oder: Der Beginn der »Via triumphalis«, in: DERS., Wolfgang RIBBE (Hg.), Via triumphalis, Berlin 1997, S. 31-46; Werner KNOPP, Kulisse der Macht im Kaiserreich, in: ibid. S. 47-60; Gottfried KORFF, Beim Anblick der Monumente im Wandel der Zeiten. Ein Beitrag zur Berliner Mentalitätsgeschichte, in: ibid. S. 197-208; DERS., Die Denkmälerund Geschichtslandschaft der Mitte Berlins, in: DERS., Wolfgang RIBBE (Hg.), Hauptstadt Berlin - wohin mit der Mitte? Historische, städtebauliche und architektonische Wurzeln des Stadtzentrums, Berlin 1993, S. 81-87; Heinz DUCHHARDT: Anspruch und Architektur: das Beispiel Berlin, in: Forschungen zur Brandenburgischen und Preußischen Geschichte NF 1 (1991) S. 31-52, hier S. 41-52, Henry NIELEBOCK, Berlin und seine Plätze, Potsdam 1996, hier S. 59-106.

79 Vgl. hier nur Gerhard BRUNN, Germania und die Entstehung des deutschen Nationalstaates. Zum Zusammenhang von Symbolen und Wir-Gefühl, in: Rüdiger VolGT (Hg.), Symbole der Politik, Politik der Symbole, Opladen 1989, S. 101-122, hier S. 110-119; Monika WAGNER, Allegorie und Geschichte. Ausstattungsprogramme öffentlicher Gebäude des 19. Jahrhunderts in Deutschland. Von der Cornelius-Schule zur Malerei der Wilhelminischen Ära, Tübingen 1989 (Tübinger Studien zur Archäologie und Kunstgeschichte, 9), hier S. 92-96.

${ }^{80}$ Vgl. Lothar GALL, Die Germania als Symbol nationaler Identität im 19. und 20. Jahrhundert (Nachrichten der Akademie der Wissenschaften in Göttingen, I. Phil.-hist. Kl. Nr. 2), Göttingen 1993, besonders S. 44-46 und 53-58 sowie DERS., Germania. Eine deutsche Marianne? Une Marianne allemande? (Reflexions sur l'Allemagne au $20^{\circ}$ siècle. Reflexionen über Deutschland im 20. Jahrhundert), Bonn 1993. 
dessen sind die Traditionen des Symbols in der Historienmalerei und in Gestalt alltäglicherer Reminiszenz- und Zeichenformen wie Münzen oder Briefmarken erörtert worden. Als progressivere und weniger elitäre, vor allem nicht statuarisch-idealisierende Verkörperung der deutschen Nation wurde daneben auch die karikaturistische Michel-Figur zum Untersuchungsgegenstand ${ }^{81}$.

Als kategorial distinkte Denkmalgruppe, die in der vorliegenden Untersuchung ausgeblendet bleiben muß, sind demgegenüber die Kriegerdenkmäler identifiziert worden. Im deutsch-französischen Vergleich hat Reinhart Koselleck erhellt, daß die Kriegerdenkmäler durch eine international gleichartige Ikonographie ausgewiesen sind. Sie erklärt sich aus einer ähnlichen Intention ihrer Stifter, den Opfertod für die zum Souverän hypostasierte nationale Gemeinschaft und ihre Werte in den Mittelpunkt des Bildprogramms zu stellen, den Prozeß des »gewaltsamen Sterbenmüssens« und seine Begründung hingegen zu »verschweigen ${ }^{82}$. In beiden Ländern wurde die Entwicklung der Kriegerdenkmäler dadurch geprägt, daß auch Soldaten sukzessive als denkmalfähig galten und sich die Stiftungsinitiativen jenseits des monarchischen Handlungsmonopols verselbständigten ${ }^{83}$.

Vgl. Karl RIHA, Deutscher Michel. Zur literarischen und karikaturistischen Ausprägung einer nationalen Allegorie im 19. Jahrhundert, in: LINK, WULFING (Hg.), Nationale Mythen und Symbole, S. 146-171; Eda SAGARRA, Selbstbestimmung durch Fremdbestimmung. On the history of Der deutsche Michel as a cartoon image in the Vormärz, in: Helmut KOOPMANN, Martina LAUSTER (Hg.), Vormärzliteratur in europäischer Perspektive, Bd. 1: Öfentlichkeit und nationale Identität, Bielefeld 1996 (Studien zur Literatur des Vormärz, 1), S. 281-292.

82 Reinhart KOSELLECK, Zur politischen Ikonologie des gewaltsamen Todes. Ein deutschfranzösischer Vergleich, Basel 1998 (Jakob-Burckhardt-Gespräche auf Castelen, 3), S. 8 und DERS., Kriegerdenkmale als Identitätsstiftungen der Überlebenden, in: Odo MARQUARD, Karlheinz STIERLE (Hg.), Identität, München ${ }^{2}$ 1996, (Politik und Hermeneutik, 8), S. 255-276. Vgl. als umfangreiche »Datenbasis« aus kunstgeschichtlicher Perspektive LURZ, Kriegerdenkmäler, Bd. 1 bis 3. Ohne sozialpolitische Kontextuierung Martina WEINLAND, Kriegerdenkmäler in Berlin (1813/15 und 1914/18), in: BLOCH, EINHOLZ, VON SIMSON (Hg.), Ethos und Pathos, S. 281-29l und DIES., Kriegerdenkmäler in Berlin 1870-1930, Frankfurt a. M. u. a. 1990 (Europäische Hochschulschriften, Reihe XXVIII, Kunstgeschichte, 105).

${ }^{83}$ Vgl. Michael JEISMANN, Rolf WESTHEIDER, Wofür stirbt der Bürger? Nationaler Totenkult in Deutschland und Frankreich seit der Französischen Revolution, in: KOSELLECK, JEISMANN (Hg.), Der politische Totenkult, S. 23-50; REUSSE, Das Denkmal, S. 94-99; Ulrich BISCHOFF, Denkmäler für die Befreiungskriege in Deutschland 1813-1815, 2 Bände, Berlin 1977; Christopher CLARK, The Wars of Liberation in Prussian Memory: Reflections on the memorialization of War in early nineteenth-century Germany, in: Journal of Modern History (JMH) 68 (1996) S. 550-576; Peter HUTTER, "Die feinste Barbarei $($. Das Völkerschlachtdenkmal bei Leipzig, Mainz 1990 und von kunstgeschichtlicher Seite bereits Siegmar HoLSTEN: Allegorische Darstellungen des Krieges 1870-1918. Ikonologische und ideologiekritische Studien, München 1976. Für eine kulturhistorische Analyse wie für den historischen Vergleich noch fruchtbarer zu machen bleiben Untersuchungen kolonialer Denkmäler, vgl. für die Phase seit 1884 bis in die Gegenwart Joachim ZELLER, Ko- 
Zwar hat inzwischen der Import des Nora'schen »Lieux de mémoire«Modells $^{84}$ in die deutsche Historiographie mit dem von Étienne François und Hagen Schulze herausgegebenen mehrbändigen Werk »Deutsche Erinnerungsorte« längst stattgefunden ${ }^{85}$. Eine Analyse öffentlicher Denkmäler fand hier allerdings mit dem Hinweis auf die weit entwickelte deutsche Denkmalforschung nach Maßgabe einer Erinnerungsort-Logik eher sporadisch statt ${ }^{86}$.

Ein Korrelat zur Bürgertum- und Denkmalforschung bildet in Deutschland nicht anders als in Frankreich und besonders in England das Interesse an Formen öffentlichen Gegenkultes, wie er in den Reihen der Arbeiterschaft unter Benutzung anderer Medien und Symbole in den letzten Jahrzehnten des ausgehenden Jahrhunderts an Bedeutung gewonnen hat ${ }^{87}$. Der Frage, in welchem Maße hier auch zu oppositioneller Symbolmacht in Form öffentlicher Monumente zu gelangen war, ist systematisch und flächendeckend für Deutschland im 19. Jahrhundert noch nicht erörtert worden. Anders als vor allem in der englischen Forschungsliteratur hat die Frage des öffentlichen Raums als nicht nur ästhetischer, sondern auch politisch-symbolischer Wirkkontext im ländlichen oder urbanen Zusammenhang in Verbindung mit der Plazierung von Monumenten in Deutschland kaum Beachtung gefunden ${ }^{88}$.

Sofern sich die deutsche Denkmalforschung mit den Trägern der Bewegung auseinandergesetzt hat, ist ihnen in der Regel ein bürgerliches Profil und eine spezifische Staatsnähe bescheinigt worden ${ }^{89}$. Neben den zahlreichen Studien

lonialdenkmäler und Geschichtsbewußtsein. Eine Untersuchung der kolonialdeutschen Erinnerungskultur, Frankfurt a. M. 2000.

${ }^{84} \mathrm{Vgl}$. dazu ausführlicher das folgende Kapitel.

${ }^{85}$ Dabei ist versucht wordell, nicht nur das Modell an den spezifisch deutschen Fall anzupassen, sondern auch konzeptionelle Schieflagen des französischen Pionierprojekts auszugleichen. Eine Zuspitzung auf »Staat« und deutsche »Nation« wird daher vermieden, vor allem aber eine dezidiert »pluralistische" und »europäische « Offnung als Konsequenz aus einer nach Ausschwitz singulär anderen deutschen Erinnerungskultur angestrebt. Die assoziative Reichweite des metaphorisch begriffenen "Erinnerungsortes" und die Hypothese von dessen Symbolüberschuß, aber auch von seiner rezeptiven Dynamik und langfristig möglichen Sinnerosion wird demgegenüber gezielt beibehalten. Vgl. Étienne FRANÇOIS, Hagen SCHULZE, Einleitung, in: DIES. (Hg.), Deutsche Erinnerungsorte, 3 Bände, München 2001, hier Bd. 1, S. 9-24.

${ }^{86} \mathrm{Vgl}$. ibid. S. 20.

${ }^{87}$ Vgl. dazu Hinweise bei Werner K. BLESSING, Der monarchische Kult, politische Loyalität und die Arbeiterbewegung im deutschen Kaiserreich, in: Gerhard A. RTTTER (Hg.), Arbeiterkultur, Königstein, Ts. 1979, S. 185-208, hier S. 196.

88 Mit Sammelbänden wie von Bernhard KIRCHGÄSSNER, Joachim B. SCHULTIS (Hg.), Wald, Garten und Park: Vom Funktionswandel der Natur für die Stadt, Sigmaringen 1993, werden Anläufe zu einer kulturgeschichtlichen Aufbereitung der öffentlichen Raumdimension jedenfalls nicht erfolgreich unternommen.Vgl. zum überlegenen englischen Forschungsstand weiter unten.

Vgl. Wolfgang HARDTWIG, Nation - Region - Stadt. Strukturmerkmale des deutschen Nationalismus und lokale Denkmalkulturen, in: Gunther MAI $(\mathbf{H g}$.), Das KyffhäuserDenkmal 1896-1996, Köln, Weimar, Wien 1997, S. 53-83, hier S. 70; DERS., Nationsbil- 
zur deutschen bürgerlichen Festkultur des 19. Jahrhunderts im allgemeinen ${ }^{90}$ und deutscher Denkmalfestkultur ${ }^{91}$ im besonderen, bleiben vergleichende Überlegungen aus deutsch-englischer Sicht bislang kursorisch ${ }^{92}$. Unterdessen liefert der deutsch-französische Vergleich, konzentriert auf die zentralistischen und lokalen französischen gegenüber den regionalen deutschen Militärfeiern, Argumente dafür, daß eine Militarisierung des Nationalkultes nicht voreilig und womöglich ausschließlich nur im Blick auf die deutsche Gesellschaft zu unterstellen ist ${ }^{93}$. Als eine Facette zelebrierter nationaler Selbstdarstellung und als separate Festkategorie im Grenzbereich zwischen Vergleich und Kulturtranfer sind inzwischen die Symboleffekte von Weltausstellungen intensiv erörtert worden ${ }^{94}$. Sonst wurden Feste insbesondere im städtischen Rahmen daraufhin untersucht, welche Formen der Verknüpfung von nationalstaatlicher Rhetorik mit städtischem und/oder regionalem Sonderbewußtsein sie zu verankern suchen. So ist man bislang mit dem Sedantag verfahren, dessen Etablie-

dung und politische Mentalität. Denkmal und Fest im Kaiserreich, in: DERS., Geschichtskultur und Wissenschaft, S. 264-301; HEDINGER, Bismarck-Denkmäler, S. 282f. und TTTTEL, Monumentaldenkmäler, S. 225.

90 Vgl. Manfred HETTLING, Paul NOLTE, Bürgerliche Feste als symbolische Politik im 19 Jahrhundert, in: DIES. (Hg.), Bürgerliche Feste. Symbolische Formen politischen Handelns im 19. Jahrhundert, Göttingen 1993, S. 7-36; Ute SCHNEIDER, Politische Festkultur im 19. Jahrhundert. Die Rheinprovinz von der französischen Zeit bis zum Ende des Ersten Weltkriegs (1806-1918), Essen 1995 (Düsseldorfer Schriften zur Neueren Landesgeschichte und zur Geschichte Nordrhein-Westfalens, 41), hier S. 24-28; Dieter DUDING, Einleitung. Politische Offentlichkeit - politisches Fest - politische Kultur, in: DERS., Peter FriedEManN, Paul MÓNCH (Hg.), Öffentliche Festkultur. Politische Feste in Deutschland von der Aufklärung bis zum Ersten Weltkrieg, Reinbek bei Hamburg 1988, S. 10-24; Michael MAURER, Feste und Feiern als historischer Forschungsgegenstand, in: HZ 253 (1991) S. 101-130; Paul HUGGER (Hg.), Stadt und Fest. Zu Geschichte und Gegenwart europäischer Festkultur. Unterägeri und Stuttgart 1987.

91 Vgl. v.a. die Arbeiten von Wolfgang HARDTWIG, etwa DERS., Nationsbildung, S. 264301.

92 Vgl. George L. MOSSE, Caesars, circuses, and Monuments, in: Joumal of Contemporary History (JContH) 6 (1971) S. 167-182 und Allan MrTCHELL, Nationalfeiertage im Vergleich: Deutschland, Frankreich und die USA, in: FrANÇOIS (Hg.), Nation und Emotion, S. 396-401.

93 Vgl. Jakob VOGEL, Nations in arms: military and commemorative festivals in Germany and France, 1871-1914, in: Karin FRIEDRICH, Festive Culture in Germany and Europe from the sixteenth to the twentieth century, Lewiston, Queenston, Lampeter 2000, S. 245264.

$94 \mathrm{Vgl}$. aus einer inzwischen überbordenden Literaturfülle B. STOKLUND, The role of the International Exhibitions in the construction of national cultures in the $19^{\text {th }}$ century, in: Ethnologia Europaea 24 (1994) S. 35-44; Eckhardt FUCHS, Das Deutsche Reich auf den Weltausstellungen vor dem Ersten Weltkrieg, in: Comparativ 9 (1999) S. 61-88; Martin WORNER, Die Welt an einem Ort. Illustrierte Geschichte der Weltausstellungen, Berlin 2000 . 
rung als deutscher Nationalfeiertag langfristig scheiterte ${ }^{95}$, darüber hinaus auch mit den offiziell inszenierten Kaisergeburtstagen und den Einweihungen von öffentlichen Gebäuden oder Symbolen des industriellen Fortschritts ${ }^{96}$, die neben Thronjubiläen ${ }^{97}$ und Denkmaleinweihungen nach 1871 mit überlokaler und überregionaler Reichweite ausgerichtet zu werden begannen. Der Vergleich nationaler Feste und Festkulturen ist entweder im Stadium der Vorüberlegung steckengeblieben ${ }^{98}$ oder im Rahmen von Zweiländervergleichen getestet und bereits durchgeführt worden ${ }^{99}$. Zeitgenössische Denkmalkritik als ubiquitäres Phänomen wurde bislang systematisch nur für den deutschen Fall thematisiert ${ }^{100}$, hier allerdings nicht als Indiz durchdachter politischer Opposition gegen einen reaktionär-obrigkeitsstaatlichen Nationalismus, sondern als politikfern-ästhetisches Argument erachtet ${ }^{101}$.

95 Vgl. u. a. Ute SCHNEDER, Einheit ohne Einigkeit. Der Sedantag im Kaiserreich, in: Sabine BEHRENBECK, Alexander NUTZENADEL (Hg.), Inszenierungen des Nationalstaats. Politische Feiern in Italien und Deutschland seit 1860/1871, Köln 2000, S. 27-44; Claudia LIPP, Protestanten feiern ihre Nation - Die kulturprotestantischen Ursprünge des Sedantages, in: Historisches Jahrbuch (HJb) 118 (1998) S. 201-222; Fritz SCHELLACK, Nationalfeiertage in Deutschland von 1871-1945, Frankfurt a. M. u. a. 1990 (Europäische Hochschulschriften Reihe III. Geschichte und Hilfswissenschaften, 415), hier S. 67-132; DERS., Sedan- und Kaisergeburtstagsfeste, in: DÜDING u. a. (Hg.), Öffentliche Festkultur, S. 278-297.

96 Vgl. Tobias VON ELSNER, Kaisertage. Die Hamburger und das Wilhelminische Deutschland im Spiegel öffentlicher Festkultur (Europäische Hochschulschriften Reihe 3, 471), Frankfurt a. M. u. a. 1991, S. 462-479 zur Einweihung des Hamburger Kaiserdenkmals; sonst SCHELLACK, Nationalfeiertage, S. 17-66.

97 Vgl. Jeffrey R. SMTrH, The Monarchy versus the Nation: The »Festive Year« 1913 in Wilhelmine Germany, in: German Studies Review 23 (2000) S. 257-274, hier S. 267-272.

98 Vgl. Sabine BEHRENBECK, Alexander NUTTZENADEL, Politische Feiern im Nationalstaat. Perspektiven eines Vergleichs zwischen Italien und Deutschland, in: DES. (Hg.), Inszenierungen des Nationalstaats, S. 9-26. Der Sammelband enthält ansonsten keine explizit vergleichenden Beiträge.

99 Vgl. u. a. Jakob VOGEL, Nationen im Gleichschritt. Der Kult der 'Nation in Waffen ( in Deutschland und Frankreich, 1871-1914, Göttingen 1997 (Kritische Studien zur Geschichtswissenschaft; 118); Lyn SPILLMAN, Nation and commemoration. Creating national identities in the United States and Australia, Cambridge 1997.

${ }^{100}$ Vgl. Hans-Ernst MTTTG, Über Denkmalkritik, in: DERS., Volker PlagemanN (Hg.), Denkmäler im 19. Jahrhundert. Deutung und Kritik, München 1972, S. 283-301; Hartmut BOOKMANN, Denkmäler. Eine Utopie des 19. Jahrhunderts, in: GWU 3 (1977) S. 160173. Vgl. auch Monika ARNDT, Ehre, wem Ehre gebührt? Karikaturen zur »Denkmalinflation « der wilhelminischen Zeit, in: Gerhard LANGEMEYER u. a. (Hg.), Bild als Waffe. Mittel und Motive der Karikatur in fünf Jahrhunderten, München 1984, S. 431440 und Susanne PETERS-SCHILDGEN, »Monumentaler Kitsch«? Denkmäler im Spiegel der Karikatur des 19. und 20. Jahrhunderts, in: Gert MATTENKLOTT (Red.), Deutsche Nationaldenkmale 1790-1990, Gütersloh, Bielefeld 1993, S. 137-15I.

${ }^{101}$ Vgl. diese Einschätzung etwa bei MrTTIG, Über Denkmalkritik, S. 289-294 und 296, Anm. 70 . 
Außerhalb der hier berücksichtigten Länder hat sich etwa auch die österreichische ${ }^{102}$ und vor allem die amerikanische Historiographie mit dem Phänomen einer nationalen Symbolik ${ }^{103}$, der politischen Repräsentationsarchitektur $^{104} \mathrm{im}$ allgemeinen und nationalen Personendenkmälern ${ }^{105}$ im besonderen sowohl im eigenen Land als auch mit Blick auf Europa auseinandergesetzt. Bereits Mitte der 1970er Jahre sind Aspekte deutscher Nationaldenkmäler auch in der amerikanischen Forschung und mit besonderen Gewichtungen etwa bei Mosse diskutiert worden. Der auf Massenwirksamkeit zielende neue "politische Stil« des Nationalsozialismus wird hier als Resultat einer seit den Anfängen des 19. Jahrhunderts hergeleiteten Kontinuität der stets ambivalenten deutschen Nationalsymbolik interpretiert ${ }^{106}$. Daß die europäische Kontextuierung nationaler Symboliken und nationaler Massenbewegungen höchstens sporadisch erfolgt und hinsichtlich der öffentlichen Denkmäler ${ }^{107}$ weithin unterbleibt, begünstigt Mosses Hypothese von den singulären, mythischkultischen Verirrungen und Deformationen einer deutschen Symbolik bereits im 19. Jahrhundert, bleibt aber ohne analytisches Korrektiv ${ }^{108}$. Sofern demgegenüber die Erfindung von Ursprungsmythen wie auch die quasi-religiöse Konnotation nationalpolitischer Rhetoriken und Symboliken von einer inter-

${ }^{102}$ Vgl. u. a. Hanns HAAS, Hannes STEKL, Einleitung, in: DIES. (Hg.), Bürgerliche Selbstdarstellung: Städtebau, Architektur, Denkmäler, Wien, Köln, Weimar 1995 (Bürgertum in der Habsburgermonarchie, 4), S. 9-22.

${ }^{103}$ Vgl. kursorisch bereits HOBSBAWM, Mass-producing traditions, S. $279 f$.

${ }^{104}$ Vgl. u. a. Lawrence J. VALE, Architecture, power, and national identity, New Haven und London 1992, zum stadttopographischen und symbolischen Vergleich europäischer, (latein)amerikanischer und asiatischer "Hauptstadtwerdung ( ()Capitalization () anhand der Positionierung und Gestaltung öffentlicher Parlamentsgebäude.

${ }^{105} \mathrm{Vgl}$. Albert BOIME, The unveiling of the national icons. A plea for patriotic iconoclasm in a nationalist era, Cambridge 1998, hier S. 3-17; Jonathan L. FAIRBANKS, Eternal Celebration in American Memorials, in: Donald Martin REYNOLDS (Hg.), "Remove not the ancient landmark«. Public monuments and moral values, Amsterdam 1996, S. 161-189; Michele H. BOGART, Public Sculpture and the civic ideal in New York City, 1890-1930, Chicago u. a. 1989 und James W. LOEWEN, Lies across America. What our historic sites get wrong, New York 2000.

106 Vgl. George L. MosSE, Die Nationalisierung der Massen. Politische Symbolik und Massenbewegungen von den Befreiungskriegen bis zum Dritten Reich, Frankfurt a. M., New York 1993 [engl. The Nationalization of the Masses, 1975], S. 19, 25-27, 29 und v.a. 31.

${ }^{107}$ Thematisiert werden allerdings überwiegend Kaiser-, Kanzler- und Kriegerdenkmäler, vgl ibid. S. 62-90.

${ }^{108}$ Äußerst ungesichert bleibt auch Mosses These, wonach offenbar nur die Wilhelminische Festkultur vom Defizit geprägt war, »für die Beteiligung des Volkes« keine Möglichkeit zu bieten, vgl. ibid. S. 114. Daß etwa das Publikum englischer Denkmalfeiern mindestens ebenso rigide von offiziösen Festivitäten ausgeschlossen und hinter Barrieren abgedrängt blieb und die gleiche Ausspernungspraxis bei allen Indizien für eine pluralere Festkultur selbst in Frankreich eher die Regel als die Ausnahme bildete, wird nicht beachtet. Mosses Sonderwegkonstrukt beruht hier auf einer konsequenten Ausblendung der vergleichenden Perspektive. 
national vergleichenden Nationalismusforschung längst als ubiquitäre Phänomene erachtet werden, muß Mosses Hauptthese zumindest als unausgewogen gelten $^{109}$.

Während also der systematische transnationale Denkmalvergleich sich im deutschen Forschungszusammenhang bislang auf wenig Vorarbeit stützen kann, bietet die ertragreiche Denkmal- und - z.T. bereits vergleichend ausgerichtete - Festforschung Grundthesen an, auf die an Ort und Stelle zurückzugreifen ist.

\subsubsection{Zum Forschungsstand in Frankreich}

In einer den Beiträgen Schieders und Fehrenbachs ähnlichen Weise hat Maurice Agulhon die nationale Symbolik Frankreichs thematisiert. Flaggen, Hymnen, Personifikationen des politischen Systems und anderen, nicht anthropomorphen Emblemen wie Münzen und Wappen wird die Funktion zuerkannt, Grundprinzipen politischer Herrschaft zu veranschaulichen und zugleich - dies im Sinne von Schieders These zum "Stimulantia «-Effekt - als eine Art kognitiven und emotionalen Sympathie- und Konsensappell zu wirken ${ }^{110}$. Darüber hinaus wird hier problematisiert, daß die angebotenen Bildarsenale auch an Rezeptionsgrenzen stoßen, weil die Diffusion von Symbolen durch ein politisches Regime zugleich deren Inflation und Vulgarisierung befördert, so daß sie langfristig redundant $\mathrm{zu}$ werden drohen ${ }^{111}$. Das Argument vom drohenden Bedeutungsverlust öffentlicher Symbole konvergiert mit der im deutschen Forschungskontext von Bookmann thematisierten utopistischen Valenz zeitgenössischer Denkmäler, die mit der ihnen zugedachten Sinnstiftungsleistung gleichsam medial überlastet sind ${ }^{112}$

Im Bereich architektonischer Baudenkmäler gibt es zunächst für das ausgehende 18. Jahrhundert neben Gesamtdarstellungen zu einer in der Regel im Projektstadium stagnierten ausladenden Revolutionsarchitektur ${ }^{113}$ besonders Untersuchungen zur Bastille als »Kollektivsymbol« mit einer bis ins 19. Jahr-

${ }^{109}$ Aus verschiedenen Historiographien sind darüber hinaus zahllose Beiträge zu anderen nationalen Personendenkmälern geliefert worden. Vgl. exemplarisch für Rußland nur Richard WORTMAN, Statues of the Tsars and the Redefinition of Russia's Past, in: Donald M. REYNOLDS (Hg.), Remove not the ancient landmark, S. 111-137 oder fuir den baltischen Raum Theodore R. WEEKS, Monuments and memory: immortalizing count M. N. Muraviev in Vilna, 1898, in: Nationalities Papers 27 (1999) S. 551-564, dem ich für seinen Hinweis danke.

${ }^{110}$ Vgl. Maurice AGULHON, Politics, images, and symbols in Post-revolutionary France, in: Sean WILENTZ (Hg.), Rites of power: symbolism, ritual and politics since the Middle Ages, Philadelphia 1985, S. 177-205, hier S. 177f.

${ }^{111}$ Vgl. ibid. S. 187, zum Problem der Rezeption auch ibid. S. 199-292.

${ }^{112}$ Vgl. BOOKMaNN, Denkmäler, S. 165.

${ }^{113}$ Vgl. James A. LEITH, Space and Revolution: Projects for monuments, squares and public buildings in France 1789-1799, Montreal u. a. 1991, hier S. 119-149; JOURDAN, Les Monuments, S. 9-31. 
hundert reichenden Rezeptionsgeschichte ${ }^{114}$. Ebenfalls für das 18. Jahrhundert sind die symbolische Kodierung und machtpolitische Inbesitznahme des öffentlichen Raums betrachtet worden ${ }^{115}$. Für das 19. Jahrhundert wurden einzelne Großbaudenkmäler in Paris ${ }^{16}$ und schließlich die symbolgeschichtlich wechselhafte Entwicklung der zum Pantheon umfunktionierten Stiftskirche Sainte Geneviève in baugeschichtlich-künstlerischer ${ }^{17}$ und symbolpolitischritueller Hinsicht dargestellt ${ }^{118}$. Am Beginn der historischen Erforschung von Personendenkmälern des 19. Jahrhunderts stehen zahlreiche nach wie vor grundlegende Beiträge von Agulhon, die - unter Berücksichtigung kunsthistorischer Beobachtungen - einer historisch-kritischen Denkmalanalyse den Weg geebnet haben, indem sie Errichtungsakte vor allem als symbolische Verfahren im Rahmen des öffentlichen politischen Diskurses werten ${ }^{119}$. Mit dem entwicklungsgeschichtlichen Abriß koppelt Agulhon eine formen- und ikonogra-

114 Vgl. Hans-Jürgen LUSEBRINK, Rolf REICHARDT, Die Bastille. Zur Symbolgeschichte von Herrschaft und Freiheit, Frankfurt 1990, hier S. 12f. zum Konzept der "Symbolgeschichte《.

$115 \mathrm{Vgl}$. Richard A. ETLIN, Symbolic space. French enlightenment architecture and its legacy, Chicago und London 1994, hier S. 30-43.

${ }^{116}$ Unter den zahlreichen Beiträgen im Rahmen des Lieux de mémoire-Projekts seien hier nur genannt Henri LOYRETTE, La Tour Eiffel, in: NORA, Les lieux III, Bd. 3, S. 474-505, François LOYER, Le Sacré-Coar de Montmartre, in: ibid. III, Bd. 3, S. 450-473, Alain ERLande-Brandenburg, Notre-Dame de Paris, in: ibid. III, Bd. 3, S. 358-402. Zu Pantheon, Invalidendom, Triumphbogen und Notre-Dame vgl. Avner BEN-AMOS, Monuments and memory in French Nationalism, in: History and Memory 5 (1993) S. 50-81; Albert BOIME, Hollow Icons: The politics of sculpture in nineteenth century France, Kent, Ohio, London 1987, hier S. 8-15, 50-69, 89-92, 106-112; Thomas W. GAEHTGENS, Napoleons Arc de Triomphe, Göttingen 1974 (Abhandlungen der Akademie der Wissenschaften in Göttingen, Phil.-Hist. Kl., 3. Folge, Nr. 90); Anne PINGEOr, Le rattachement des Tuileries au Louvre: Les palais de la gloire, in: La sculpture française au XIX ${ }^{e}$ siècle, Paris 1982 (AK Galeries nationales du Grand Palais), S. 183-191, und zahlreiche weitere Beiträge im gleichen Band; Penelope WOOLF, Symbol of the Second Empire: cultural politics and the Paris Opera House, in: Stephen DanIELS und Denis COSGROVE ( $\mathrm{Hg}$.), The Iconography of landscape. Essays on the symbolic representation, design and use of past environments, Cambridge 1988 (Cambridge Studies in Historical Geography, 9), S. 214 235.

117 Vgl. Le Panthéon. Symbole des révolutions. De l'Eglise de la Nation au Temple des grands hommes, Paris 1989, hierin v.a. die Beiträge von Barry BERDOLL, Le Panthéon/Sainte Geneviève au XIX siècle. La monumentalité à l'épreuve des révolutions idéologiques, ibid. S. 175-233; Anne PINGEOT, Le décor sculpté du Panthéon sous le Second Empire et la III République, ibid. S. 259-269. Vgl. sonst Mona OzOUF, Le Panthéon. L'Ecole normale des morts, in: NORA (Hg.), Les Lieux I, S. 139-166, dt.: DIES., Das Pantheon. Freiheit, Gleichheit, Brüderlichkeit. Zwei französische Gedächtnisorte, Berlin 1996, S. 7-38, und PAPENHEIM, Erinnerung und Unsterblichkeit, S. 294-301.

${ }^{118}$ Vgl. PAPENHEIM, ibid. S. 287-301.

119 Vgl. AGULHoN, La «statuomanie«, S. 146; Ruth BUTLER, ,Long live the Revolution, the Republic, and especially the Emperor!: The political sculpture of Rude, in: Henry MIILON, L.NOCHIIN (Hg.), Art and architecture in the service of politics, Cambridge, Mass. und London 1978, S. 92-107. 
phiespezifische Skizze und entwickelt so eine mit dem Beitrag Nipperdeys vergleichbare, allerdings ausschließlich auf die Individualdenkmäler bezogene Typologie $^{120}$. Personendenkmäler sind außerdem im Zuge von Einzelfallstudi$\mathrm{en}^{121}$ oder Synopsen ${ }^{122}$ des monumentalen Kults um eine Person ${ }^{123}$ oder Figurengattung ${ }^{124}$ berücksichtigt worden. Wie kaum ein anderes Monument findet dabei die Vendômesäule einschließlich der Napoleon-Statue vor allem hinsichtlich ihres spektakulären Sturzes 1871 Beachtung ${ }^{125}$. Schließlich haben auch denkmaltopographische Analysen sowohl für ausgewählte Städte der französischen Provinz ${ }^{126}$, als auch für Paris während der Dritten Republik ${ }^{127}$

${ }^{120}$ Vgl. ibid. S. 161. In einer ausdrücklich ıästhetischen‘, ikonographischen Typologie für die Phase ab 1830 und bis zur Jahrhundertwende unterscheidet Agulhon erstens einzelne Standfiguren auf einem mit Inschrift bzw. bildlichen Relief ausgestattetem Sockel, zweitens die zusätzliche Integration weiblicher Allegorien wie der Patrie oder der Ville de Paris und drittens Kombinationen aus grand homme und sekundärem (etwa rangniedriger positioniertem) realem Personal bzw. allegorischen Begleitfiguren. Nach der Jahrhundertwende wird die formale Uniformität allmählich durch abstraktere Strukturen aufgebrochen.

${ }^{121}$ Vgl. u. a. Marie-Louise BIVER, La Colonne Napoléone et le Camp de Boulogne-sur-Mer, in: Revue de l'Institut Napoléon 95 (1965) S. 76-83.

${ }^{122}$ Vgl. kurz Guénola GROUD, Daniel IMBERT (Hg.), Quand Paris dansait avec Marianne, 1879-1889, Paris 1989 (AK) zu öffentlichen Personendenkmälem in Paris. Vgl. als essayistisches Gesamtinventar, in der Regel aber ohne Quellenangabe, für ganz Frankreich ab dem ausgehenden 19. Jh. Pierre MOREL, Les monuments des grands hommes. De la statue au modeste médaillon, o. O. 1991.

${ }^{123}$ Vgl. Maurice AGULHON, Der Mythos Garibaldi in Frankreich von 1882 bis heute, in: DERS., Der vagabundierende Blick. Für ein Verständnis politischer Geschichtsschreibung, Frankfurt a. M. 1995, S. 154-199, und DERS., Une contribution au souvenir de Jean Jaurès: les monuments en places publiques, in: DERS., Histoire vagabonde Bd. 1: Ethnologie et politique dans la France contemporaine, Paris 1988, S. 186-204.

${ }^{124}$ Vgl. aus kunstgeschichtlicher Sicht Mechthild SCHNEIDER, Denkmäler für Künstler in Frankreich. Ein Thema der Auftragsplastik im 19. Jahrhundert, Frankfurt a. M. 1977, hier S. 241-268 auch zu den Hugo-Plastiken.

${ }^{125}$ Vgl. zu Genese und Wirkungsgeschichte des Denkmals v.a. Volker SELLIN, Napoleon auf der Säule der Großen Armee. Metamorphosen eines Pariser Denkmals, in: Christof DIPPER, Lutz KLINKHAMMER, Alexander NUTTZENADEL (Hg.), Europäische Sozialgeschichte. FS für Wolfgang SCHIEDER, Berlin 2000 (Historische Forschungen, 68), S. 377402. Vgl. sonst Matt K. MATSUDA, The memory of the modern, New York, Oxford 1996, S. 19-39; Maurice CHOURY, Bonjour, Monsieur Courbet! Paris 1969; Edgar ScHMTT, Das Trojanische Pferd und die Restauration. Die Auseinandersetzung um die Colonne de la Place Vendôme als Paradigma der gescheiterten Restauration, in: Gudrun GERSMANN, Hubertus KoHLE (Hg.), Frankreich 1815-1830. Trauma oder Utopie?, Stuttgart 1993, S. $187-195$

${ }^{126}$ Vgl. bislang singulär Philippe POIRRIER, Loïc VADELORGE, La statuaire provinciale sous la Troisième République. Une étude comparée: Rouen et Dijon, in: Revue d'Histoire moderne et contemporaine (RHMC) 42 (1995) S. 240-269.

${ }^{127} \mathrm{Vgl}$. v.a. June HARGROVE, Les statues de Paris. La représentation des grands hommes dans les rues et sur les places de Paris, Anvers 1989; DIES., Shaping the national image: The cult of statues to Great Men in the Third Republic, in: Richard A. ETLIN (Hg.), Nationalism and the Visual Arts, Hanover und London 1991 (Studies in the History of Art, 13), S. 49-63; Grundlagenarbeit hat zuvor bereits geleistet: Jacques LAFRANCHI, Statues de 
stattgefunden, von denen letztere für die vorliegende Untersuchung wichtige Überblicke vermitteln und erstere bereits die Indikatorfunktion von Kontroversen um das Monumentpersonal für (national)politische Konfliktlinien betonen ${ }^{128}$. Auch konzipieren sie die Denkmalerrichtungen schon als Modus öffentlicher politischer Kommunikation und als symbolische Variante eines nationalen Diskurses.

Vereinzelt sind Beiträge zu öffentlichen Denkmälern auch im Rahmen des umfangreichen Lieux de mémoire-Projekts von Pierre Nora zur Sprache gekommen, das nationale Sinnstiftung vor allem als kollektive Erinnerungsleistung der französischen Gesellschaft auffaßt ${ }^{129}$. Nora bezieht sich einerseits auf die Thesen des Soziologen Maurice Halbwachs, wonach Geschichte im Zuge ihrer »Erinnerung" rekonstruiert und verfremdet wird ${ }^{130}$ und die erinnerte Vergangenheit oder "mémoire collective ${ }^{131}$ als soziales Konstrukt erscheint ${ }^{132}$. Andererseits lehnt sich Nora an eine kulturwissenschaftliche Studie zur »Mnemotechnik» an, wonach die Fixierung geistiger Orte einer Strategie der antiken Rhetorik entspricht, indem deren imaginäres Abschreiten das Gedächntis unterstützt ${ }^{133}$. Die kompendiösen Ausmaße des Gesamtprojekts zei-

Paris. Les statues des Grands Hommes élevées à Paris des lendemains de la Révolution à 1940. Leur insertion dans l'histoire politique, sociale et culturelle. Thèse pour le doctorat du $3^{\text {ième }}$ cycle, Paris 1979, unveröff. Ms; vgl. auch Geneviève BRESC-BAUTIER, Anne PINGEOT (Hg.), Sculptures des jardins du Louvre, du Carrousel et des Tuileries, 2 Bände, Paris 1986. Vgl. auch HOBSBAWM, Mass-producing traditions, S. 272f.

${ }^{128} \mathrm{Vgl}$. programmatisch Thierry GASNIER, Les héros de l'histoire locale au XIX ${ }^{e}$ siècle en France, in: den BOER, FRIJHOFF (Hg.), Lieux de mémoire, S. 219-225; daneben mit einer nicht eigens begründeten Auswahl an Denkmälern in verschiedenen französischen Provinzstädten und spärlicher Kontextuierung der Einzelfälle William COHEN, Symbols of Power: Statues in Nineteenth-century Provincial France, in: Comparative Studies in Society and History (CSSH) 31 (1989) S. 491-513.

${ }^{129}$ Vgl. Pierre NORA (Hg.), Les lieux de mémoire, I. La République, Paris 1984; II. La Nation, Paris 1986, 3 Bände; III. Les France, Paris 1992, 3 Bände. Vgl v.a. June HARGROVE, Les statues de Paris, in: NORA (Hg.), Les lieux II. La Nation Bd. 3, S. 243-282.

${ }^{130}$ Vgl. Maurice HaLBWACHS, Das kollektive Gedächtnis, Frankfurt a. M. 1985, S. 12, 30 f. und 56. Vgl. dazu Patrick H. HUTTON, History as an Art of Memory, Hanover und London 1993, S. 73-90.

${ }^{131}$ Vgl. kritisch Marc BLOCH, Mémoire collective, tradition et coutume. A propos d'un livre récent, in: Revue de synthèse historique 39/40 (1925) S. 73-83. Vgl. auch Ingrid GLCHER-HOLTEY, Plädoyer für eine dynamische Mentalitätsgeschichte, in: GG 24 (1998) S. 476-497, hier S. 494.

${ }^{132} \mathrm{Vgl}$. Maurice HALBWACHS, Das Gedächtnis und seine sozialen Bedingungen, Frankfurt a. M. 1985, S. 368 [frz.: Les cadres sociaux de la mémoire] und Lucian HÖLSCHER, Geschichte und Vergessen, in: HZ 249 (1989) S. 1-17.

${ }^{133} \mathrm{Vgl}$. Frances A. YATES, Gedächtnis und Erinnern. Mnemotechnik von Aristoteles bis Shakespeare, Weinheim, Berlin ${ }^{3} 1990$, S. 11-31 [engl.: The Art of memory, London, Chicago 1966.] 
gen, daß Noras »Gedächtnis- $\varkappa^{134}$ bzw. »Erinnerungsorte ${ }^{135}$ gleichermaßen als fiktiv-symbolisch und physisch-real erscheinen ${ }^{136}$. Eine kritische Historiographie der Lieux de mémoire mündet Nora zufolge in eine Art analytischen "Ikonoklasmus ${ }^{137}$, in die Demontage von Selbstbildern, die für verbindlich erachtet werden, historisch legitimiert erscheinen und gegenständlich wie diskursiv tradiert werden. Zwar richtet sich Nora stark am französischen Nationalstaatsmodell aus ${ }^{138}$, das Programm des Dekonstruierens von Symbollandschaften bleibt aber ein fruchtbares Konzept für eine kulturgeschichtliche $\mathrm{Na}$ tionalismus- und nicht zuletzt Denkmalforschung.

Stärker als die beiden anderen hier berücksichtigten nationalen Historiographien hat sich die französische Geschichtswissenschaft darüber hinaus im engen thematischen Kontext der zeitgenössischen Denkmalbauten mit dem Phänomen des personalen Kults der grands hommes auseinandergesetz ${ }^{139}$. Untersuchungen zum allegorischen Rekurs auf die Nation haben gelegentlich auch

${ }^{134}$ Vgl. Pierre NORA, Zwischen Geschichte und Gedächtnis, Frankfurt a. M. 1998, Vorwort, S. 7f. Nora betont ausdrücklich, daß der in Anlehnung an Yates gebildete Begriff mlieux de mémoire « im Französischen einen Neologismus darstellt.

${ }^{135}$ Entgegen dem von Nora selbst gewählten Begriff des "Gedächtnisortes« ist dafür plädiert worden, Noras Konzept adäquater mit "Erinnerungsort " wiederzugeben, sofern die "lieux" eben nicht ein »eigenständiges Gedächtnis « bewahrten, sondern Orte und Gegenstände einer ihnen von der Gesellschaft zugeschrieben Erinnerung bildeten; vgl. so nachdrücklich FrANÇOIS, SIEGRIST, VoGEL, Die Nation, Anm. 52.

${ }^{136}$ Vgl. NORA, Comment écrire l'histoire de France?, in: DERS. (Hg.), Les lieux III, Bd. 1, S. 11-32, hier S. 20. Vgl. auch Jan ASSMANN, Das kulturelle Gedächtnis. Schrift, Erinnerung und politische Identität in frühen Hochkulturen, München ${ }^{3} 2000$, S. 30. Vgl. kritisch Klaus GROSSE-KRACHT, Gedächtnis und Geschichte: Maurice Halbwachs - Pierre Nora, in: GWU 47 (1996) S. 21-31, hier S. 27, und besonders Lucette VALENSI, Histoire nationale, histoire monumentale. Les lieux de mémoire (note critique), in: Annales 50 (1995) S. 1271-1277, und Steven ENGLUND, The Ghost of Nation Past, in: JMH 64 (1992) S. 299-320, hier S. 302. Positiver argumentiert François HARTOG, Temps et histoire. "Comment écrire I'histoire de France?«, in: Annales 50 (1995) S. 1219-1236, hier S. 1231 .

${ }^{137}$ Vgl. NORA, Entre Mémoire et Histoire, S. XXI.

${ }^{138}$ Vgl. auch TACKE, Denkmal im sozialen Raum, S. 14f. Auch hier gilt aber, daß Nora diese Zuspitzung nicht programmatisch betrieben hat; vgl. besonders deutlich DERS., Présentation, in: DERS. (Hg.), Les lieux I, S. VII-XIII, hier S. Xf. Vgl. Noras Kommentar in DERS., Comment écrire l'histoire de France, in: DERS. (Hg.), Les lieux III, Bd. 1, S. 11-32, hier S. 17-19.

${ }^{139}$ Vgl. v.a. Annie JouRDAN, Le culte des grands hommes sous la Révolution: l'invention d'un lieu de mémoire, in: DEN BOER, FRIJHOFF (Hg.), Lieux de mémoire, S. 165-183; Albert SOBOUL, Sentiment religieux et cultes populaires pendant la Révolution, saintes patriotes et martyres de la liberté, in: Archives de Sociologie des Religions 2 (1956) S. 7387, wieder in: Annales Historiques de la Révolution Française 29 (1957) S. 193-213; [engl.: Religious feeling and popular cults during the French Revolution: "patriot saints" and martyrs for liberty, in: Stephen WISON (Hg.), Saints and their cults. Studies in religious Sociology, Folklore and History, Cambridge 1997, S. 217-232, hier S. $219 f$. 
andere Popularisierungsmedien ${ }^{140}$ berücksichtigt, sich aber häufig auf Denkmäler verlegt. So hat Agulhon im Rahmen seiner flächendeckenden Studien zur Marianne/République-Allegorie deren bildliche wie programmatischinhaltliche Tradition auch in ihrer Erscheinungsform als öffentliches Denkmal oder Büste im Innenraum seit der Französischen Revolution nachgezeichnet ${ }^{141}$. Deutlich geringere Aufmerksamkeit ist anderen allegorischen Repräsentationen wie dem Hercule ${ }^{142}$ oder dem nie zum Status eines offiziellen Emblems vorgedrungenen Gallischen Hahn ${ }^{143}$ gewidmet worden. Vergleichende Blicke auf die deutsche Germania oder die englische Britannia sind aber unterblieben. Ebenso fehlen Studien zu den Trägern der Denkmalbewegung des 19. Jahrhunderts in Frankreich ${ }^{144}$.

Ähnlich wie in der deutschen Forschung wurden die Kriegerdenkmäler als eigene Monumentkategorie besonders beachtet. Neben den bereits genannten, am deutsch-französischen Vergleich orientierten Studien sind sowohl Denk-

140 Vgl. Patrick LAURENS, La figure officielle de la République Française: Monnaies et timbres, in: CHARLE u. a. (Hg.), La France démocratique, S. 421-429; David SCOTT, National lcons: the semiotics of the French stamp, in: French Historical Studies (FrenchHSt) 3 (1992) S. 215-234, hier S. 215-223; Gudrun GERSMANN, Der Streit um die Straßennamen. Städtische Gedenkpolitik zwischen Französischer Revolution und III. Republik, in: DIES., KOHLE (Hg.), Frankreich 1848-1870, S. 43-57.

${ }^{14 l} \mathrm{Vgl}$. Maurice AGULHON, Pour une archéologie de la République. L'allégorie civique féminine, in: Annales E.S.C. 28 (1973) S. 5-34, hier v.a. S. 17-28; DERS., Marianne au combat. L'imagerie et la symbolique républicaines de 1789 à 1880, Paris 1979; DERS., Marianne au pouvoir. L'imagerie et la symbolique républicaines de 1880 à 1914, Paris 1989; DERS., Von der Republik zum Vaterland. Die Gesichter der Marianne, in: Marie-Louise VON PLESSEN (Hg.), Marianne und Germania 1789-1889. Frankreich und Deutschland. Zwei Welten - eine Revue, Berlin 1996 (AK), S. 17-22; DERS., Pierre BONTE (Hg.), Marianne. Les visages de la République, Paris 1992; Vive la République 1792-1992, Paris 1992 (AK), hier S. 65-77; Christian AMALVI, Combats pour la mémoire à l'ombre du clocher et de la mairie: la Révolution au village de 1870-1914, in: Annuaire-Bulletin de la Société de l'Histoire de France, Années 1989-1990 S. 23-40, hier S. 23-25.

142 Vgl. Lynn HuNT, Politics, culture, and class, S. 87-119.

${ }^{143}$ Vgl. Michel PastoureaU, Le coq gaulois, in: NORA (Hg.), Les lieux III, Bd. 3, S. 506539.

${ }^{144}$ Diese Schieflage ist auch der Differenz zentraler analytischer Begriffe (Verein und sociabilité) geschuldet. Vgl. Otto DANN, Conclusion. Sociabilité und Vereinsbildung, in: Etienne FranÇOIS ( $\mathrm{Hg}$.), Sociabilité et société bourgeoise en France, en Allemagne et en Suisse, 1750-1850, Paris 1986, S. 313-316; Etienne FRANÇOIS und Rolf REICHARDT, Les formes de sociabilité en France du milieu du XVIII ${ }^{e}$ siècle au milieu du XIX ${ }^{e}$ siècle, in: RHMC 34 (1987) S. 453-472, hier S. 470-472; TACKE, Denkmal im sozialen Raum, S. 27. Vgl. ohne Verbindung zur Denkmalbewegung Sylvie APRIE, La République au Salon: vie et mort d'une forme de sociabilité politique (1865-1885), in: RHMC 38 (1991) S. 473-487; Benoît LECOQ, Les cercles Parisiens au début de la troisième République: de l'apogée au déclin, in: RHMC 32 (1985) S. 591-616. 
malvergleiche ${ }^{145}$ als auch Einzelfallstudien zu den überwiegend auf private Initiativen in den Départements zurückgehenden und meist erst im Anschluß an die abflauende Boulangerkrise um die Jahrhundertwende errichteten Denkmälern nach $1870 / 71^{146}$ erarbeitet worden. Für die französischen Kriegerdenkmäler nach dem Ersten Weltkrieg ${ }^{147}$ liegt eine Typologie auf der Grundlage von Standort- und Ikonographie-Kriterien vor ${ }^{148}$.

Vor allem weist die französische Historiographie eine inzwischen beträchtliche Literatur zum Themenkomplex politischer Feste auf ${ }^{149}$, die insbesondere die Geschichte des Nationalfeiertags ${ }^{150}$ und einer Reihe großer Staatsbegräb-

${ }^{145}$ Vgl. im französisch-amerikanischen Vergleich Annette BECKER, Monuments aux morts après la guerre de sécession et la guerre de 1870-1871: un legs de la guerre nationale?, in: Guerres mondiales et conflits contemporains 167 (1992) S. 23-40.

${ }^{146}$ Vgl. als regionale Fallstudien zu Frankreich William KDD, Les monuments aux morts mosellans. De 1870 à nos jours, Metz 1999; David G. TROYANSKY, Monumental Politics: National History and Local Memory in French Monuments aux Morts in the Department of the Aisne since 1870, in: FrenchHSt 15 (1987) S. 121-141; vgl. auch J.A. SCHMOLL gen. EISENWERTH, Rodins "Ehernes Zeitalter« und die Problematik Französischer Kriegerdenkmäler nach 1871, in: KOSELLECK, JEISMANN (Hg.), Der politische Totenkult, S. 223-247, hier S. 231-234 und 238.

${ }^{147} \mathrm{Vgl}$. Antoine PROST, Mémoires locales et mémoires nationales: les monuments de 19141918 en France, in: Guerres mondiales et conflits contemporains 167 (1992) S. 41-50; Annette BECKER, Der Kult der Erinnerung nach dem Großen Krieg. Kriegerdenkmäler in Frankreich, in: KOSELLECK, JEISMANN (Hg.), Der politische Totenkult, S. 315-324; Daniel J. SHERMAN, Monuments, mourning and masculinity in France after World War 1 , in: Gender \& History 8 (1996) S. 82-107.

${ }^{148}$ Vgl. Antoine PROST, Les monuments aux morts. Culte républicain? Culte civique? Culte patriotique?, in: NORA (Hg.), Les Lieux I, S. 195-225, hier S. 201-207. Prost unterscheidet laizistische "monuments civiques « zum einen von triumphalen "monuments patriotiques-républicains«, zum anderen von auf eine Opfermystik zielenden "monuments funéraires-patriotiques" sowie schließlich von reinen »monuments funéraires«. Sozialprofile und Sozialhandeln im Umfeld der Denkmäler spielen bei der Typologiebildung eine untergeordnete Rolle.

${ }^{149} \mathrm{Vgl}$. etwa zu den Revolutionsfeierlichkeiten zwischen 1790 und 1806, auch unter Berücksichtigung von Denkmälern und Denkmalprojekten in Paris, Marie-Louise BIVER, Fêtes révolutionnaires à Paris, Paris 1979; zur zweiten Hälfte des 19. Jhs. u. a. Maurice AGULHON, Fête spontanée et fêtes organisées à Paris en 1848, in: Jean EHRARD, Paul ViallaNEDX (Hg.), Les fêtes de la Révolution. Colloque de Clermont-Ferrand, Paris 1977, S. 243-271; Stéphane GERSON, Town, nation or humanity? Festive delineations of place and past in northem France, ca. 1825-1865, in: JMH 72 (2000) S. 628-682; Charles REARICK, Festivals in Modern France: The Experience of the Third Republic, in: JContH 12 (1977) S. 435-460; Dietmar HUUSER, Bauern und Franzosen, Integration und Eigensinn. Zur ländlichen Politisierung und kulturellen Nationsbildung im Frankreich des 19. Jahrhunderts, in: AfS 41 (2001) S. 409-431, hier S. 422-425.

${ }^{150}$ Olivier IHL, Des fêtes sans Dieu. L'enjeu de laïcité dans les célébrations républicaines de la Troisième République, in: DEN BOER, FRIHOFF (Hg.), Lieux de mémoire, S. 227-235 und DERS., La fête républicaine, Paris 1996; Pascal ORY, Une nation pour mémoire, 1889, 1939, 1989, Trois jubilés révolutionaires, Paris 1992; Christian AMALVI, Le 14 Juillet. Du "dies irae« à »Jour de fête«, in: NORA (Hg.), Les Lieux I, S. 421-472 und Jean-Pierre BoIS, Histoire des 14 juillet, 1789-1919, Rennes 1991. Vgl. zur Hymne in vergleichender 
nisse $^{151}$ einschließlich der spektakulär inszenierten Rückführung des Leichnams Napoleons 1840 berücksichtigt ${ }^{152}$. Im Vergleich zur deutschen Historiographie greifen die französische Fest- und die Denkmalforschung dabei weniger stark ineinander ${ }^{153}$. Im Blick auf die öffentliche Inszenierungspraxis konnte gezeigt werden, daß nationale Feste in Frankreich durchaus auch deutliche Zeichen einer militarisierten Symbolik trugen. Der These vom symbolischen Ausverkauf bürgerlicher Sinnstiftungsansprüche, mit der dieses Phänomen in Deutschland in der Forschung kommentiert worden ist, steht im französischen Fall die Tendenz entgegen, im militarisierten bürgerlich-nationalen Kult etwa anläßlich der Feiern zum 14. Juli eher eine symbolische Integrationsleistung zumal auf dem Hintergrund der zu bewältigenden Niederlagenerfahrung von 1870/71 zu erkennen ${ }^{154}$. Ähnlich wie in Deutschland hat sich die französische Forschung auch für die großen Weltausstellungen unter dem Gesichtspunkt inszenierter nationaler Selbstbildproduktion interessiert ${ }^{155}$. Anders als dort ist allerdings die Kritik am öffentlichen Denkmalwesen in Frankreich durchaus als Indikator für die zeitgenössische politisch-ideologische Aufladung dieser Praxis gewertet worden ${ }^{156}$. Vor allem wurde in einer weder mit der deutschen noch mit der englischen Forschung vergleichbaren Intensität das Phänomen des Ikonoklasmus als Höhepunkt destruktiver Denkmalkritik eigens im Rah-

Perspektive knapp Anne-Sophie LETERRIER, Les hymnes nationaux euopéens, in: CHARLE u. a. (Hg.), La France démocratique, S. 449-455; Michel VovelLE, La Marseillaise, in: NORA (Hg.), Les lieux I, S. 85-136.

${ }^{151} \mathrm{Vgl}$. zu den offiziösen Begräbnissen während des Ancien Régime und der Revolution PAPENHEIM, Erinnerung und Unsterblichkeit, S. 76-105; zur Dritten Republik Avner BENAMOS, The sacred center of power: Paris and the state funerals of the French Third Republic, in: Journal of Interdisciplinary history 22 (1991) S. 27-48.

${ }^{152} \mathrm{Vgl}$. u. a. Jean TULARD, Le retour des cendres, in: NORA (Hg.), Les Lieux II, La Nation, Bd. 3, S. 81-1 10. Zum Napoleongrab im Invalidendom einschließlich der zahlreichen nicht umgesetzten Entwürfe Michael Paul DRISKEL, As befits a legend: building a tomb for Napoleon, 1840-1861, Kent, Ohio und London 1993; zeitgenössisch ausführlich H. FAUVEZ, Projet de tombeau pour l'Empereur Napoléon Premier par Louis Auvray, statuaire. Dédié à sa Majesté l'Empereur Napoléon III, Paris 1861.

${ }^{153} \mathrm{Vgl}$. weitgehend losgekoppelt von Denkmalaspekten Rosemonde SANSON, La »Fête de Jeanne d'Arc« en 1894. Controverse et célébration, in: RHMC 20 (1973) S. 144-162. Zu den Jeanne-Festen in Orléans einschließlich der dortigen Monumente vgl. Antoine PROST, Jeanne et la fête. Identité collective et mémoire à Orléans depuis la Révolution Française, in: CHARLE u. a. (Hg.), La France démocratique, S. 379-395.

${ }^{154} \mathrm{Vgl}$. VOGEL, Nationen im Gleichschritt, S. 13.

155 Vgl. kunstgeschichtlich Patricia MANARDI, Arts and politics in the Second Empire. The universal expositions of 1855 and 1867, New Haven, London 1987. Zur französischen Selbstdarstellung auf den Weltaustellungen 1878 und 1889 im Bereich der bildenden Künste vgl. auch Robert Allen JAY, Art and nationalism in France 1870-1914, Ann Arbor 1979, hier S. 61-141.

${ }^{156} \mathrm{Vgl}$. AGULHON, La »statuomanie«, S. 150 und 158. 
men einer Geschichte des Vandalismus ${ }^{157}$ erörtert, die der Verquickung von nationalem und ikonoklastischem Diskurs vor allem während der Französischen Revolution nachgeht ${ }^{158}$.

Ungeachtet eines im Detail überaus reichen Forschungsertrags bleibt damit auch im Falle der französischen Historiographie der transnationale Denkmalvergleich ein Desiderat.

\subsubsection{Zum Forschungsstand in England}

Eine mit der in der deutschen und französischen Historiographie vergleichbare Konjunktur des Denkmalthemas zeichnet sich demgegenüber für den britischen Raum nicht auch nur annähernd $\mathrm{ab}$. So wenig bislang nationale Personendenkmäler in der englischen Forschung Beachtung gefunden haben ${ }^{159}$, sind jenseits dieser Monumentkategorie am ehesten große architektonische Baudenkmäler und hier neben Westminster Abbey ${ }^{160}$ vor allem das Parlamentsgebäude samt seiner Innenausstattung ${ }^{161}$ berücksichtigt worden ${ }^{162}$. Kunstgeschichtliche Untersuchungen liegen zu den Denkmälern für die Kriegsheroen

${ }^{157} \mathrm{Vgl}$. Louis RÉAU, Histoire du Vandalisme. Les monuments détruits de l'art français, Paris 1994, hier S. 640f., 713, 776-781, 791-796 (zur Colonne Vendôme); zu den nachrevolutionären Denkmalstürzen um die Jahrhundertwende M. WAGNER, Outrages. Sculpture and kingship in France after 1789, in: Ann BERMINGHAM, John BREWER ( $\mathrm{Hg}$.), The consumption of culture, 1600-1800. Image, object, text, London und New York 1995, S. 294-318.

${ }^{158}$ Vgl. Edouard POMMIER, Discours iconoclaste, discours culturel, discours national, 1790 1794, in: Simone BERNARD-GRIFFITHS, Marie-Claude CHEMIN, Jean EHRARD (Hg.), Révolution française et "vandalisme révolutionnaire«. Actes du colloque international de Clermont-Ferrand, Paris 1992, S. 299-313. Vgl. in diesem Sammelband zahlreiche Fallstudien zu Denkmalstürzen in der Provinz.

${ }^{159}$ Vgl. knapp zu frühneuzeitlichen Grabmonumenten Nigel LLEWELLYN, Honour in life, death, and in the memory, Funeral monuments in early modern England, in: Transactions of the Royal Historical Society (TRHS) 6 (1996), $6^{\text {th }}$ ser. S. 179-200. Vgl. sonst eher als Ausnahmen F. Darrell MUNSELL, The Victorian controversy surrounding the Wellington War Memorial, Lewiston, Queenston, Lampeter 1991; Stephen BAYLEY, The Albert Memorial, London 1981; Tori SMITH, ,A grand work of noble conceptionc: the Victoria Memorial and imperial London, in: Felix DRIVER, David GLBERT ( $\mathrm{Hg}$.), Imperial cities. Landscape, display and identity, Manchester und New York 1999, S. 21-39 sowie unerläßlich BLACKWOOD, London's immortals.

${ }^{160} \mathrm{Vgl}$. John PHYSICK, Prime Ministers in Westminster Abbey, in: Church Monuments 9 (1994) S. 93-106.

${ }^{161}$ Vgl. Michael H. PORT (Hg.), The Houses of Parliament, New Haven und London 1976; Joan W. M. HICHBERGER, Images of the army. The military in british art 1815-1914, Manchester 1988, S. 36-48; Lavinia HANDLEY-READ, Whitehall Sculpture, in: Architectural Review 128 (1970) S. 276-279. Vgl. zum unpolitischen Säulendenkmal nahe der London Bridge W. A. SPECK, The Monument, in: History Today 23 (1973) S. 664-668.

${ }^{162}$ Nicht überzeugen kann der Versuch, einen spezifischen »architektonischen Nationalismus« in England zu identifizieren, bei Stefan MUTHESIUs, Some aspects of English architectural nationalism in the $19^{\text {th }}$ and early $20^{\text {th }}$ centuries, in: Anna KWILCKA, Francis AMES-LEWIS (Hg.), Art and National Identity in Poland and England, London 1996, S. 65-71. 
vor $^{163}$. Entsprechend vorläufig ist der Stand methodischer Reflexion über den historischen Erkenntniswert von Monumenten als Symbolen kollektiver Werthaltungen. Aspekte der Personalisierung nationaler Leitideen wurden zum Teil bereits vergleichend, allerdings außerhalb jeden Bezugs zu öffentlichen Denkmälern thematisiert ${ }^{164}$ oder aus einer stärker geistesgeschichtlichen Perspektive mit der zeitgenössisch umfassend rezipierten Schrift Carlyles zum viktorianischen Heroentum in Verbindung gebracht ${ }^{165}$. Die allegorische Repräsentation der Nation durch die Britannia und durch die auf England bezogene, in Schottland erfundene, dezidiert nicht-britische Populärversion des John Bull $^{166}$ ist zwar beachtet, aber nicht für den Bereich öffentlicher Monumente erörtert worden ${ }^{167}$. Ebenso wie in der französischen Historiographie sind vergleichende Rekurse auf die großen nationalen Allegorien Europas auch außerhalb des konkreten Denkmalbezugs ausgeblieben.

Ausschließlich die Sonderkategorie britischer Kriegerdenkmäler zum Ersten Weltkrieg wurde eingehender berücksichtigt. Dies ist zunächst nicht systematisch vergleichend geschehen, aber doch mit punktuellen Ausblicken auf Europa und vor allem anhand ikonographisch-kunstgeschichtlicher Fragestellungen $^{168}$. Die jüngste Behandlung von Kriegerdenkmälern findet bei Jay Winter im Rahmen eines "sites of memory «-Konzepts statt, das anders als Noras Lieux de mémoire nicht auf ein Land konzentriert bleibt, sondern eine international vergleichende kulturgeschichtliche Untersuchungsanordnung zugrundelegt ${ }^{169}$. Die englische, französische und deutsche Nachkriegsgesellschaft werden gleichermaßen im Hinblick auf die Leitfrage nach den kulturellen Folgen des Ersten Weltkrieges betrachtet, zu denen unter anderem die Errichtung von

${ }^{163} \mathrm{Vgl}$. Alison YARRINGTON, The Commemoration of the Hero 1800-1864. Monuments to the British Victors of the Napoleonic Wars, New York, London 1988, zu Birmingham, Liverpool, Great Yarmouth, Shrewsbury, London. Vgl. auch Elisabeth DARBY, Nicola SMTTH, The cult of the Prince Consort, New Haven, London 1983.

${ }^{164} \mathrm{Vgl}$. ohne Verweise auf Denkmäler Peter KARSTEN, Patriot-Heroes in England and America. Political Symbolism and Changing values over three centuries, Wisconsin 1978.

${ }^{165}$ Vgl. C.I. HAMIITON, Naval hagiography and the Victorian Hero, in: The Historical Journal (HJ) 23 (1980) S. 381-398; John MORROW, The paradox of Peel as Carlylean Hero, in: HJ 40 (1997) S. 97-110.

${ }^{166} \mathrm{Vgl}$. Miles TAYLOR, John Bull and the Iconography of Public Opinion in England c. 1712 1929, in: P\&P 134 (1992) S. 93-128.

${ }^{167}$ Vgl. Madge DresSER, Britannia, in: SAMUEL (Hg.), Patriotism, Bd. 3, S. 26-49

${ }^{168}$ Vgl. Alan BORG, War Memorials from antiquity to the present, London 1991, hier S. 6985 zu nach 1918 errichteten Kriegerdenkmälern in London; Alex KING, Memorials of the Great War in Britain: The symbolism and politics of Remembrance, Oxford, New York 1998.

${ }^{169} \mathrm{Vgl}$. Jay WINTER, Sites of memory, sites of mouming. The Great War in European cultural history, Cambridge 1995 (Studies in the Social and Cultural History of Modern Warfare), S. 10f. Zentral verhandelt werden der Tranchée des Baionnettes bei Verdun, der Cenotaph in London, das Denkmal für die Vermißten der Sommeschlacht bei Thiepval und die Kollwitz-Skulptur »Die Eltern« auf dem Kriegsgräberfriedhof bei Vladslo. 
Kriegerdenkmälern gezählt wird, die als Modi der Bewältigung einer genuin neuen Kriegserfahrung gelten ${ }^{170}$. Daß Winters Studie sich auf Kriegerdenkmäler kapriziert, die einer eigenständigen zeitgenössischen Logik folgen, und daß sie einen anderen Zeitrahmen als die vorliegende Untersuchung wählt, verringert direkte Anknüpfungsmöglichkeiten. Beachtenswert bleibt dennoch Winters Leitthese vom »special path ${ }^{171}$ als dem Weg, auf dem nicht nur die deutsche, sondern ebenso die englische wie französische Nation in die Nachkriegsmoderne gelangt seien.

Mehr als dem Denkmal hat die englische Forschung dem politischen Fest ${ }^{172}$ und hier besonders den großen Regierungsjubiläen der Monarchin ${ }^{173}$ während der zweiten Jahrhunderthälfte größere Aufmerksamkeit gewidmet ${ }^{174}$. Die erfolgreiche Selbstinszenierung der Monarchie und die Stilisierung Georges III. zum Repräsentanten eines $\gg$ British patriotism « im frühen 19. Jahrhundert ${ }^{175}$ wurden demnach mit öffentlichen Inszenierungen der Opposition konterkariert $^{176}$. Schließlich hat David Cannadine Fragen der Festkultur im Großbritannien des 19. Jahrhunderts innerhalb eines umfangreichen Beitrags zum Invention of tradition-Projekt verhandelt ${ }^{177}$. Ritueller (imperialistischer) Populismus und matriarchalischer Anachronismus werden als Spezifika der britischen Monarchie und des von ihr entworfenen nationalen Selbstbildes ausgewie$\operatorname{sen}^{178}$. Gleichwohl unterbleibt eine eigenständige Gewichtung öffentlicher

${ }^{170}$ Vgl. ibid. S. 1-11.

${ }^{171} \mathrm{Vgl}$. zu diesem $»$ special ( path (...) of collective slaughter« ibid. S. 227.

${ }^{172}$ Vgl. David CANNADINE, Introduction: Divine rights of kings, in: DERS., Simon PRICE (Hg.), Rituals of royalty: power and ceremonial in traditional societies, Cambridge, New York, Oakleigh 1992 (Past and Present Publications), S. 1-19 und Cannadines Fallstudie: The transformation of civic ritual in Modern Britain: The Colchester Oyster Feast, in: P\&P 94 (1982) S. 107-130.

${ }^{173}$ Vgl. DEBRETT's Queen Victoria's Jubilees 1887 \& 1897, compiled by Carolin CHAPMAN und Paul RABEN, London 1977; Thomas RICHARDS, The image of Victoria in the year of jubilee, in: Victorian Studies 31 (1987) S. 7-32; David CANNADNE; Elizabeth HAMMERTON, Conflict and consensus on a ceremonial occasion: The Diamond Jubilee in Cambridge in 1897, in: HJ 24 (1981) S. 111-146; Malcolm CHASE, From millennium to anniversary: the concept of Jubilee in late eighteenth- and nineteenth-century England, in: P\&P 129 (1990) S. 132-147.

${ }^{174} \mathrm{Vgl}$. auch Roland QUINAULT, The cult of the Centenary, c. 1784-1914, in: Historical Research (HR) 71 (1998) S. 303-323.

${ }^{175} \mathrm{Vgl}$. Linda COLLEY, The apotheosis of George III: Loyalty, royalty and the British nation, 1760-1820, in: P\&P 102 (1984) S. 94-129.

${ }^{176} \mathrm{Vgl}$. Anthony TAYLOR, Reynold's Newspaper, Opposition to Monarchy and the Radical Anti-Jubilee: Britain's Anti-Monarchist Tradition reconsidered, in: HR 68 (1995) S. 318 337 , v.a. S. $330-337$.

${ }^{177}$ Vgl. David CANNADINE, The context, performance and meaning of ritual: The British Monarchy and the Invention of Tradition, c. 1820-1977, in: HOBSBAWM, RANGER (Hg.), The invention of tradition, S. 101-164, hier S. 103-106.

${ }^{178}$ Vgl. ibid. S. 133. Vgl. auch bis Ende des 18. Jhs. Marilyn MORRIS, The British monarchy and the French Revolution, Binghamton, New York 1998, hier S. 1-12. 
Denkmäler, die hier lediglich als ein Aspekt der gesamten Londoner Repräsentationsarchitektur ${ }^{179}$ und des »state pageant $/$ gelten. Da die Denkmalbewegung im 19. Jahrhundert außerhalb eng abgesteckter Fallstudien in der englischen Forschung kaum behandelt worden ist, liegen auch keine Angaben zu Sozialprofilen der Träger derartiger Unternehmungen vor ${ }^{180}$.

Anders als der deutsche Sedantag und die fête nationale in Frankreich sind die um 1900 einsetzende kontroverse Vorgeschichte und die erst spät von der Regierung sanktionierte Feierpraxis des Empire Day seit dem 24. Mai 1916 hinsichtlich ihrer Reichweite und ihrer rituellen Formen deutlich weniger untersucht worden ${ }^{181}$. Den zeitgenössischen Medien, deren Vehikelfunktion für die imperialistische Propaganda im ausgehenden Jahrhundert anhand von Pamphleten und Journalen, Postkarten, Postern, Bannern, Flaggen u.ä. verfolgt wurde $^{182}$, sind schließlich an keiner Stelle öffentliche Denkmäler zugerechnet worden, obgleich ein ausgeprägter Visualisierungsbedarf und die Tendenz zum personalen Kult als Charakteristika der Massenbewegung identifiziert worden sind. Vor allem im Vergleich mit Paris, aber auch mit der englischen Provinz, erscheint die bürgerliche Festkultur der Metropole im 19. Jahrhundert erheblich stärker durch eine dezidiert unterbürgerliche, politisch radikale Demonstrationskultur konterkariert. Den staatlich-royalistisch wie städtisch ${ }^{183}$ lan-

${ }^{179}$ Vgl. ibid. S. 128. Vergleichend zur Londoner Repräsentationsarchitektur, allerdings ohne Berücksichtigung öffentlicher Denkmäler, auch bereits Donald J. OLSEN, The City as a work of art. London, Paris, Vienna; New Haven, London 1986.

${ }^{180}$ Vgl. zur Rolle der Vereine (»associations «, )voluntary societies«) bei der Formierung bürgerlicher Gruppen unabhängig vom Denkmalphänomen Geoffrey CROSSICK, La bourgeoisie britannique au $19^{e}$ siècle. Recherches, approches, problématiques, in: Annales 53 (1998) S. 1089-1130, hier S. 1103-1105; F.M.L. THOMPSON (Hg.), The Cambridge Social History of Britain 1750-1950, Cambridge 1990, S. 406-430; Andreas WIRSCHING, Parlament und Volkes Stimme. Unterhaus und Öffentlichkeit im England des frühen 19. Jahrhunderts, Göttingen, Zürich 1990 (Veröffentlichungen des DHI London, 26), S. 9295; Christiane EISENBERG, Arbeiter, Bürger und der »bürgerliche Verein« 1820-1870. Deutschland und England im Vergleich, in: Jürgen KoCKA (Hg.), Bürgertum im 19. Jahrhundert. Deutschland im europäischen Vergleich, Bd. 2, München 1988, S. 187-219, hier S. $189 f$. und 218.

181 Vgl. J.A. MANGAN, , The grit of our forefathers $\mathrm{A}$. Invented traditions, propaganada and imperialism, in: John M. MACKENZIE (Hg.), Imperialism and popular culture, Manchester 1986, S. 113-139, hier S. 130-136 und J.O. SPRINGHALL, Lord Meath, Youth, and Empire, in: JContH 5 (1970) S. 97-111, hier S. 105-111. 1958 wurde der Empire- zum Commonwealth Day. Vgl. sonst zu Weltausstellungen Jeffrey Aaron AUERBACH, Exhibiting the Nation: British national identity and the Great Exhibition of 1851, Ann Arbor 1995.

${ }^{182}$ Vgl. John MACKENZIE, The vehicles of imperial propaganda, in: DERS., Propaganda and Empire. The manipulation of British Public Opinion, 1880-1960, Manchester 1984, ND 1988, S. 16-38, hier S. 16-18; Robert GIDDNGS, Delusive seduction, pride, pomp, circumstance and military music, in: John MACKENZIE $(\mathrm{Hg}$.), Popular Imperialism and the military, 1850-1950, Manchester 1992, S. 25-49.

${ }^{183} \mathrm{Vgl}$. T.B. SMTTH, In defence of privilege: The City of London and the challenge of municpal reform 1875-1890, in: Journal of Social History (JSocH) 27 (1993) S. 59-83 und De- 
cierten politischen Festen in London standen bis weit in die zweite Jahrhunderthälfte hinein immer auch Konflikte um radikale Versammlungen und Demonstrationen entgegen, die angesichts einer inkohärenten Binnenverwaltung schwer domestizierbar erschienen bzw. unmittelbar eine Konfrontation mit den staatlichen Instanzen nach sich zogen ${ }^{184}$.

Sofern die englische Historiographie bislang die Denkmalforschung eher vernachlässigte, sind Anknüpfungspunkte in Gestalt von Beiträgen zum übergeordneten Thema nicht nur der Invention of tradition, sondern auch der Etablierung politischer Symbole im England des 19. Jahrhundert zu suchen. Hier steht zunächst ein Zugriff in der Tradition der Chartismus-Historiographie im Vordergrund, die sich mit der sozialrevolutionären Bewegung des frühen 19. Jahrhunderts auf dem Wege einer intensiven politischen Diskursanalyse auseinandersetzt und auch der Sprach-Symbolik eine Indikatorfunktion für die Entwicklung eines soziopolitischen Selbstbewußtseins radikaler Gruppen zuerkennt. »Chartist radicalism « wird dann nicht als Ideologie einer bestimmten sozialen Klasse, sondern primär als sprachlich-semantisch transportierter Protest gegen politische und ökonomische Exklusion interpretiert ${ }^{185}$. Parallel dazu ist das Repertoire an politischen Symboliken weit über den Bereich der Sprache hinaus etwa auch auf die Untersuchung des Effekts von Flaggen, Bannern, politischem Liedgut, offiziellen Banketts ${ }^{186}$ oder der "cap of liberty" ausgedehnt worden ${ }^{187}$. Hier wird das Verfahren der Bedeutungszuweisung als Resultat des Zusammenwirkens von gewähltem Symbol, seiner Inszenierung und seinem Handlungskontext gedeutet, der, wenngleich von Fragen einer Monumentalsymbolik gänzlich absehend, methodische Rahmenbedingungen auch

borah S. RYAN, Staging the imperial city: The Pageant of London, 1911, in: DRIVER, GILBERT (Hg.), Imperial cities, S. 117-135

${ }^{184} \mathrm{Vgl}$. Antony TAYLOR, "Common stealers «, »Land-grabbers $«$ and »Jerry-Builders $«:$ Space, popular radicalism and the politics of public access in London, 1848-1880, in: International Review of Social History 40 (1995) S. 383-407, hier S. 385-394.

${ }^{185} \mathrm{Vgl}$. Gareth Stedman JONES, The language of Chartism, in: James EPSTEIN, Dorothy THOMPSON (Hg.), The Chartist Experience: Studies in Working-class radicalism and culture, 1830-60, London, Basingstoke 1983, S. 3-58, hier S. 6f., 11, 14-16, 44, 48-52. Vgl. allerdings die Kritik u. a bei Hugh CUNNINGHAM, The language of patriotism, in: SAMUEL (Hg.), Patriotism I, S. 57-89, hier S. 70-82.

${ }^{186} \mathrm{Vgl}$. Peter BRETT, Political Dinners in early nineteenth-century Britain: Platform, meeting place and battleground, in: History 81 (1996) S. 527-552.

187 Vgl. Patrick JOYCE, Visions of the people. Industrial England and the question of class 1848-1914, Cambridge 1991, hier S. 9-12; James A. EPSTEIN, Understanding the cap of liberty: symbolic practice and social conflict in early nineteenth-century England, in: P\&P 122 (1989) S. 75-118. Vgl. sonst den Literaturbericht von James THOMPSON, After the fall: class and political language in Britain, 1780-1900, in: HJ 39 (1996) S. 785-806. Vgl. zum Public Park-Movement als Strategie der Kontrolle öffentlichen Raums durch die wmiddle classes « Robert ALLEN, The battle for the commons: politics and populism in midVictorian Kentish London, in: Social History (SocH) 22 (1997) S. 61-77, hier S. 61-64 sowie TAYLOR, »Common stealers «. 
für eine Denkmalanalyse liefern kann. Zum entscheidenden Kriterium wird hier nämlich die Deutungsmacht im öffentlichen Raum, um die mit dem Ziel gerungen wird sto provide an interpretation of Britain's past, and therefore, to give direction to the nation's political and social future ${ }^{188}$. Zugleich erscheinen Symbolbedeutungen als Ausdruck einer variablen Konstruktion und ihre Umstrittenheit als Symptom politischer Konflikte. Methodische Überlegungen zur Analyse öffentlicher Denkmäler, wie sie im deutsch-französischen Vergleich entwickelt worden sind, fehlen also. Mit der Symbolanalyse vergleichbare Prozesse werden aber längst betrachtet und in diesem Zusammenhang auch Kontextuierungsgebote formuliert.

Eine Adaption des Nora'schen Lieux de mémoire-Konzepts, das inzwischen auch auf andere Länder angewandt worden ist ${ }^{189}$, hat in der britischen Historiographie bislang nicht stattgefunden. Bestätigt wurde, daß Noras Konzept eher zur Dekonstruktion als zur Identitätsbeschwörung beiträgt und ein vergleichbarer Zugang auch $\mathrm{zu}$ britischen Erinnerungsorten wünschenswert bleibt ${ }^{190}$. Andererseits wurde gemutmaßt, daß Großbritannien im Vergleich womöglich über einen erheblich geringeren Vorrat an dezidiert politisch konnotierten Nationalsymbolen verfüge, weil die Kontinuitätstradition britischer Geschichte hier im Gegensatz zur Mythen forcierenden unruhigen Umbruchsgeschichte Frankreichs eine deutlich weniger emphatische Produktion eines nationalen Gedächtnisses begünstigt habe, das sich in nostalgischer Rückbesinnung und einer bezuglosen »sheer pastness « erschöpfe ${ }^{191}$. Zum Argument gehört die Unterstellung, daB eine Umbruchsgeschichte erheblich stärker zur nationalen Sinnschöpfung und Symbolproduktion dispositioniert, Gedächtnisbildung mithin vom Moment der »discontinuity« nachgerade profitiert, weil sie einen Mechanismus von wrepetitive discord and unsparingly reflexive explicitness ${ }^{192}$ provoziert. Darauf wird etwa im Blick auf die Londoner Nelsonoder Wellington-Denkmäler zurückzukommen sein. Daß die nationale Memorialisierung darüber hinaus in der Tat häufig staatsfern und nicht zentral gelenkt stattgefunden hat, konnte den Effekt verzögerter Symbolbildung nur verstärken ${ }^{193}$.

Schließlich sind Fragen einer politischen Symbolik als Indikator für den modernen englischen Patriotismus in einer Noras Projekt für Frankreich aller-

${ }^{188} \mathrm{Vgl}$. EPSTEIN, Understanding the cap of liberty, S. 116f. Vgl. auch TAYLOR, "CommonStealers«, S. 387-393.

${ }^{189}$ Vgl. z.B. Gudmundur HÁLFDANARSON, lingvellir. An icelandic »Lieu de mémoire«, in: History and Memory 12 (2000) S. 5-29.

${ }^{190}$ Vgl. Stefan CollIN, French Contrasts: From the Panthéon to Poet's Corner, in: DERS., English Pasts. Essays in History and Culture, Oxford 1999, S. 38-66, hier S. 51-53.

${ }^{191}$ Vgl. ibid. S. 49 und 54-56.

192 Ibid. S. 56.

193 Vgl. ibid. S. 58-66. 
dings kaum vergleichbaren Form von Raphael Samuel aufgegriffen worden ${ }^{194}$. Anders als Nora hat Samuel das Konzept jener Sammlung von (zeit-)historischen Momentaufnahmen eines englischen Patriotismus, die eng mit eher apolitischen, lebensweltlich ${ }^{195}$ unmittelbaren Alltags-Identifikationen verquickt erscheinen, kaum konzeptionell und methodisch erläutert ${ }^{196}$. Zunächst impliziert Samuels Argument das mit Nora übereinstimmende Ziel, latente nationale Denkmuster hinter den verschiedenen bildlichen und programmatischen Konkretionen bewußt zu machen ${ }^{197}$. Demgegenüber divergiert die Motivation beider Projekte für eine Synopse nationaler Sprach-, Symbol- und DenkTraditionen: Während Nora der Historisierung und Nivellierung von nationalen Gedächtnismilieus ${ }^{198}$ im Frankreich des ausgehenden 20. Jahrhunderts Rechnung tragen will, konstatiert Samuel im Großbritannien der 1980er Jahre gerade einen kompensatorisch reaktivierten Patriotismus ${ }^{199}$. Unter dem Eindruck dieses Phänomens ist Samuel bemüht, die Nation als Konstrukt und eine durch Sozialisation vermittelte Zugehörigkeitsfiktion zu entlarven ${ }^{200}$. Nationale Kultfiguren werden zwar ausgemacht, aber nicht mit Denkmälern in Verbindung gebracht. Eher interessiert die literarische, publizistische und karikaturistische Präsenz von »Everyman figures« als zeitgenössischen Medien des nationalen Selbst- und Fremdbildentwurfs, deren »cross-class appeal« erklärungsbedürftig erscheint ${ }^{201}$. Dabei votiert Samuel weniger für einen historischen als einen anthropologisch-folkloristischen Ansatz, weil nur so die Grenzen nationaler Kulturen zu transzendieren und vergleichende Perspektiven möglich seien ${ }^{202}$. Der Verzicht auf die Einbeziehung von Denkmalpersonal wird nicht begründet, resultiert aber erkennbar aus der Absicht, anders als bei Noras Lieux de mémoire jedwede Form der staatlich-offiziell beeinflußten

${ }^{194}$ Vgl. Raphael SAMUEL (Hg.), Patriotism: The making and unmaking of British National Identity, Bd. 1: History and Politics, Bd. 2: Minorities and Outsiders, Bd. 3: National Fictions, London 1989; vgl. v.a. DERS., Introduction: exciting to be English, in: DERS. (Hg.), Patriotism 1, S. XVIII-LXVII, hier vor allem S. LVIII-LX.

${ }^{195}$ Vgl. v.a. Rudolf VIERHAUS, Die Rekonstruktion historischer Lebenswelten. Probleme moderner Kulturgeschichtsschreibung, in: Hartmut LEHMANN $(\mathrm{Hg}$.), Wege zu einer neuen Kulturgeschichte, Göttingen 1995 (Göttinger Gespräche zur Geschichtswissenschaft 1), S. 7-28, hier S. 13-17.

${ }^{196}$ Mangelhafte Begriffsschärfe beklagt David CANNADINE, Patriotism, in: DERS., History in our time, New Haven und London 1998, S. 89-95, hier S. 91.

${ }^{197}$ Vgl. SAMUEL, Introduction: exciting, S. XXXII.

${ }^{198}$ Vgl. NORA, Entre mémoire et histoire, S. XVII.

199 Vgl. SAMUEL, Preface, in: Ders. (Hg.), Patriotism Bd. 1, S. X. Samuel nennt die Verarbeitung des Falkland-Krieges in Großbritannien als Initialereignis einer massiven Polarisierung und Politisierung

${ }^{200}$ Vgl. DERS., Preface, S. XV. Freilich teilen nicht alle Autoren der Bände Samuels streng konstruktivistische Position, vgl. ibid. S. XVIf.

${ }^{201}$ Vgl. DERS., Introduction: The figures of national myth, in: DERS., Patriotism Bd. 3, S. XIXXXVI, hier S. XIII-XIX.

${ }^{202}$ Vgl. ibid. S. XXXf. 
Hervorbringung nationaler Symbole, denen etwa auch die Britannia und John Bull zugerechnet werden, zugunsten eines in der "popular imagination « verankerten Personalbestands auszublenden.

Schließlich sind auch aus der Invention of tradition-Perspektive öffentliche Denkmäler nur an untergeordneter Stelle erwähnt und ohnedies nicht im Hinblick auf England, sondern eher auf Deutschland und Frankreich thematisiert worden ${ }^{203}$. Ein »revival of royal ritualism« als strategische Reaktion auf einen perhorreszierten Wandel zur Massendemokratie im Großbritannien des letzten Jahrhundertdrittels wird dann ohne Identifizierung der treibenden Akteure und Erwähnung der Denkmalpolitik veranschlagt ${ }^{204}$.

Die Bestandsaufnahme zur britischen Forschung zeigt damit insgesamt, daß hier gemessen am Stand deutscher und französischer Beiträge für einen transnationalen Denkmalvergleich die geringsten Anknüpfungsmöglichkeiten bestehen.

\section{Zum transnationalen Denkmalvergleich}

Weil Denkmalvergleiche bislang selten sind, besteht ein erhebliches analytisch-methodisches Defizit. Mit den nationsintern entwickelten und nicht europäisch kompatiblen Typologien liegen darüber hinaus keine theoretischen Reflexionen oder empirischen Tests zur Durchführung eines transnationalen Vergleichs vor. Ein analytisches Vergleichsraster ist folglich erst noch zu entwerfen.

\subsection{Vergleich}

Die folgende Untersuchungsanordnung ergibt sich aus dem Ziel, einen historischen Vergleich zu leisten, indem die Prozesse öffentlicher Denkmalerrichtung in den Hauptstädten systematisch nach Ähnlichkeiten und Unterschieden befragt werden ${ }^{205}$. Vor dem Hintergrund einer möglichst exakten Deskription, die Unterschiede und Ähnlichkeiten erst identifizierbar macht, ist analytisch nach Genesen und Bedingungen derselben zu fragen und nach Erklärungen zu suchen $^{206}$.

${ }^{203}$ Vgl. HOBSBAWM, Mass-producing traditions.

${ }^{204}$ Vgl. ibid. S. 282.

${ }^{205}$ Vgl. Marc BLOCH, Pour une histoire comparée des sociétés européennes, in: DERS., Mélanges historiques Bd. 1, Paris 1963, S. 16-40, hier S. 17; Otto HINTZE, Soziologische und geschichtliche Staatsauffassung. Zu Franz Oppenheimers System der Soziologie, in: DERS., Soziologie und Geschichte. Gesammelte Abhandlungen zur Soziologie, Politik und Theorie der Geschichte, 3 Bände, Göttingen 1962-1967, hier Bd. 2 (1964), S. 251.

${ }^{206}$ Vgl. Heinz-Gerhard HAUPT, Jürgen KOCKA, Historischer Vergleich: Methoden, Aufgaben, Probleme. Eine Einleitung, in: DIES. (Hg.), Geschichte und Vergleich. Ansätze und Ergeb- 
Im Blick auf die Vergleichsanordnung ${ }^{207}$ ist nicht die häufig praktizierte Variante der asymmetrischen Anordnung der Vergleichsobjekte vorgesehen, die empirisch vor allem auf einen Fall ausgerichtet ist und alle übrigen eher punktuell und entlang der jeweiligen nationalen Historiographien einbezieht. Ebenso soll kein summarischer thematischer Vergleich erarbeitet werden, wie er in der Forschungsliteratur häufig vorliegt, wenn Autorenkollektive Spezialstudien zu einer übergeordneten Fragestellung liefern, deren Synthese von Herausgebern in knappen Einleitungen bzw. Schlußworten kursorisch zur Sprache kommt, aber nicht systematisch geleistet wird ${ }^{208}$. Schließlich können

nisse international vergleichender Geschichtsschreibung, Frankfurt a. M., New York 1996, S. 9-45, hier S. 12f.; Wolfgang SCHMALE, Europäische Geschichte als historische Disziplin. Überlegungen zu einer "Europäistik «, in: Zeitschrift für Geschichtswissenschaft (ZfG) 46 (1998) S. 389-405, hier S. 393-395; Hartmut KAELBLE, Der historische Vergleich. Eine Einfuihrung zum 19. und 20. Jahrhundert, Frankfurt a. M. 1999; Hans-Jürgen PUHLE, Theorien in der Praxis des vergleichenden Historikers, in: Jürgen KOCKA, Thomas NIPPERDEY (Hg.), Theorie und Erzählung in der Geschichte, München 1979, S. 119-136; Hartmut BERGHOFF, Dieter ZIEGLER, Pionier und Nachzügler. Kategorien für den deutschbritischen Vergleich?, in: DIES. (Hg.), Pionier oder Nachzügler?: Vergleichende Studien zur Geschichte Großbritanniens und Deutschlands im Zeitalter der Industrialisierung, FS für Sidney Pollard (Veröffentlichungen des ADEF, 28), Bochum ${ }^{2} 1996$, S. $18 f$.

${ }^{207}$ Vgl. für eine soziologische Typologie A.A. VAN DEN BRAEMBUSSCHE, Historical explanation and comparative method: Towards a theory of the history of society, in: History and Theory 28 (1989) S. 1-24, v.a. S. 9-21; Charles TILLY, Big structures, large processes, huge comparisons, New York 1984, S. 80-85; aus der Perspektive der Politikwissenschaft Giovanni SARTORI, Compare why and how. Comparing, miscomparing and the comparative method, in: Mattei DoGAN, Ali KAZANCIGL (Hg.), Comparing Nations. Concepts, strategies, substance, Oxford und Cambridge, Mass. 1994, S. 14-34; zum historischen Vergleich von Zivilisationen vgl. Jürgen OSTERHAMMEL, Sozialgeschichte im Zivilisationsvergleich. Zu künftigen Möglichkeiten komparativer Geschichtswissenschaft, in: GG 22 (1996) S. 143-164, hier S. 151-163.

${ }^{208}$ Dies gilt zum Teil auch für die ungleichgewichtigen Beiträge in dem Sammelband von Ilja MIECK (Hg.), Paris und Berlin in der Restaurationszeit (1815-1830). Soziokulturelle und ökonomische Strukturen im Vergleich, Sigmaringen 1996; vgl. aber v.a. den Beitrag von Angelika ScHASER, Paris - Berlin: Zur Problematik des Vergleichs zweier Metropolen, ibid. S. 295-308. Systematisch vergleichend verfahren mehrere Beiträge in dem Band von Ilja MECK, Horst MÖLLER, Jürgen VOSS (Hg.), Paris und Berlin in der Revolution 1848, Sigmaringen 1995 sowie zahlreiche Beiträge in Jay WINTER, Jean-Louis ROBERT (Hg.), Capital Cities at War. Paris, London, Berlin 1914-1919 (Studies in the Social and Cultural History of Modern Warfare), Cambridge 1997, so v.a. Jay WINIER, Paris, London, Berlin 1914-1918/19: Capital cities at war, S. 3-24 mit methodischen Überlegungen zum Vergleich. Ebenso WINTER und ROBERT, Une recherche comaparative: Berlin, Londres et Paris pendant la Guerre, in: Rainer HUDEMANN, François WALTER (Hg.), Villes et guerres mondiales en Europe au XX ${ }^{e}$ siècle, Paris 1997, S. 29-48. Vgl. zur nationalen Repräsentationsarchitektur Hans OTTOMEYER, Ein Städtevergleich. Staatsarchitekturen in Paris und München 1799-1848, in: Hans-Michael KORNER, Katharina WEIGAND (Hg.), Hauptstadt. Historische Perspektiven eines deutschen Themas, München 1995, S. 95-1 16. Zu europäischen, amerikanischen, lateinamerikanischen und asiatischen Kapitalen im 20. Jh. vgl. VALE, Architecture. Zum Kapitalenvergleich aus stadtgeschichtlicher und stadtplanerischer Perspektive vgl. Anthony SUTCLIFFE, London and Paris: Capitals of the Nineteenth centu- 
Aspekte des Kulturtransfers ${ }^{209}$ im Sinne transnationaler Wechselwirkungen zwischen den drei europäischen Kapitalen höchstens punktuell als slieux de mémoire étrangère ${ }^{210}$ berücksichtigt werden. Statt dessen gilt im folgenden eine synchrone Anordnung des thematisch auf die hauptstädtischen Denkmallandschaften zugespitzten kulturgeschichtlichen Dreiländervergleichs. Die symmetrische Gleichberechtigung der drei Fälle verlangt eine weitgehend gleichgewichtige Behandlung nicht nur der Vergleichsfälle, sondern auch ihrer jeweiligen unmittelbaren historischen Kontexte. Aus diesem Umstand ergibt sich die Notwendigkeit, die Anzahl der Vergleichsfalle zu begrenzen, obgleich außer Zweifel steht, daß die Ausdehnung der vergleichenden Fragestellung nach einer nationalen Symbolik wenigstens in Richtung Süd- oder Osteuropa theoretisch wünschenswert wäre und ein dringliches Desiderat bleibt.

Der historische Vergleich ist bislang, sofern für ihn nicht nur theoretisch Lanzen gebrochen werden ${ }^{211}$, sondern er auch empirisch eingelöst worden ist, vor allem im Bereich des Vergleichs von soziopolitischen oder ökonomischen Strukturen $^{212}$, weniger hingegen im Rahmen von Ansätzen unternommen worden, die sozialhistorische mit kulturgeschichtlichen Fragestellungen kombinieren und nach kulturellen Deutungsmustern bzw. nach der gesellschaftlichen Verwendung nationaler (Denkmal)Symbole fragen ${ }^{213}$. Die Lücke zwischen

ry, Leicester (The Fifth H.J. Dyos Memorial Lecture), 1983, hier S. 2-5; Lynn LEES, Metropolitan Types. London and Paris compared, in: Harold J. DYOS, Michael WOLFF (Hg.), The Victorian City. Images and realities, Bd. 1, London und Boston 1973, S. 413-428 und im Hinblick auf europäische wie amerikanische Städte Jean-Luc PINOL, Le monde des villes au XIX ${ }^{e}$ siècle, Paris 1991, hier u. a. S. 3-9. Zur Vergleichbarkeit der Öffentlichkeit vgl. John BREUILLY, Civil society and the public sphere in Hamburg, Lyon and Manchester, 1815-1850, in: Helmut KOOPMANN, Martina LAUSTER (Hg.), Vormärzliteratur in europäischer Perspektive, Bielefeld 1996, S. 15-39. Zum asynchronen kunsthistorischen Vergleich für Frankreich ab ca. 1830, England ab 1837 und Deutschland ab 1871 vgl. Rainer SCHOCH, Das Herrscherbild in der Malerei des 19. Jahrhunderts, München 1975 (Studien zur Kunst des 19. Jahrhunderts, 23).

${ }^{209}$ Vgl. hier nur Michel ESPAGNE, Les transferts culturels franco-allemands, Paris 1999 (Perspectives germaniques), hier bes. Kap. IV, S. 75-94.

${ }^{210}$ Vgl. ibid. S. 268.

${ }^{211}$ Vgl. u. a. Dieter LANGEWIESCHE, Die Revolution von 1848/49 im europäischen Kontext. Bemerkungen zu einer Regional- und Lokalforschung in vergleichender Absicht, in: DERS. (Hg.) Demokratiebewegung und Revolution 1847 bis 1849. Internationale Aspekte und europäische Verbindungen, Karlsruhe 1998, S. 185-194.

${ }^{212} \mathrm{Vgl}$. Jürgen KOCKA, Historische Komparatistik in Deutschland, in: HAUPT, DERS. (Hg.), Geschichte und Vergleich, S. 47-60; Oliver JANZ, Probleme und Perspektiven des historischen Gesellschaftsvergleichs, in: Comparativ 5 (1995) S. 135-155, hier S. 154.

${ }^{213}$ Vgl. HAUPT, KOCKA, Historischer Vergleich, S. 39; Utz HALTERN, Krone und Palast. Zur politischen Metaphorik des Bürgertums, in: AKG 82 (2000) S. 121-155, hier S. 122f;; David G. HORN, Reading History: Towards a Comparative Cultural Studies. A review Article, in: CSSH 39 (1997) S. 734-741; William SEWELL, Sind Kulturgeschichte und die vergleichende Methode vereinbar?, in: Comparativ 1 (1998) S. 90-94; Dick GEARY, Wor- 
Einforderung und Umsetzung klafft insbesondere im Rahmen der Denkmalforschung ${ }^{214}$, die bislang auf die deutsch-französische Perspektive beschränkt bleibt. Hier wird sie tendenziell auf die Kriegerdenkmäler zugespitzt ${ }^{215}$, kann allerdings immerhin auch mit Tackes bereits erwähntem regionenspezifischen Vergleich der Hermann- und Vercingetorix-Denkmäler aufwarten, der neben den nationalen Ursprungsmythen zugleich die Frage der Kombination regionaler und nationaler Selbstzuordnung von Trägern der Denkmalbewegung berücksichtigt. Erheblich kursorischer ist demgegenüber ein erster Versuch zur Kontrastierung deutscher und italienischer Großmonumente geblieben ${ }^{216}$. Als Beitrag zum Ausgleich der skizzierten Schieflage im internationalen Vergleich national intendierter Denkmäler versteht sich die vorliegende Untersuchung.

\subsection{Eingrenzungen}

\subsubsection{Länderauswahl und Hauptstädte}

Die Länderauswahl für den vorliegenden Vergleich orientiert sich an den bisherigen Typologiebildungen zum europäischen Nationalismus im 19. Jahrhundert, indem sie nicht deren Hypothesen, wohl aber deren prominente Exempel herausgreift, die in der binären Entgegensetzung von erfolgreich-demokratischem Nationalismus des Westens und ebenso verspätetem wie autoritärem Nationalismus in Deutschland thematisiert worden sind. Die Zuspitzung auf den Denkmalvergleich in den Kapitalen versteht sich dann auch als Testfrage an die Tragweite der idealtypischen Polarisierung und historiographischen Konstruktion nationaler Entwicklungsstandards, die die Typologien mittransportieren. Seit Meinecke firmieren Deutschland und Frankreich als gegensätzliche »Kultur«- bzw. "Staatsnationen«, die durch Sprache, gemeinsame Geschichte und Kultur zum einen, durch die Ideen von 1789 und Ideale von Selbstbestimmung und Souveränität zum anderen zusammengehalten wer$\operatorname{den}^{217}$. In Kohns Typologie kehrt das historiographische Muster wieder, indem Frankreich und England einem subjektiven, rational-demokratischen, westli-

king-class identities in Europe, 1850-1914, in: Mary FULBROOK (Hg.), National histories and European history, London 1993, S. 204-215, hier S. 213.

${ }^{214}$ Vgl. AGULHON, La »statuomanie«, S. 154; Wolfgang HARDTWIG, Bürgertum, Staatssymbolik und Staatsbewußtsein im Deutschen Kaiserreich 1871-1914, in: GG 16 (1990) S. 269-295, hier S. 286; HAUPT, KOCKA, Historischer Vergleich, S. 19; HAUPT, TACKE, Die Kultur des Nationalen, S. 266

${ }^{215}$ Vgl. Reinhart KOSELleCK, Einleitung, in: JeISMANN, DERS., (Hg.), Der politische Totenkult, S. 9-20, und JEISMANN, WESTHEIDER, Wofür stirbt der Bürger.

${ }^{216} \mathrm{Vgl}$. BAUER, Gehalt und Gestalt.

${ }^{217}$ Vgl. Friedrich MEINECKE, Weltbürgertum und Nationalstaat. Studien zur Genesis des deutschen Nationalstaates, München, Berlin ${ }^{3} 1915$, S. 5 und $7 f$. 
chen $^{218}$, Deutschland hingegen einem objektiven, kulturell-irrationalen, östlichen Nationalismus ${ }^{219}$ zugeordnet werden. Obwohl die idealtypische Differenzienung relativiert wurde ${ }^{220}$, ist die Kultur-/Staatsnation-Formel vielfach aufgegriffen worden ${ }^{221}$ und prägt noch jüngere Typologiebildungen ${ }^{222}$. Auch Theodor Schieder identifiziert bei aller Binnendifferenzierung, die sein Erklärungsmodell darüber hinaus enthält, Frankreich und England als demokratischemanzipatorische sintegrierende» Nationalstaaten, Deutschland hingegen als Inbegriff des »unifizierenden«, aus einem vorstaatlich-kulturellen Nationsverständnis erwachsenden Nationalstaats ${ }^{223}$.

Die Plausibilität, mit der sich die Begriffsdichotomie an prominenter Stelle auf Ernest Renan stützt, ist längst angezweifelt worden. Der prominente Rückgriff auf dessen Diktum von der Nation als »plébiscite de tous les jours ${ }^{224}$ hat in den Hintergrund gedrängt, daß auch diese Terminologie nicht im histori-

${ }^{218}$ Vgl. Hans KOHN, Die Idee des Nationalismus. Ursprung und Geschichte bis zur Französischen Revolution, Frankfurt a. M. 1962, S. 17, 25, 195, 222, 309-312, 434f. [engl.: The Idea of Nationalism. A study in its origins and backgrounds, New York 1948].

${ }^{219} \mathrm{Vgl}$. ibid. S. 334f. und 424f.

${ }^{220}$ Es wird ausdrücklich darauf hingewiesen, ndaß die Kulturnation zugleich Staatsnation sein kann, so daß man oft nicht weiß, was sie stärker zusammenhält«; vgl. MEINECKE, Weltbürgertum und Nationalstaat, $S .3$.

${ }^{22 !}$ Vgl. LANGEWIESCHE, Nation, Nationalismus, Nationalstaat, S. 199. Etwa LEPSIUS, Nation und Nationalismus, S. 12-27, hat sich gezielt auf Meineckes Terminologie berufen, um sie um diejenige von »Volks«- und »Klassennation« zu erweitern. Vgl. die Wiederaufnahme der Dichotomie etwa auch bei Adrian HASTINGS, The construction of nationhood. Ethnicity, religion and nationalism, Cambridge 1997, S. 109.

${ }^{222}$ Die Dichotomie benutzt auch wieder Greenfeld, wenn sie den pionierhaft liberalen »individualistic civic nationalism « in England vom deutschen, kollektivistisch-autoritären und tendenziell ethnischen Nationalismus abgrenzt und Frankreich als Mischtypus dem anglo-amerikanischen Idealfall nachordnet. Vgl. Liah GREENFELD, Nationalism. Five Roads to Modernity, Cambridge, Mass. 1992, S. 14, 23, 42; DIES., Is Nation unavoidable? Is Nation unavoidable today?, in: Hanspeter KRIESI u. a. (Hg.), Nation and National Identity. The European experience in perspective, Zürich 1999, S. 37-53, hier S. 48f. Vgl. dazu kritisch David BELL, Recent Works on Early Modem French National Identity, in: JMH 68 (1996) S. 84-113, hier S. 93-97. Kritisch zu Kohn vgl. Thomas NIPPERDEY, Auf der Suche nach der Identität: Romantischer Nationalismus, in: DERS., Nachdenken über die deutsche Geschichte: Essays, München 1986, S. 110-125, hier S. 123.

${ }^{223} \mathrm{Vgl}$. Theodor SCHIEDER, Typologie und Erscheinungsformen des Nationalstaates in Europa, in: HZ 202 (1966) S. 58-81, hier v.a. S. 62-65. Die Typologie ist vielfach aufgegriffen worden, vgl. hier nur Günther LOTTES, Zur Einführung: Staat, Nation, Region - Zu den Prinzipien der Formationsgeschichte Europas, in: DERS. (Hg.), Region, S. 10-43, hier S. 30f. Vgl. kritisch Dieter LANGEWIESCHE, Staatsbildung und Nationsbildung in Deutschland - ein Sonderweg? Die deutsche Nation im europäischen Vergleich, in: Ulrike VON HIRSCHHAUSEN, Jörn LEONHARD (Hg.), Nationalismen in Europa. West- und Osteuropa im Vergleich, Göttingen 2001, S. 49-67, hier S. 56-57; DERS., Nationalismus im 19. und 20. Jahrhundert: zwischen Partizipation und Aggression, Bonn, Bad-Godesberg 1994 (Gesprächskreis Geschichte, 6), S. 17.

${ }^{224}$ Ernest RENAN, Qu'est-ce qu'une nation? Conférence faite en Sorbonne le 11 mars 1882 , Paris 1882, S. 307. 
schen Vakuum gebildet wurde, sondern 1882 dezidiert auf die revanchistische Rückforderung Elsaß-Lothringens abhob, über die auf plebiszitärem Wege entschieden werden sollte ${ }^{225}$. Schließlich spiegelt die Typologie Renans Argument durchaus ausschnitthaft wider und übergeht zahlreiche Passagen, die die Gültigkeit »objektiver« Kriterien für eine Nation nicht zwingend nachrangig verhandeln ${ }^{226}$. Darüber hinaus ist zu bedenken gegeben worden, daß die polarisierende Typologiebildung implizit oder explizit zu wertenden Bestimmung von Prototypen oder Pionieren der Nationsbildung tendiert, deren Entwicklung so normativ veranschlagt wird, da $B$ anders geartete Prozesse als "Sonderwege« von Abweichlern ausgemacht werden ${ }^{227}$. Angemessener scheint eine analytische Erwartungshaltung, die die »Geschichte der europäischen Staaten « zunächst als »Geschichte von lauter Sonderwegen ${ }^{228}$ gelten läßt. Der folgende Denkmalvergleich wird also die Typologiebildungen ebenso wie ihre Kritik mitreflektieren müssen.

Die metropolitanen Räume, deren Denkmallandschaft zu analysieren ist, stehen zum jeweiligen gesamtstaatlichen Raum in Form ihres Hauptstadtstatus in einem analogen und also vergleichbaren Bezug. Im Hinblick auf die deut-

${ }^{225}$ Vgl. Jean-Jacques BECKER, Stéphane AUDOIN-ROUZEAU, La France, la nation, la guerre: 1850-1920, Paris 1995, S. 134-141; Zeev STERNHELL, The political culture of nationalism, in: Robert TOMBS (Hg.), Nationhood and nationalism in France, London 1991, S. 22-38, hier S. 36.

${ }^{226}$ Vgl. u. a. RENAN, Qu'est-ce qu'une nation, S. 306-307; dazu HAUPT, Der Nationalismus, S. 48.

${ }^{227}$ Vgl. u. a. Winfried SchULZE, Vom "Sonderweg« bis zur "Ankunft im Westen«. Deutschlands Stellung in Europa, in: GWU 53 (2002) S. 226-240; David BLACKBOURN, Geoff ELEY, The peculiarities of German History. Bourgeois society and politics in NineteenthCentury Germany, Oxford, New York 1984; Jürgen KoCKA, Bürger und Bürgerlichkeit als Probleme der deutschen Geschichte vom späten 18. zum frühen 19. Jahrhundert, in: DERS. (Hg.), Bürger und Bürgerlichkeit im 19. Jahrhundert, Göttingen 1987, S. 21-63, hier S. 48-54; Bernd Jürgen WENDT, "Sonderweg" oder "Sonderbewußtsein«?, in: DERS. (Hg.), Vom schwierigen Zusammenwachsen der Deutschen: nationale Identität und Nationalismus im 19. und 20. Jahrhundert, Frankfurt a. M. 1992, S. 111-141. Vor dem Hintergrund seiner Denkmalanalyse argumentiert KOSHAR, From monuments to traces, S. 290 und 294 vehement gegen die Sonderweg-These. Vgl. dafür aber zuletzt wieder Heinrich August WINKLER, Der lange Weg nach Westen, Bd. 2: Deutsche Geschichte vom »Dritten Reich« bis zur Wiedervereinigung, München 2001, S. 648: »Es g a b einen `deutschen Sonderweg «.« [H. i. O.].

${ }^{228}$ SCHULZE, Staat und Nation, S. 126; vgl. auch Ludger MEES, Der spanische "Sonderweg«. Staat und Nation(en) im Spanien des 19. und 20. Jahrhunderts, in: AfS 40 (2000) S. 29 66; Bernd WEISBROD, Der englische »Sonderweg" in die neuere Geschichte, in: GG 16 (1990) S. 233-252; Bernd FAULENBACH, Die Reichsgründungsepoche als formative Phase des deutschen "Sonderwegs «? Zu Hans-Ulrich Wehlers "Deutscher Gesellschaftsgeschichte «, in: AfS 38 (1998) S. 368-384, hier S. 384; Gérard RAULET, Die Hypothek des Sonderwegs, in: DERS. (Hg.), Historismus, Sonderweg und Dritte Wege, Frankfurt a. M. u. a. 2001, S. 7-31; HAUPT, TACKE, Die Kultur des Nationalen, S. 263; BERGHOFF, ZIEGLER, Pionier und Nachzügler, S. 15-28. 
sche Situation vor 1871 ist diese Analogie gebrochen, so daß Berlin für diese Phase im Sinne eines funktionalen Äquivalents als Kapitale des mit Abstand dominantesten Einzelstaates im später gegründeten Nationalstaat einbezogen wird. $\mathrm{Daß}$ die späte Nationalstaatsgründung Berlin zur verspäteten Kapitale machte, fällt ins Gewicht, sofern erst nach der nicht ausdrücklich verfassungsrechtlich verankerten und durchaus umstrittenen politischen Entscheidung ${ }^{229}$ zugunsten der neuen Hauptstadt des kleindeutschen Reiches die politischen und administrativen Ressourcen nach Berlin gelenkt und dort konzentriert wurden, bevor sie in der Folge eine massive Sogwirkung im wirtschaftlichen, kulturellen und wissenschaftlichen Bereich entfalteten. Mit Ausnahme des in Leipzig verbliebenen Reichsgerichts avancierte Berlin also anders als Paris und London erst im letzten Jahrhundertdrittel zum Standort der nationalstaatlichen Institutionen. Andererseits begann die zunächst handelsstrategisch mit der günstigen Lage am Spreeübergang in Richtung Osten verknüpfte Erlangung eines frühen Hauptstadtstatus Berlins in der Mark Brandenburg bereits im 15. Jahrhundert. Dies begründete im 19. Jahrhundert längst das Renommee der Stadt als Wirtschafts- und Handelszentrum ${ }^{230}$ und bereits ab 1848 auch als "zweites Zentrum national koordinierter Verbands- und Parteipolitik« neben Frankfurt a.M. ${ }^{231}$. Im Vergleich dazu konnte Paris bereits unter Henri IV. als politisches, kulturelles und wirtschaftliches Zentrum Frankreichs gelten, dessen Prestigegewinn im Rahmen einer konsequenten Zentralisierungspolitik durch die französische Krone zunächst befördert, dann massiv zugunsten repräsentativer Machtpolitik genutzt wurde. Im Zuge der revolutionären Ereignisse wurde Paris im Juli 1789 offizielle Hauptstadt der französischen Nation $^{232}$ und erschien während des 19 . Jahrhunderts mindestens in politischer und kultureller Hinsicht sehr viel mehr als Zentrale, als dies für Berlin selbst

${ }^{229}$ Vgl. Gerhard BRUNN, Die deutsche Einigungsbewegung und der Aufstieg Berlins zur deutschen Hauptstadt, in: DERS., Wolfgang ScHIEDER ( $\mathrm{Hg}$.), Hauptstädte in europäischen $\mathrm{Na}$ tionalstaaten, München, Wien 1983 (Studien zur Geschichte des 19. Jahrhunderts, 12), S. 15-33.

${ }^{230}$ Vgl. Wolfgang RIBBE, Berlin im Europa der Neuzeit: Nationale Hauptstadt und europäische Metropole, in: DERS., Jürgen SCHMÄDEKE (Hg.), Berlin im Europa der Neuzeit. Ein Tagungsbericht, Berlin 1990 (Veröffentlichungen der Historischen Kommission zu Berlin, 75), S. 17-51, hier S. 23-29; SCHÄCHE, Platz für die Macht, S. 36; Lothar GaLL, Berlin als Zentrum des deutschen Nationalstaates, in: RIBBE, SCHMÄDEKE, Berlin, S. 229-238. Der Reichstag versammelt sich nach 1871 und vor dem Umzug in das Reichstagsgebäude am Königsplatz (heute Platz der Republik) 1894 zunächst im preußischen Abgeordnetenhaus am Dönhoffplatz, dann in einem provisorischen Gebäude in der Leipziger Straße.

${ }^{231}$ Vgl. Wolfgang HARDTWI, Nationsbildung und Hauptstadtfrage. Berlin in der deutschen Revolution 1848/49, in: DERS., Nationalismus und Bürgerkultur in Deutschland 15001914: Ausgewählte Aufsätze, Göttingen 1994, S. 149-164, hier S. 163.

${ }^{232}$ Vgl. Jean TULARD, La vocation révolutionnaire de Paris, in: MIECK, MÖLLER, Voss (Hg.), Paris und Berlin, S. 15-18 und Johannes WILLMS, Paris. Hauptstadt Europas, München 1988, S. 15ff. 
nach 1871 gelten konnte ${ }^{233}$. Auch London firmierte bis ins 18. Jahrhundert hinein als dominanter Faktor im regionalen wie im gesamtnationalen Rahmen, bevor sich die Beziehungen der Kapitale zum Umland komplexer gestalteten. Ungeachtet seiner massiven demographischen Sogkraft gingen aber die entscheidenden Impulse der Industriellen Revolution stärker von den Midlands und den Städten im Norden wie Liverpool, Manchester oder Birmingham aus. Die zentralen politischen Bewegungen allerdings nahmen ihren Ausgang in der Metropole ${ }^{234}$.

Varianten einer erheblichen quantitativen Aufstockung der Vergleichsfalle auf der Ebene der Länder wie der Städte sind mühelos denkbar und mit guten Gründen zu fordern. Ein dringliches Desiderat bleibt etwa die Weitung der vergleichenden Perspektive auf nationale (Denkmal)Symboliken zugunsten der osteuropäischen Nationen. Wünschenswert wäre für die ausgelassenen wie für die hier berücksichtigten Länder auch die Einbeziehung zahlreicher Provinzstädte $^{235}$ und hier besonders eine vergleichende Kontrastierung periphärer Städte insbesondere in den Grenzregionen, in denen Symbolkonkurrenzen zu erwarten $\operatorname{sind}^{236}$. Im Forschungsüberblick war allerdings zu erkennen, daß die systematischen Vergleiche angesichts des historischen Kontextuierungsgebots nur unter rigider thematischer Einschränkung durchgeführt werden konnten ${ }^{237}$. Dies gilt einmal mehr für eine vergleichende Denkmaltopographie dreier Kapitalen, die über möglichst detaillierte Daten und Kontexte zu jedem monu-

${ }^{233}$ Vgl. RrBBE, Berlin im Europa der Neuzeit, S. 34.

${ }^{234}$ Vgl. aber zurückhaltend Francis SHEPPARD, London and the Nation, in: TRHS $5^{\text {th }}$ ser. 35 (1985) S. 51-74, hier S. 56.

${ }^{235}$ Vgl. POIRRIER, VADELORGE, La statuaire provinciale, S. 242, 247 und 268.

${ }^{236}$ Vgl. Marie-Noëlle DENIS, Fêtes et manifestations dans la ville impériale de Strasbourg (1870-1918). Entre dérision et blasphème, in: Revue des Sciences Sociales de la France de l'Est 21 (1994) S. 12-17, v.a. S. 15-17; Annette MAAS, Kriegerdenkmäler und Gedenkfeiern um Metz. Formen und Funktionen kollektiver Erinnerung in einer Grenzregion (1870/71-1918), in: Rainer HUDEMANN, Rolf WITTENBROCK (Hg.), Stadtentwicklung im deutsch-französisch-luxemburgischen Grenzraum (19. und 20. Jahrundert), Saarbrücken 1991, S. 89-118; DIES., Zeitenwende in Elsaß-Lothringen. Denkmalstürze und Umdeutungen der nationalen Erinnerungslandschaften in Metz (November 1918-1922), in: Winfried SPEITKAMP (Hg.), Denkmalsturz. Zur Konfliktgeschichte politischer Symbolik, Göttingen 1997, S. 79-108.

${ }^{237}$ Auch TACKE, Denkmal im sozialen Raum, kontrastiert, freilich auf der Basis einer immens dichten Überlieferung, nicht mehr als zwei Denkmalfiguren in zwei Ländern. Die folgende Untersuchung verfügt über erheblich weniger optimale Überlieferungssituationen für ihre Anschauungsfälle, berücksichtigt dafür aber ein deutlich größeres Sample. Vgl. mit geringerer Quellendichte pro Denkmal auch SCHMOLL, Verewigte Nation, der für Württemberg in der Zeit zwischen 1800 und 1918 ein Sample von 72 Denkmälem zugrundelegt und ZELLER, Kolonialdenkmäler, der für die Phase ab 1884 über 170 Monumente in Deutschland und den Kolonien berücksichtigt. ALINGS, Monument und Nation, argumentiert demgegenüber für das gesamte Kaiserreich zwischen 1873 und 1910 mit 11 Monumenten. 
mentalen Zeichen im abgesteckten Terrain verfügen soll ${ }^{238}$. Mit der Beschränkung auf (haupt)städtisches Terrain muß auch die Perspektive auf regionale Eigenkulturen weitgehend ausgeblendet bleiben. Auszuklammern sind genauso die dynastischen oder städtischen, z.T. auch konfessionel1 ${ }^{239}$ divergenten Symboltraditionen in den deutschen Einzelstaaten vor 1871, die nicht einfach in einer Einheitsstaatsloyalität aufgingen, sondern parallel und zum Teil konkurrierend weiterwirkten ${ }^{240}$. Angesichts einer zumindest für Deutschland und Frankreich breiteren Forschung kann die Konzentration auf die Metropole hier am ehesten zugunsten wenigstens sporadischer Seitenblicke auf ähnliche oder divergente Entwicklungen andernorts ergänzt werden.

Für die Konstellation von Nation und Kapitale kann unterdessen gelten: Erstens sind die Kapitalen nicht anders als die Nation als durchaus inhomogene, ebenso Kräften der Konzentration wie der Dissoziierung ausgesetzte Phänome zu sehen. Metropolen entstanden durch Wachstum bestehender lokaler Einheiten und vor allem durch Zuwanderung von außen, bildeten also eine Summe aus lokalen communities, die spezifische soziopolitische und ökonomische Prägungen aufwiesen und Veränderungen unterlagen. Aus der Zuwanderung resultierte eine starke regionale, ethnische, religiös-konfessionelle, politische und soziale Diversifizierung ${ }^{241}$ der metropolitanen Gesellschaften, die mit Fortschreiten des Jahrhunderts zum geringsten Teil aus indigenen Gruppen bestanden. Ökonomische Zwänge und Abhängigkeiten beförderten am ehesten eine die Metropole als ganze betreffende Interessensolidarität, während soziale Ungleichheit und kulturelle Distinktion dieses Zugehörigkeitsgefühl einerseits

${ }^{238}$ Vgl. Willem FRIJHOFF, La ville: lieu de mémoire de l'Europe moderne?, in: DEN BOER, DERS. (Hg.), Lieux de mémoire, S. 61-77, hier S. 69f.

${ }^{239}$ Ausgeblendet bleiben mit dem Berliner Fallbeispiel die in überwiegend katholischen Gebieten um die Jahrhundertmitte beobachteten Anstrengungen zur Nationalisierung katholischer Heiliger und zu einer päpstlichen oder bischöflichen Jubiläumpolitik, bei der aber rasch nationale gegenüber katholischen Sinnstiftung dominierten; vgl. Barbara STAMBOLIS, Nationalisierung trotz Ultramontanisienung oder: "Alles für Deutschland. Deutschland aber für Christus«. Mentalitätsleitende Wertorientierungen deutscher Katholiken im 19. und 20. Jahrhundert, in: HZ 269 (1999) S. 57-97, hier S. 65-67 und 70-72; DIES., Religiöse Festkultur. Tradition und Neuformierung katholischer Frömmigkeit im 19. und 20. Jahrhundert: Das Liborifest in Paderborn und das Kilianfest in Würzburg im Vergleich, Paderborn u. a. 2000 (Forschungen zur Regionalgeschichte, 38). Zu konfessionellen Färbungen offentlicher Symbolpolitik vgl. Stefan LAUBE, Konfessionelle Brüche in der nationalen Heldengalerie - protestantische, katholische und jüdische Erinnerungslandschaften im deutschen Kaiserreich (1871-1918), in: Heinz-Gerhard HAUPT, Dieter LANGEWESCHE (Hg.), Nation und Religion in der deutschen Geschichte, Frankfurt, New York 2001, S. 293-332

${ }^{240} \mathrm{Vgl}$. SELLIN, Nationalismus und Partikularismus.

${ }^{241}$ Vgl. z.B. Stefi JERSCH-WENZEL, Barbara JOHN (Hg.), Von Zuwanderem zu Einheimischen. Hugenotten, Juden, Böhmen, Polen in Berlin, Berlin 1990; Dominique BOUREL, Les Juifs à Berlin et à Paris, in: MIECK, MÖLLER, Voss (Hg.), Paris und Berlin in der Revolution, S. 229-239, hier S. 230 mit statistischen Daten bis 1848. 
unterlaufen konnten, andererseits innerhalb der sozialen Segregationsgrenzen neue Homogenität und Loyalität begünstigten ${ }^{242}$. Für die drei Kapitalen ist also ebensowenig von einer per se gegebenen metropolitanen Identität einschließlich konsensfähiger Erwartungen an eine nationale Symbolik wie umgekehrt von einer kompletten Dissoziierung in Einzelinteressen und -identitäten auszugehen. Damit blieben Hauptstädte weit über ihre Eigenschaft als reine Repräsentationsstätten der zentralen politischen Kräfte hinaus polyvalente Symbolorte. Inwiefern die hauptstädtischen Monumente bis in die provinziellen Landesteile mit nationalen Ideen konnotiert wurden ${ }^{243}$, wird näherungsweise durch eine Analyse landesweit kursierender Presseorgane zu untersuchen sein.

Zweitens erlaubt aber gerade dieser Faktor einer starken Binnendifferenzierung und Disparität von Strukturen und sozialen Formationen in den Kapitalen, die landesweit vorhandene soziale, politische, konfessionelle, ethnische und andere Diversifizierungen in konzentrierter Form widerspiegelten, den hauptstädtischen Symbollandschaften eine eigene nationale Signifikanz zuzusprechen. Die spezifische Indikatorfunktion, die die Kapitalen für die Nationen hatten, lag in der differenzierten Bevölkerungsstruktur einerseits und der Zentralisierung gesamtstaatlicher Funktionsträger und Institutionen andererseits begründet, bei denen kommunale und hauptstädtische neben regionalen, womöglich internationalen und schließlich gesamtstaatlich-nationalen Interessen zusammenliefen. Schließlich sind die Kapitalen als Zentren administrativer, politischer und bürokratischer Macht sowie als Brennpunkte des nationalen, publizierenden Meinungsmarktes vergleichbar. Ein kontrollierender Zugriff zentraler Regierungen auf sie ist jeweils evident ${ }^{244}$, ohne daß damit eine vollständige Manipulierbarkeit durch staatliche Autoritäten zu unterstellen ist, zumal ähnliche Ambitionen seitens zentraler nationaler Regierungen durchaus auch im Hinblick auf provinzielle und periphere Städte bestanden ${ }^{245}$. Die Kapitalen können insofern an der Schnittstelle zwischen einer soziopolitisch und

${ }^{242}$ Vgl. John DAVIS, Reforming London. The London Government Problem 1855-1900, Oxford 1988, S. 1-9; Harold J. DYOS, Greater and greater London: metropolis and provinces in the nineteenth and twentieth centuries, in: David CANNADINE, David REEDER (Hg.), Harold J. DYOS: Exploring the urban past. Essays in urban history, Cambridge u. a. 1982, S. 37-55, hier S. 43; BRIGGS, Victorian Cities, S. 325.

${ }^{243}$ Vgl. zurückhaltend im Hinblick auf eine nationale Rezeption Berlins Hellmut SEIER, Berlin und die deutsche Nation. Die Hauptstadt und ihr Modernisierungspotential im Bewußtsein der Deutschen, in: Berlin in Geschichte und Gegenwart. Jahrbuch des Landesarchivs Berlin, hg. v. H. J. REICHHARDT, Berlin 1989, S. 33-52; positiver für die nationale Repräsentanz Londons David FELDMAN, Gareth Stedman JONES, Introduction, in: DIES. (Hg.), Metropolis London. Histories and representations since 1800, London und New York 1989, S. 6; skeptisch CANNADINE, The context, performance and meaning of ritual, S. 110.

${ }^{244}$ Vgl. GaLl, Berlin als Zentrum, S. 235f.; SHEPPARD, London and the Nation, S. 72; WILLMS, Paris, S. 429.

${ }^{245}$ Vgl. DYOS, Greater and Greater London, hier S. 45. 
ökonomisch je unterschiedlich geprägten »experienced community« und einer den nationalpolitischen Diskurs widerspiegelnden und selbst gestaltenden simagined community « begriffen werden ${ }^{246}$.

\subsubsection{Chronologische und thematische Präzisierung}

Die Epoche seit 1848, auf die sich nach der Zäsur der Revolutionen in den meisten europäischen Staaten die ältere Historiographie unter der Rubrik "Zeitalter des Bürgertums« bzw. »der Nationalstaaten« zugewandt hat, ist inzwischen hinsichtlich ihrer ungleichzeitigen Wandlungsprozesse und vielfach binnendifferenzierten Erscheinungsformen im politischen, sozialen, wirtschaftlichen und kulturellen Bereich als »dynamische Transformationsepoche ${ }^{247}$ apostrophiert worden. Die Bezeichnungen, die auf das Spezifikum der historischen Phase zielen, fußen in der Regel bereits auf einer dezidiert europäisch vergleichenden Perspektive auf das »lange« 19. Jahrhundert bis zum Kriegsausbruch $1914^{248}$. 1848 gilt als Bruch des europäischen politischen Systems, sofern die Revolutionen nicht einfach die Summe disparater Bewegungen bildeten, sondern eruptive Symptome einer langfristig wirkenden sozio-ökonomischen und politisch-konstitutionellen Doppelkrise darstellten ${ }^{249}$. An der Fundamentalpolitisierung nahm, wenngleich ohne entsprechende Erfahrungen, auch England teil, so daß dort ungeachtet der ausgebliebenen Revolution 1848 ebenfalls eine politische Trendwende verzeichnet werden kann, die unmittelbare Folgen in einer verstärkten Agitation für die Demokratisierung des parlamentarischen Systems und vor allem im zweiten Reform Act von 1867 zeitig$\mathrm{te}^{250}$. Der skizzierte chronologische Rahmen der Untersuchung wird aber nicht starr veranschlagt, vielmehr wird er vor allem für London und in gelegentlichen Rückgriffen auch für die beiden anderen Städte vor allem im Blick auf die Zeit vor 1848 durchlässig gehalten.

In der Darstellung werden zwei große Entwicklungsphasen voneinander abgekoppelt, die sich für Deutschland und Frankreich aus den Zäsuren der Jahre 1870/71 ergeben, die in beiden Fällen Umbruchdaten markieren und jeweils

${ }^{246}$ Vgl. WINTER, Paris, London, Berlin, S. 4f.

${ }^{247}$ Vgl. WEHLER, Deutsche Gesellschaftsgeschichte Bd. 3, S. 449.

${ }^{248}$ Vgl. zum »langen « 19. Jh. Timothy C.W. BLANNING (Hg.), The nineteenth century: Europe 1789-1914, Oxford 2000, hier S. 1-9; Lothar GALL, Europa auf dem Weg in die Moderne 1850-1890, München ${ }^{3} 1997$, S. 1-3, 103-110.

${ }^{249}$ Vgl. Wolfram SIEMANN, Die deutsche Revolution von 1848/49, Frankfurt a. M. 1985, u. a. S. $49 \mathrm{f}$.

${ }^{250}$ Vgl. Roland QUINAULT, 1848 and Parliamentary Reform, in: HJ 31 (1988) S. 831-851, hier S. 836f., 849; John SAVILLE, 1848. The British State and the Chartist Movement, Cambridge 1987, S. 220-229; Margot FINN, wA vent which has conveyed our principles«: English Radical Patriotism in the Aftermath of 1848, in: JMH 64 (1992) S. 637-659; Miles TAYLOR, The 1848 Revolutions and the British Empire, in: P\&P 166 (2000) S. 145180. 
einen nationalen Diskurs unter erheblich veränderten Bedingungen einleiteten. Mit der Zweiphasengliederung soll nun keinesfalls unterstellt werden, daß innerhalb der Perioden gleichsam diskursiver Stillstand herrschte. Eine derartige Deutung vertrüge sich insbesondere nicht mit der zweiten, vier Dekaden umfassenden Phase, während der Denkmalsetzungen und -programmatiken insbesondere in Frankreich und Deutschland in der Tat von Entwicklungen gekennzeichnet schienen. Umgekehrt waren von derartigen Veränderungen nicht alle thematischen Parameter der Nationsprogrammatik betroffen, so daß sie unter den jeweiligen thematischen Gliederungspunkten gesondert $\mathrm{zu}$ behandeln sind. Infolge ausgebliebener Regimewechsel und politischer Umbrüche während des 19. Jahrhunderts muß eine Phasenunterteilung für die Londoner Denkmallandschaft zunächst artifiziell wirken. In der Tat ließe sich weder im Hinblick auf die institutionellen Rahmenbedingungen noch auf die Formsprache der Monumente eine Zäsur rechtfertigen. Eine parallele Zuordnung des englischen Falls zur zweiten Untersuchungsphase ergibt sich demgegenüber aus zentralen Modifikationen von Zeremoniell und vor allem Festrhetorik ab Mitte der 1870er Jahre, die an entsprechender Stelle im einzelnen analysiert werden, hier aber im Vorgriff kurz zu summieren sind: Mit Beginn der 1870er Jahre zeichneten sich markante Veränderungen in der Londoner Denkmallandschaft $a b$, die nicht an Regimewechsel und Zusammenbruchs- respektive Gründungszäsuren und -erfahrungen gebunden waren, bei allem transitorischen Charakter aber deutlich identifizierbare Umschwünge markierten. Drei zentrale Wandlungen traten auf, die sich in ihrer Kombination zu einem eigenen Phasenabschnitt im monumentalen Nationsdiskurs verdichteten. Zunächst gelang es dem politischen Konservativismus, mit den beiden Statuen für Lord Derby und Benjamin Disraeli ein ausdrücklich konservatives Nationsmodell zu inszenieren. Zum zweiten differierten die Deutungsmuster im Umfeld der militärischen Figuren, die ab den späten 1880er Jahren verstärkt zu Denkmalwürde gelangten, erheblich von den Topoi, die noch in den 1860er Jahren anläßlich der Feier der Kolonialhelden benutzt worden waren. Schließlich kam es drittens langfristig zumindest seit Beginn der 1890er Jahre zur Reaktivierung eines aufwendigen Monarchiekults, mit dem die traditionelle Instanz demonstrativ Repräsentations- und Symbolterrain in Beschlag zu nehmen begann und sich damit zugleich in den nationalen Diskurs aktiv einschaltete. Einzelne Aspekte des Wandels, die die Zuordnung Londons zur Phaseneinteilung rechtfertigen, werden im empirischen Teil detaillierter dargestellt.

Deutlich geringer gewichtet als die Analyse der Textzeugnisse im Umfeld der Denkmalentstehung werden sowohl ästhetische Denkmalformen als auch die Frage nach sozialen Trägerschaften. Einen Vergleich von Trägern dreier nationaler Denkmalbewegungen läßt die Überlieferungslage nicht zu. Generell sind eher die Profile von Denkmalkomitees als von Subskribenten zu ermitteln gewesen, so daß volle Einsicht in die soziale und/oder politische Reichweite 
finanzieller Beteiligung schwer zu gewinnen ist. Häufig enthalten Listen ohnedies nur (Nach-)Namen, nicht aber Berufsbezeichnungen, so daß soziale $\mathrm{Zu}$ gehörigkeiten nicht verifiziert werden können. Weil Subskriptionslisten selten periodisch, sondern unregelmäßig bereits Jahre vor der Denkmalerrichtung und unabhängig voneinander in mehreren Gazetten publiziert wurden, können sie nicht systematisch recherchiert werden. Über vorsichtige Tendenzaussagen ist daher im Blick auf die Sozialprofile nicht hinauszugelangen.

Eine letzte Präzisierung betrifft sowohl das berücksichtigte Terrain als auch die Kategorie untersuchter Denkmäler. Mit dem hauptstädtischen Denkmalareal sind für Paris die Mitte der 1860er Jahre gültig definierten 20 Arrondissements, für Berlin die 1861 festgelegte und bis 1920 geltende Begrenzung des Stadtbildes vor der administrativen Einführung von Groß-Berlin 1920 und für London die Ausdehnung in die seit 1899 definierten 28 metropolitan boroughs bezeichnet. Das ohnedies erst nach 1919 jeweils expandierte Areal der metropolitanen Großräume - zum Départment de la Seine, zu Groß-Berlin ${ }^{251}$ sowie zu Greater London bleibt nicht systematisch ausgeblendet, kann aber nur fallweise berücksichtigt werden. Unter öffentlichen Standorten werden in der Regel Straßen, Plätze, Gärten und Parks gefaßt, sofern die Denkmalfiguren hier mit der wichtigen Ausnahme des Grundsteinlegungs- oder Einweihungsaktes faktisch permanent und ohne gegenständliche oder materielle Zugangsbarriere ungeachtet der sozialen oder politischen Herkunft ihrer potentiellen Betrachter und also im alltäglichen Stadtbild präsent sind. Sofern nicht genuin politische Motivationen erkennbar sind (wie dies für Paris und Berlin zeitweise gilt), bleiben Friedhöfe mit dem Argument ausgegrenzt, daß sich hier der Akt des Kommemorierens Verstorbener in der Regel in einen genuin anderen Traditi-

${ }^{251}$ Seit ihrer Gründung als Residenzstadt des Kurfürsten Friedrich Wilhelm erstreckte sich Berlin über die Bezirke der ehemals selbständigen Städte Berlin und Cölln einschließlich der landesherrlichen Neugründungen Friedrichswerder, Dorotheenstadt und Friedrichstadt. Vgl. Hans J. REICHHARDT, Die Enstehung der Verfassung von Berlin. Eine Dokumentation, Bd. 1, Berlin 1990, S. 1. Per Eingemeindung weitete sich das Areal 1861 um Moabit, Wedding, die nördlichen Teile von Schöneberg und Tempelhof, bevor 1881 auch Tiergarten, Zoo, Seepark und Schloß Bellevue integriert wurden. Der weitere Regierungsbezirk umfaßte zusätzlich etwa auch Charlottenburg im Westen, Steglitz im Süden und Tegel im Norden. Vgl. Richard DIETRICH, Verfassung und Verwaltung, in: Hans HERZFELD (Hg.), Berlin und die Provinz Brandenburg im 19. und 20. Jahrhundert, Berlin 1968 (Veröffentlichungen der Historischen Kommission zu Berlin, 25), S. 183-251, hier S. 200; REICHHARDT, Die Enstehung, S. 10f. Erst mit dem Gesetz über die Einrichtung des "Zweckverbandes Groß-Berlin« von 1911/12 wurde der Berliner Stadtkern mit Charlottenburg, Schöneberg, Wilmersdorf, Rixdorf (Neukölln), Lichtenberg, Köpenick, Spandau und den Landkreisen Teltow und Niederbarnim in den Landkreis Berlin einbezogen. Vgl. Heinrich HEFFTER, Die deutsche Selbstvenwaltung im 19. Jahrhundert. Geschichte der Ideen und Institutionen, Stuttgart 1969, S. 780. 
onszusammenhang einordnet und zugleich auf eine künstlerisch eigenwertige Form der vorrangig christlich besetzten Sepulchralskulptur zurückgreift ${ }^{252}$.

Berücksichtigt werden demgegenüber grundsätzlich alle Personendenkmäler in den Kapitalen im Untersuchungszeitraum, für die zeitgenössische Konnotationen mit dem Nations-Begriff seitens der Initiatoren und/oder Rezipienten nachweisbar sind. Unberücksichtigt bleiben alle Denkmäler, für die diese Sinnzuschreibung trotz vorhandener Quellen fehlt, weil z.B. keine öffentliche Einweihung stattgefunden hat, in deren Rahmen sich eine soziale Praxis und programmatische Sinnzuschreibungen hätten entfalten können, oder für die sie schlicht nicht in der genannten Weise intendiert waren. Weitgehend ausgeblendet bleiben notwendig auch diejenigen Denkmäler, für die keine hinreichende Dokumentierung aufgrund archivalischer und anderer Textfunde zu leisten war.

Architektonische, nicht-figürliche Monumente, wie sie die Forschung ohnedies bereits umfangreich berücksichtigt hat, bleiben mit dem Argument ausgegrenzt, daß sie in der Regel eine spezifische Verquickung von Erinnerungszeichen und kollektiver Begräbnisstätte aufweisen, die beim Personendenkmal so nicht gegeben ist. Ebenso werden zweitens Kriegerdenkmäler ausgeblendet, die zwar in den öffentlichen Raum expandierten, aber primär innerhalb von Friedhöfen oder als kirchliche Innenmonumente errichtet wurden. Der spezifischen Dimension des Totengedenkens nach folgten sie einer Eigenlogik, die anderskategorialen öffentlichen Monumenten so nicht innewohnt ${ }^{253}$. Nur gelegentlich werden die Eingrenzungen außer Acht gelassen. So kommt der Pariser Mur des Fédérés auf dem Friedhof Père Lachaise zur Sprache, der sich zum asynchronen Vergleich mit dem gescheiterten Berliner Projekt für das Märzgefallenendenkmal eignet. Ebenso wird die Berliner Invalidensäule einbezogen, weil sie als Replik zum ungebauten Revolutionsdenkmal grundlegende Deutungsverfahren und demonstrative symbolische Deutungshoheiten nach 1848 in Berlin dokumentierte. Nach den genannten Präzisierungen liegt der Untersuchung einschließlich gescheiterter Denkmalprojekte ein Sample von etwa 207 öffentlichen Denkmälern zugrunde, davon neben den nur vereinzelt erwähnten und daher nicht mitgezählten Statuen 81 in Paris, 62 in Berlin und 64 in London ${ }^{254}$.

${ }^{252}$ Vgl. AGULHON, La statuomanie, S. 145f.; Klaus HAMMER, Historische Friedhöfe und Grabmäler in Berlin, Berlin 1994, hier S. 10-16; Sibylle EINHOLZ, Was der Nachwelt bleibt - Einblicke in die Berliner Spepulchralplastik, in: BLOCH, VON SIMSON, DIES. (Hg.), Ethos und Pathos, S. 257-280; Maurice RHEIMS, Nineteenth-century sculpture, New York 1977, S. 329-335.

${ }^{253} \mathrm{Vgl}$. KOSELLECK, Kriegerdenkmale; REUSSE, Das Denkmal, S. 94-99.

${ }^{254} \mathrm{Vgl}$. die chronologische Übersicht über die berücksichtigten Denkmäler im Anhang. 


\subsection{Analytisches Raster}

1. Gegenstand der Analyse sind national intendierte Denkmäler, die zeitgenössisch gelegentlich, aber nicht konsequent als "Nationaldenkmal« bzw. "monument national« oder "national monument«, häufig aber auch nur als "national« apostrophiert oder anders mit Begriff und Idee der Nation in Verbindung gebracht wurden. Die umschreibende analytische Begrifflichkeit des national intendierten oder nationalen Denkmals soll bewußt halten, daß das im einzelnen mit der Nation Gemeinte zeitgenössisch je neu wieder explizit gemacht wurde. Weder die Referenzgröße Nation noch das ästhetische und symbolische Reservoir waren dabei immer schon objektiv etabliert und allgemein anerkannt. Als Merkmal des national intendierten Denkmals erscheint dieser Verweisungscharakter ${ }^{255}$ auf eine nicht allgemeingültig objektivierbare Größe Nation und das gleichzeitige Insistieren darauf, daß die nationale Idee in der Anschauung reflektiert und in der unterbreiteten Deutungsvariante akzeptiert werden sollte.

2. Von einer ikonographischen Analyse ${ }^{256}$ der Denkmäler wird abgesehen. Dies geschieht vor allem, weil der formalen Ästhetik der Denkmäler nur zum geringsten Teil schon gesicherte Einsichten in die programmatische Aussage zur Nation zu entnehmen sind, die aber im Zentrum des Erkenntnisinteresses dieser Studie steht. Den monumentalen Bildprogrammen wird aber durchaus eine visuelle Kommunikationsfunktion zuerkannt und folglich die Denkmäler weniger als Kunstwerke denn als visuelle Zeichen im Rahmen einer zeitgenössischen monumentalen Bildsprache gewertet, ihre Darstellungs- und Stilmittel also primär als bildrhetorische und didaktische Strategien eingeschätzt ${ }^{257}$. Um die thematische Eingrenzung der Untersuchung einzuhalten, ist nicht die gewählte Symbolik im einzelnen zu behandeln, sondern höchstens kursorisch zu berücksichtigen, ob und wie zeitgenössische Betrachter die Bildprogrammatik im Kommentar zum Denkmal und in ihrem Votum mitreflektierten.

${ }^{255}$ Vgl. NIPPERDEY, Nationalidee und Nationaldenkmal, S. 538.

${ }^{256}$ Vgl. Erwin PANOFSKY, Ikonographie und Ikonologie. Eine Einführung in die Kunst der Renaissance, in: DERS., Sinn und Deutung in der bildenden Kunst (meaning in the Visual Arts), Köln 1975, S. 36-67, hier S. 40 und v.a. S. 39-41; dazu Donald R. KELLEY, Something happened: Panofsky and cultural history, in: Irving LAVIN (Hg.), Meaning in the visual arts: views from the outside. A centennial commemoration of Erwin Panofsky, Princeton 1995, S. 113-121, hier S. 117; Francis HASKELL, History and its images: Art and the interpretation of the past, New Haven, London 1993, [dt. Die Geschichte und ihre Bilder: Die Kunst und die Deutung der Vergangenheit, München 1995], S. 9-19.

${ }^{257}$ Vgl. Heike TALKENBERGER, Von der Illustration zur Interpretation: Das Bild als historische Quelle. Methodische Überlegungen zur Historischen Bildkunde, in: ZHF 21 (1994) S. 289-313, hier S. 303. 
Künstlerisch-ästhetische Form und nationalpolitische Aussageintention der Denkmäler stehen nicht in einem mimetischen Abbildungsverhältnis ${ }^{258}$. Genausowenig bezeichnen sie gänzlich autarke Aspekte des Monuments ${ }^{259}$. So ist aus der Dominanz militärischen Personals bei den öffentlichen Denkmalehrungen an sich nicht schon auf eine militaristische Nationsidee zu schließen. Ebensowenig ist vom Ende monarchischer Nationsentwürfe in Frankreich nach 1848 zu sprechen, nur weil in der Kapitale keine Monarchenstatuen mehr zustande gekommen sind. Auch dokumentieren Mehrfachehrungen für einzelne Figuren keineswegs bereits deren zentrale Relevanz für die Nationsvorstellungen einer Gesellschaft ${ }^{260}$. Dagegen muß mit komplexen Interferenzen von ästhetischer Form, intendierter Aussage und strukturellen Entstehungs- und Wirkkontexten gerechnet werden. Ikonographie und soziopolitische Ereignisse folgten durchaus je eigenen historischen Entwicklungen ${ }^{261}$. Sie konnten - etwa im Rahmen regelmäßiger Jubiläumsfeiern im Umfeld der Monumente, sukzessiver Umdeutung, massiver Kritik oder revolutionären Sturzes der Denkmäler - produktiv oder destruktiv aufeinander bezogen, beziehungsweise entkoppelt werden, wenn das Monument wenig Aufmerksamkeit auf sich zog und am Ende in Vergessenheit geriet. Um als Symbol funktionieren zu können, mußten monumentale Form und Gehalt ebenso an entsprechende, bereits in einem hinreichenden Maße jedenfalls bei einem Teil der zeitgenössischen Betrachter vorhandene Dispositionen und Werthaltungen anknüpfen, wie sie diese umgekehrt programmatisch zu prägen suchten.

3. Der im Folgenden häufig verwendete Begriff der Kultfigur betont die mediale Funktion der personalisierten (beziehungsweise allegorischen ${ }^{262}$ ) Darstellungsform ebenso wie die soziale Kultpraxis im Rahmen ihrer feierlichen Inszenierung: Zum einen leistete die Denkmalfigur zeitgenössisch - über die allgemeine mediale Funktion der Visualisierung einer nationalen Idee hinaus die Reduktion des Komplexen und Abstrakten, das der Idee wie der Rede von der Nation eigen ist, sie personifizierte und verkörperte, sie anthropomorphi-

${ }^{258}$ Vgl. BAUER, Gehalt und Gestalt, S. 19f. und 31; Ries ROOWAN, Nationaldenkmäler zwischen Geschichte und Kunstgeschichte, in: AKG 78 (1996) S. 453-466, hier S. 461

${ }^{259}$ Vgl. NIPPERDEY, Nationalidee und Nationaldenkmal, S. 531.

${ }^{260}$ Das läßt sich am Beispiel Pariser Mehrfachehrungen zeigen. Etwa erhält hier Alfred de Musset in relativ dichter Folge um 1890, 1906 und 1910 Denkmäler, die eher das Resultat aneinander vorbeigelaufener privater Initiativen darstellen und in keinem der Fälle signifikante (national)politische Aufladungen erkennen lassen.

${ }^{261} \mathrm{Vgl}$. AGULHON, La »statuomanie«, S. 163; KOSELLECK, Einleitung, in: JEISMANN, DERS., (Hg.), Der politische Totenkult, S. 10; DERS., Kriegerdenkmale als Identitätsstiftungen, S. $257,274 \mathrm{f}$.

${ }^{262}$ Vgl. Günter HESS, Allegorie und Historismus. Zum »Bildgedächtnis« des späten 19. Jahrhunderts, in: Hans FROMM, Wolfgang HARMS, Uwe RUBERG (Hg.), Verbum et Signum, Bd. 1: Beiträge zur mediävistischen Bedeutungsforschung, München 1975, S. 555-591, hier S. 565. 
sierte $^{263}$ das nationale Identitätsstiftungsangebot. Das Personendenkmal stereotypisierte und pluralisierte zugleich das Programm und Bild der Nation, für die es dem Willen seiner Errichter zufolge stehen sollte. Zugleich konnte schon die Auswahl dieses Personals zum konfliktträchtigen Stadium der Denkmalgenese geraten. Zum anderen reflektiert der Kultfigurbegriff, daß insbesondere der Akt der Denkmaleinweihung oder andere mit dem Monument verbundene Riten der Figur einen dezidiert nationalen Symbolstatus zu verleihen versuchten, der weniger programmatisch festgeschrieben als sozial konstituiert werden sollte.

4. Die Einbeziehung von Standortaspekten trägt dem Umstand Rechnung, daß monumentale Sinnkonstruktionen und Visualisierungen von Nationsvorstellungen neben einem Vorstellungs- auch einen konkreten topographischen Raum einnahmen. Dabei ist die räumliche Dimension von Sozialhandeln nicht nur im Zusammenhang mit kultursoziologischer und kulturhistorischer Theoriebildung bereits thematisiert worden ${ }^{264}$. Eine im Rahmen der Kulturgeschichte entwickelte kritische Kartographie hat längst das Verfahren der Raummarkierung als eminent politischen Akt identifiziert ${ }^{265}$, als der sich auch die Anlegung öffentlicher Plätze und Parks ${ }^{266}$ und schließlich die exakte Positionierung von Monumenten im Stadtareal erwies. In der Tat entstand in den drei berücksichtigten Kapitalen eine Art programmatische Binnenvernetzung der Monumente nach Maßgabe einer symbolischen nationalpolitischen Kartographie $^{267}$. Dabei erschien der öffentliche Raum zum Zeitpunkt der Denkmaleinweihung in der Regel hermetisch abgeriegelt. Erst im Anschluß wurde er

${ }^{263}$ Vgl. dazu Gerd TELLENBACH: Erinnern und Vergessen. Geschichtsbewußtsein und Geschichtswissenschaft, in: Saeculum 46 (1995) S. 317-329, hier S. 327; SCHIEDER, Das deutsche Kaiserreich, S. 82; BRUNN, Germania, S. 102f.

${ }^{264} \mathrm{Vgl}$. zu BOURDIEU bereits oben; sonst James EPSTEIN, Spatial practices/democratic vistas, in: SocH 24 (1999) S. 294-320, hier S. 295 mit Anm. 5; David BLACKBOURN, A sense of place. New directions in German History, London 1999 (Annual lectures of the German Historical Institute London. The 1998 Annual Lecture), S. 16; Denis E. COSGROVE, Social formation and symbolic landscape, London und Sydney 1984, hier S. 1-5, 9.

${ }^{265}$ Vgl. hier nur Frithjof Benjamin SCHENK, Mental maps. Die Konstruktion von geographischen Räumen in Europa seit der Aufklärung, in: GG 28 (2002) S. 493-514; Jeremy BLACK, Maps and Politics, London 1997; Alan R.H. BAKER, Introduction: on ideology and landscape, in: DERS., Gideon BIGER ( $\mathrm{Hg}$.), Ideology and landscape in historical perspective. Essays on the meanings of some places in the past, Cambridge 1992, S. 1-14, hier S. 2; Stephen DANIELS, Mapping national identities: the culture of cartography, with particular reference to the Ordnance Survey, in: CUBIT (Hg.), Imagining nations, S. 112131.

${ }^{266} \mathrm{Vgl}$. R. ROSENZWEIG, The parks and the people: social history and the urban parks, in: JSocH 18 (1984) S. 289-295.

${ }^{267}$ Das Untersuchungspogramm greift skizzenhaft gebliebene Überlegungen von ARNDT, Denkmaltopographie als Programm, S. 186f., wieder auf, die dort allerdings keine Vergleichsperspektive enthalten. Vgl. Helmut ENGEL, Die Denkmäler- und Geschichtslandschaft der Mitte Berlins, in: ENGEL, RIBBE (Hg.), Hauptstadt Berlin, S. 81-87. 
weitgehend schranken- und voraussetzungslos zugänglich. Hier gerieten die Monumente in eine Sphäre öffentlichen Diskurses, die nicht für alle sozialen und politischen Gruppen gleichberechtigte Voten vorsah ${ }^{268}$. Daher waren zeitgenössische Voten zu den Monumenten oftmals bereits Teil der Konkurrenz um eine verbindliche Deutung der Nation.

5. Die Analyse öffentlicher Feste in Verbindung mit Grundsteinlegung oder Enthüllung von Denkmälern kann in allen drei Fällen in die bereits vielfach eingeübte und bewährte Praxis einer politischen, tendenziell bürgerlichen Festkultur des 19. Jahrhunderts eingeordnet werden ${ }^{269}$. Denkmalfestordnungen und verwendete Handlungs- und Symbolmuster bilden von daher einerseits reale Strukturen der jeweiligen urbanen und gesamtstaatlichen Gesellschaften ab, erfüllen andererseits aber auch eine visionäre Erfindungs-Funktion, indem sie die Nation, von der programmatisch die Rede ist, bisweilen im Zeremoniell bereits vorwegzunehmen suchen ${ }^{270}$. Riten, Symbole und Handlungsmuster, Festordnungen, Platzgestaltungen und die Beteiligung von Gästen bzw. Ausgrenzung von Zuschauern der Denkmalfeste werden also untersucht, um die nicht versprachlichte Symbolfunktion der Feste für die je thematisierten Nationskonzepte abzuschätzen ${ }^{271}$. Da in der Regel stilisierte (d.h. auch stilisiert homogene, dissensfreie), stereotypisierte repetitive Handlungsketten geplant waren $^{272}$, kommt zeitgenössischen Versuchen, diese Formalisierung zu unterbrechen, eine besondere Bedeutung $\mathrm{zu}^{273}$.

Festakte, Symbole und musikalische Umrahmung schufen einen $»$ Erlebnisraum $\aleph^{274}$, in dem die Festgemeinschaft ebenso rational-programmatisch wie

${ }^{268} \mathrm{Vgl}$. die revidierte Version des Arguments bei Jürgen HABERMAS, Strukturwandel der Öffentlichkeit. Untersuchungen zu einer Kategorie der bürgerlichen Gesellschaft, Neuauflage, Frankfurt a. M. ${ }^{3} 1993$, S. 21, 45; Geoff ELEY, Nations, Publics, and Political Cultures, in: Craigh CALHOUN u. a. (Hg.), Habermas, Boston 1992, S. 289-339, hier S. 303305; Harold MASH, Phantasies of the Public Sphere: Rethinking the Habermas of Historians, in: JMH 72 (2000) S. 153-182, hier S. 159; BREUILLY, Civil society and the public sphere, S. 35-39.

${ }^{269} \mathrm{Vgl}$. dazu die im Forschungsüberblick zur Festkultur vor allem in Deutschland bereits genannte Literatur.

${ }^{270}$ Vgl. u. a. HETTLING, NOLTE, Bürgerliche Feste als symbolische Politik, S. 7-36.

${ }^{271}$ Vgl. das Plädoyer für und die methodische Berücksichtigung von Geertz' sthick description « bei Johannes PAUlmaNN, Pomp und Politik. Monarchenbegegnungen in Europa zwischen Ancien Régime und Erstem Weltkrieg, Paderborn u. a. 2000, S. 189-194; vgl. auch DERS., Peripatetische Herrschaft, Deutungskontrolle und Konsum. Zur Theatralität in der europäischen Politik vor 1914, in: GWU 53 (2002) S. 444-461.

${ }^{272}$ Vgl. vor allem Paul CONNERTON, How societies remember, Cambridge 1989, ND 1998, S. $4 f ., 25,37 f ., 58$.

${ }^{273} \mathrm{Vgl}$. ibid. S. 44.

${ }^{274}$ Zum theoretischen Konzept des "Erlebnisraums« zur parallelen Analyse sozialer und symbolischer Strukturen vgl. Manfred HETTLING, Erlebnisraum und Ritual. Die Geschichte des 18. März 1848 im Jahrhundert bis 1948, in: Historische Anthropologie (HA) 5 (1997) S. 417-434, hier S. 420f. 
affektbezogen angesprochen wurde. Die emotionale Komponente des Denkmalfestes ist allerdings analytisch kaum zu sichern: zum einen ergibt sich das Ausmaß freigesetzter Emotion nicht aus einer Beschreibung der aufgewendeten Symbole, die keine Affekt- oder gar Legitimationsgarantie bei sich haben. Zum anderen behalten Symbole generell einen nicht vollends zu versprachlichenden Wirkeffekt, so daß sie nur näherungsweise zu erschließen sind.

6. Mehr als die Analyse der Denkmalikonographie und der rituellen Praxis einschließlich ihrer topographischen und sozialen Verortung steht nun also die Analyse der Textzeugnisse im Vordergrund, die im Zusammenhang mit der Denkmalgenese entstanden sind. Der historisch kontinuierliche und vielfach inflationäre Gebrauch des zeitgenössischen Begriffs "Nation« wird daher auf die mit ihm im Einzelfall konkret bezeichneten Identitätsangebote, Ordnungsoder Zielvorstellungen hin geprüft. Sofern mit einem spezifisch begrenzten Quellenkorpus, nämlich in der Regel unmittelbar der Entstehung, Ausführung und Inszenierung der öffentlichen Denkmäler zuzuordnenden Texten gearbeitet wird, ist keinesfalls an eine eigenständige vergleichende Begriffsgeschich$\mathrm{te}^{275}$ von »Nation« gedacht. Beabsichtigt ist dagegen eine Analyse zeitgenössischer Argumentationsmuster und rhetorischer Strategien zur inklusiven oder exklusiven Bestimmung und Legitimation der Nation, um thematische und konzeptionelle Varianten, kontinuierliche und innovative Bedeutungszuschreibungen zum mehrdeutigen Kollektivbegriff Nation herauszufilterm ${ }^{276} . \mathrm{Da} B$ alle Sprachäußerungen einer analogen Kommunikationssituation entstammen, sichert dabei ihre Vergleichbarkeit ab. Die sprachliche Konstruktion nationaler Identität erfolgt zugleich in allen Texten aus der thematischen Verknüpfung von Nation und jeweiligen Kultfiguren als "grands hommes" oder "grands patriotes«, als »nationalen Helden« und »national heroes ${ }^{277}$. Insgesamt gleichen die sozialhistorisch konstituierten metropolitanen Landschaften öffentlicher Personendenkmäler auf sprachlicher Ebene Konnotationsfeldern des zeitgenössischen Begriffs Nation: Anhand der Vielzahl von Denkmalerrichtungen durch gleiche oder ähnliche Stifter und der veröffentlichten Reaktionen von Rezipienten wird die Bedeutung des mit der Nation Gemeinten definiert und parallel zur topographischen Streuung inhaltlich ausdifferenziert oder perpetuiert und abgegrenzt.

${ }^{275}$ Vgl. Monika WIENFORT, Monarchie in der bürgerlichen Gesellschaft: Deutschland und England 1640-1848, Göttingen 1993 (Bürgertum, 4), S. 14f.

${ }^{276} \mathrm{Vgl}$. Heiner SCHULTZ, Begriffsgeschichte und Argumentationsgeschichte, in: Reinhart KOSELLECK (Hg.), Historische Semantik und Begriffsgeschichte, Stuttgart 1979, S. 43-74, hier v.a. S. 69-74. Vgl. zu einer Argumentations- oder Toposgeschichte WIENFORT, Monarchie, S. 14.

${ }^{27}$ Die folgenden Überlegungen orientieren sich am Interpretationsmodell der historischen Semantik bei Rolf REICHARDT, Einleitung, in: DERS., Eberhard SCHMIDT (Hg.), Handbuch politisch-sozialer Grundbegriffe in Frankreich 1680-1820, Heft 1/2 München 1985, S. 39-148, hier S. 62-68, 84f. 
Die Textanalyse erfolgt nach festen Kriterien. Zunächst wird geprüft, in welcher Weise die Signifikanz oder Repräsentanz der monumentalisierten Person für die Nation behauptet, wie ein nationales Leistungsprofil der Personen aus den Bereichen der Wirtschaft, Gesellschaft, Kunst oder des Militär unter Auslassung oder Einbeziehung ihres Geschlechts, ihrer (als gesamtstaatlich, regional, lokal bewerteten) Herkunft oder Konfession erstellt wurde. Damit werden zugleich Deutungsmuster ${ }^{278}$, Definitionen und inhaltliche Ausdifferenzierungen des Nationsbegriffs untersucht. Relevant ist, wie die Binnenkonstituierung der Nation bezeichnet wurde, etwa, indem weite soziale Inklusion oder politische Partizipation in Aussicht gestellt, ausgeschlossen wurden oder unerwähnt blieben. Gefragt wird nach von den Denkmalstiftern anvisierten politischen Idealen wie der klassenlosen Bürgergesellschaft oder Volksgemeinschaft, nach Homogenitätsutopien und Konformitätspostulaten, nach Strategien der Ausgrenzung, Delegitimierung oder Diffamierung von politischer, konfessioneller, sozialer oder ethnischer Differenz. Dabei ist zu berücksichtigen, daß sich die Analyse von Festschriften, Festreden und kommentierender Publizistik auf eine über weite Strecken zur liturgischen stilisierten Sprache und ein beschränktes, fast kanonisches Reservoir an Formulierungen und Topoi bezog ${ }^{279}$.

Schließlich werden die Befunde der Textanalyse ebenso wie die der rituellen Verfahrensweisen und symbolischen Darstellungsformen mit den zeitspezifischen soziopolitischen Umständen der Denkmalerrichtung in Beziehung gesetzt. Es geht hier zentral um die Frage, inwiefern die zeitgenössische Rede von der Nation bestehende soziale Ungleichheit, soziopolitischen und ökonomischen Wandel und Umbrüche mitreflektiert und sich also gemessen an ihren historischen Bedingungen progressiv, defensiv-rückwärtsgewandt oder kompensatorisch ausnimmt. Die skizzierten analytischen Schritte machen einen zeitgenössischen »Diskurs«, eine »historisch spezifische, nach bestimmten impliziten Regeln funktionierende Redeweise ${ }^{280}$ über Konzept und Idee der Nation sichtbar. Verengt auf den Ausschnitt öffentlicher PersonendenkmalSetzungen in den europäischen Hauptstädten wird er dann sowohl symbolisch-

${ }^{278} \gg$ Das Deutungsmuster leitet Wahrnehmungen, interpretiert Erfahrenes und motiviert Verhalten«. Aus analytischer Perspektive tritt es als Versprachlichung eines »kollektiven Wirklichkeitsbewußtseins « oder sozial vermittelter »Relevanzstrukturen« auf. Folglich zielt die Analyse des Deutungsmusters darauf, Verfahren historischer $\gg$ Sinnbildung und symbolischer Vergesellschaftung « offenzulegen. Vgl. Georg BOLLENBECK, Bildung und Kultur. Glanz und Elend eines deutschen Deutungsmusters, Frankfurt 1994, S. 16, 19f. In nationale Deutungsmuster gehen demnach ebenso Erfahrungen wie zukunftsgerichtete Erwartungen ein.

${ }^{279}$ Vgl. CONNERTON, How societies remember, S. 56-61.

${ }^{280}$ Peter SCHÖTTLER, Sozialgeschichtliches Paradigma und historische Diskursanalyse, in: Jürgen FOHRMANN, Harro MÜLlER ( $\mathrm{Hg}$.), Diskurstheorien und Literaturwissenschaft, Frankfurt a. M. 1988, S. 159-199, hier S. 177. 
rituell in den Festakten als auch sprachlich und rhetorisch im Rahmen der Festreden, Verlautbarungen und publizistischen Voten faßbar ${ }^{281}$.

7. Fragen der Rezeption, i.e. der gesellschaftlichen Aneignung, Ablehnung oder Ignoranz der nationalen Sinndeutungen um die öffentlichen Denkmäler bleiben in methodischer Hinsicht ein Problem ${ }^{282}$. Hier stößt die Untersuchung an die Grenze des empirisch Ermittelbaren ${ }^{283}$ : Nicht immer fiel die v.a. in der Tagespresse veröffentlichte Rezeption hinreichend explizit und nachhaltig aus, während die Ablehnung von Sinnstiftungsangeboten bisweilen durch eine gleichsam sprechende Ignoranz zum Ausdruck gebracht wurde. Darüber hinaus unterlagen kritische Voten fallweise restriktiven Bedingungen der Meinungsäußerung, die das Meinungsbild verfälschten ${ }^{284}$. Insofern ist in allen Ländern zumindest vor dem letzten Jahrhundertdrittel auch mit einer Kontrolle publizierter Voten zu rechnen, mit engeren Spielräumen für publizierbare Deutungen. Je mehr Artikulationsfreiheit die zeitgenössische Presse hatte, umso weniger stellte sie eine rein rezeptive Textsorte dar, sondern war an der Konstruktion von Deutungsmustern und am nationalen Sinnstiftungsdiskurs aktiv beteiligt ${ }^{285}$. Insofern griffen Stiftung und Rezeption nationaler Deutungsmuster zu öffentlichen Denkmälern eng ineinander ${ }^{286}$.

Die Rezeption öffentlicher Denkmäler anhand der Verbreitung von reproduzierten Miniaturen, von Lithograhien und Drucken, Postkarten ${ }^{287}$, Abbildungen

${ }^{281}$ Vgl. Ute DaNIEL, Kompendium Kulturgeschichte. Theorien, Praxis, Schlüsselwörter, Frankfurt a. M. 2001, S. 345-360; Peter SCHÓTTLER, Wer hat Angst vor dem slinguistic turn«?, in: GG 23 (1997) S. 134-151.

${ }^{282}$ Vgl. auch BAUER, Gehalt und Gestalt, S. 13; JOURDAN, Les monuments, S. 29.

283 Vgl. ibid.

${ }^{284}$ In Paris und Berlin war die Massenpresse zunächst gleichermaßen durch Dekrete und Gesetze behindert, faktisch gewährten erst die Gesetze von 1874 in Deutschland und 1881 in Frankreich eine freiere Presse. Vgl. Ursula E. KOCH, La presse et son public à Paris et à Berlin (1848/49). Une étude exploratoire, in: MIECK, MOLLER, VOSS (Hg.), Paris und Berlin, S. 19-78, hier S. 75f; Claude BELLANGER u. a. (Hg.), Histoire générale de la Presse Française, Bd. 2: De 1815 à 1871, Paris 1969, S. 313-327, 345-347; Bd. 3: De 1871 à 1940, Paris 1972, S. 135-145, 149-165; Christian DELAPORTE, Presse et culture de masse en France (1880-1914), in: Revue historique (RH) 299 (1998) S. 93-121. Zur englischen Presse u. a. Alan LEE, The structure, ownership and control of the press, 1855 1914, in: George BOYCE, James CURRAN, Pauline WINGATE (Hg.), Newspaper History from the $17^{\text {th }}$ century to the present day, London 1978, S. 117-129. Für Deutschland vgl. Heinz-Dietrich FISCHER, Handbuch der politischen Presse in Deutschland 1480-1908: Synopse rechtlicher, struktureller und wirtschaftlicher Grundlagen der Tendenzpublizistik im Kommunikationsfeld, Düsseldorf 1981, hier S. 37-89.

${ }^{285}$ Vgl. Lyn PYKETT, Reading the periodical press: text and context, in: Laurel BRAKE, Aled JONES, Lionel MADDEN, Investigating Victorian Journalism, Houndmills 1990, S. 3-18

${ }^{286} \mathrm{Vgl}$. dies ausdrücklich im Gegensatz zu ALINGS, Monument und Nation, der im Untersuchungsaufbau seiner Studie scharf zwischen Initiierung und Rezeption (in der Presse) unterscheiden will.

${ }^{287}$ Vgl. z.B. Otto MAY, Deutsch sein heißt treu sein. Ansichtskarten als Spiegel von Mentalität und Untertanenerziehung in der Wilhelminischen Ära (1888-1918), Hildesheim 1998 
in pädagogischer, Unterhaltungs- und anderer Literatur und von Photographien bleibt schließlich ebenfalls unberücksichtigt. Ohnedies belegen aber Quantum und Verteilungsdichte an sich noch keinerlei inhaltliche Identifikation mit einer nationalen Stifterprogrammatik ${ }^{288}$. Daß Prozesse der Trivialisierung von ursprünglich national intendierten Denkmälern stattgefunden haben ${ }^{289}$, die gleichwohl Phänomene einer »nationalen Kultur« in den drei beobachteten Gesellschaften bleiben ${ }^{290}$, ist anzunehmen.

\subsection{Quellen}

Die strukturelle Kontextuierung der Denkmalerrichtungen stützt sich für alle drei Hauptstädte vor allem auf archivalisches Material. Hier ist idealiter die gesamte Abfolge der Denkmalgenese von der privaten, städtischen oder staatlichen Denkmalinitiative bis zum bewilligenden (oder bei reinen Projekten verweigernden) Letztentscheid dokumentiert. So sind Initiatoren zu identifizieren und Informationen zu Entscheidungsverfahren, Kompetenzen, teilweise zur Finanzierung und Programmatik und schließlich zur Vorbereitung der Einweihungsakte zu gewinnen. Die Dokumentationsdichte ist unregelmäßig; grundsätzlich überragt die Quellenfülle für Paris diejenige für beide Vergleichsstädte bei weitem. Insbesondere erweist es sich hinsichtlich der Londoner, danach auch der Berliner Monumente als erheblich schwieriger, Initiatoren- oder Trägerprofile zu erstellen. Das Überlieferungsdefizit spiegelt im englischen Fall vor allem den Tatbestand weithin in privatem, staatsfernem Rahmen entstandener Initiativkontexte wider. Für alle drei Städte ist die Überlieferung auf staatlicher (Archives Nationales/Paris, Public Record Office/London, Royal Archives/Windsor; Geheimes Staatsarchiv PK und Bundesar-

(Untersuchungen zu Kultur und Bildung, 1); Karin WALTER, Die Ansichtskarte als visuelles Massenmedium, in: Kaspar MAASE, Wolfgang KASCHUBA (Hg.), Schund und Schönheit. Populäre Kultur um 1900, Köln, Weimar, Wien 2001 (alltag \& kultur, 8), S. 46-61.

${ }^{288} \mathrm{Vgl}$. diese Überlegungen im AnschluB an AGULHON, Marianne au pouvoir, S. 49. Zur Denkmalreproduktion allgemein vgl. Gerhard RUPP, Gips, Zink und Bronze - Berliner Vervielfältigungsfirmen im 19. Jahrhundert, in: BLOCH, EINHOLZ, VON SIMSON (Hg.), Ethos und Pathos, S. 337-351; Meinhold LURZ, Erhalt der Aura trotz technischer Reproduktion. Berliner Künstler arbeiten für die WMF, in: ibid. S. 325-336.

${ }^{289} \mathrm{Vgl}$. dazu am Beispiel von Württemberg SCHMOLL, Verewigte Nation, S. 72-78.

${ }^{290}$ Auf dem Hintergrund dieser Einschätzung ist schwer vorstellbar, wie das überzeugende Postulat von HAUPT, TACKE, Die Kultur des Nationalen, S. 278f., empirisch einzulösen wäre, nach Verwendungsweisen einer nationalen Denkmalsymbolik gerade auch im zunächst noch privaten Raum zu suchen, um die wechselseitige Durchdringung von öffentlicher und privater Sphäre im Namen der Nation historisch nachzuweisen. Wenn auch nicht unter dezidiert kulturgeschichtlichen Vorgaben gehen DARBY, SMTTH, The cult of the Prince Consort, hier S. 58-105, in diese Richtung, indem sie den Kult um den Prince Consort Albert nach dessen Tod anhand einer exzessiven Konjunktur von Memorialobjekten (Miniaturen, Medaillons etc.) verfolgen. 
chiv/Berlin, Brandenburgisches Landeshauptarchiv/Potsdam) und kommunaler (v.a. Archives de Paris, Direction des affaires culturelles/Paris; Metropolitan Archives, Corporation of London Record Office/London; Landesarchiv/Berlin) Ebene geprüft worden.

Bei den gedruckten Quellen liegen gute analytische Konditionen im Falle der Festschriften vor, die oft nicht nur Denkmalstifter und Komitees identifizieren, sondern das Prozedere der Denkmaleinweihung einschließlich einer wörtlichen Wiedergabe der Reden schildern und rituelle Elemente und Symbole sowie das Denkmal selbst beschreiben. Der analytische Erkenntniswert von Texten sinkt dabei mit einem deskriptiven, fiktional-narrativen oder anekdotenhaften Stil, steigt hingegen, wenn politisch reflektiert oder dezidiert gewertet und kommentiert wird. Sofern diese Texte wie die Zeitungsartikel stark an den situativen Kontext der Denkmalgenese in ihren verschiedenen Stadien gekoppelt bleiben, sind sie für die drei Länder während der zweiten Jahrhunderthälfte nicht repräsentativ, dürfen aber für die spezifische Frage nach dem Verhältnis von Nation und Denkmal und für einen konventionalisierten "gesellschaftlichen Sprachgebrauch ${ }^{291}$ durchaus als signifikant gelten.

Daneben werden zeitgenössische Diskurse auf der Ebene erstens involvierter städtischer, dann auch der staatlichen parlamentarischen Gremien einbezogen. Auf städtischer Ebene erwiesen sich die Akten (Procès-verbaux des débats) des Conseil Municipal de la Ville de Paris ${ }^{292}$ als mit weitem Abstand ertragreichste Dokumentationsreihe für die Jahre nach 1871, während die Sitzungsberichte (Minutes) des Metropolitan Board of Works wie des London County Council nur geringfügige Befunde liefern. Die substanzielleren, aber wenig umfangreichen Sequenzen zu öffentlichen Denkmälern im Rahmen der Berichte über die Tagungen der Berliner Stadtverordnetenversammlung können durch Überlieferungen aus dem Landesarchiv ergänzt werden. Diese Gewichtung verkehrt sich auf der Ebene der Parlamentsdebatten, sofern hier die Hansard-Akten der Parliamentary Debates am ertragreichsten erscheinen, während die Sichtung des Journal Officiel für Frankreich fast ergebnislos geblieben ist; dies gilt ebenso für die Stenographischen Berichte über die Verhandlungen des preußischen Landtages und wird geringfügig besser bei den Berichten über die Reichstagsverhandlungen.

Die Recherche nach Artikeln in der politischen Tagespresse erfolgte unter der Voraussetzung, daß relevante Festdaten vorlagen. Ein darüber hinausgehender unsystematischer Zugriff ist arbeitsökonomisch nicht praktikabel. Presseorgane werden dann nach dem Kriterium möglichst überregionaler Mas-

291 Vgl. REICHARDT, Einleitung, S. 65f.

${ }^{292}$ Aufgrund des Brandes des Hôtel de Ville 1871 ist die Überlieferung praktisch komplett verloren gegangen. Zur Überlieferungssituation städtischer Dokumente bis 1870 vgl. Pierre CASSELLE, Les publications officielles parisiennes: une source pour l'histoire de la capitale entre 1800 et 1870, in: Recherches Contemporaines 2 (1994) S. 131-147. 
senverbreitung, größtmöglicher Repräsentativität für das politische Meinungsspektrum einer Gesellschaft und weitgehend kontinuierlicher Erscheinungssequenz im untersuchten Zeitraum konsultiert, ohne nuancierten Verästelungen der politischen Lager jeweils mit einem eigenen Presseorgan Rechnung tragen zu können. Berücksichtigt werden für Frankreich ${ }^{293}$ vor allem der eher linksrepublikanische Petit Journal und Le Siècle, die katholisch-ultramontan geprägten Blätter L'Univers, L'Union und La Croix und der monarchistisch (bonapartistisch) ausgerichtete Gaulois, weiter der gemäßigt konservative Constitutionnel, der liberale Temps sowie die extrem links positionierten Organe Le Rappel und La Bataille. Wichtig sind für Deutschland ${ }^{294}$ vor allem die konservative Neue Preußische Kreuzzeitung und die Norddeutsche Allgemeine Zeitung, die nationalliberale National-Zeitung, die liberale Vossische Zeitung, für das Zentrum die Germania und für die Linke der Neue Socialdemokrat sowie der Vorwärts. Als Pendant zum Petit Journal wird die Illustrirte Zeitung (Leipzig) einbezogen. Schließlich wird für England ${ }^{295}$ vor allem die eher unabhängige Times (flächendeckend für den gesamten Untersuchungszeitraum anhand der CD-Rom-Version des Palmer's Index) ausgewertet. Hinzu kommen die konservativen Blätter The Standard und Morning Post und die liberaleren Organe The Daily Telegraph, Daily Chronicle und The Daily News sowie die beiden linksorientierten Massenblätter Lloyd's Weekly Newspaper und Reynold's Weekly Newspaper. Die Illustrated London News wird als direktes Pendant zu den großen Pariser und Berliner Illustrierten berücksichtigt. Unter den periodisch erscheinenden Zeitschriften ${ }^{296}$ sind etwa die Revue des deux Mondes und das Magasin pittoresque sowie die erst liberalen, dann freikonservativen Preußischen Jahrbücher, die sozialdemokratische Neue Zeit, sowie die rechtsliberale, später konservative Gartenlaube über entsprechende Indizes ge-

${ }^{293}$ Vgl. v.a. BELlanger u. a. (Hg.), Histoire générale, Bd. 2, hier S. 207-382 und Michel SOULIE, Histoire de la Presse. Dossier du Centre International d'Etudes pédagogiques de Sèvres, Sèvres 1983, hier S. 42-70.

${ }^{294} \mathrm{Vgl}$. zu politischer Ausrichtung, Auflagenstärke und Verbreitung der Organe im einzelnen WEHLER, Gesellschaftsgeschichte, Bd. 3, S. 434-441, 1236-1249; zur Gattung der politischen Zeitschrift Wilmont HAACKE, Günter PÖTTER, Die Politische Zeitschrift 16651965, Bd. 2: 1900-1980, Stuttgart 1982, hier S. 3-29; zu den im folgenden genannten Zeitungen Heinz-Dietrich FISCHER (Hg.), Deutsche Zeitungen des 17. bis 20. Jahrhunderts, Pullach bei München 1972, S. 25-40, 177-190, 209-224, 299-314, 329-348.

${ }^{295} \mathrm{Vgl}$. zu den einzelnen Organen The Waterloo Directory of English Newspapers and Periodicals 1800-1900, 10 Bände, North Waterloo, Ontario 1997; generell Michael HARRIS, London's Local Newspapers: patterns of change in the Victorian Period, in: BRAKE, JONES, MADDEN (Hg.), Investigating Victorian Journalism, S. 104-119; Lucy BROWN, The growth of a National Press, in: ibid. S. 133-140.

${ }^{296} \mathrm{Vgl}$. Rüdiger VOM BRUCH, Kunst- und Kulturkritik in führenden bildungsbürgerlichen Zeitschriften des Kaiserreichs, in: Ekkehard MAI u. a. (Hg.), Ideengeschichte, S. 313-347; John MASON, Monthly and Quarterly Reviews 1865-1914, in: BOYCE, CURRAN, WINGATE (Hg.), Newspaper History, S. 281-293. 
sichtet worden ${ }^{297}$. Der inzwischen als CD-Rom-Version nutzbare WellesleyIndex erlaubte eine systematische Suche von Artikeln in den wichtigsten englischen Quarterlies unterschiedlichster politischer Provenienz, die am ehesten beim moderat liberalen Nineteenth Century zu Hinweisen führte. Sporadisch ist das Spektrum der genannten, hauptsächlich konsultierten Publikationen, zugunsten weiterer politischer Zeitungen und stichprobenartig auch einer einschlägigen künstlerischen Fachpresse wie etwa den Kunstzeitschriften $L ' A r$ tiste, Kunst fur Alle und The Builder ausgedehnt worden. Ausgelassen werden demgegenüber dezidiert literarische Textsorten wie Theaterstücke, Dichtung und bis auf wenige Ausnahmen auch fiktionale Prosa, die dem Genre nach eigenen Regeln der Darstellung folgen.

\subsection{Themenachsen und Darstellung}

Die zentralen Themenachsen, an denen sich die Darstellung innerhalb der oben vorgestellten Analysekriterien ausrichtet, ergeben sich vor dem Hintergrund der intemationalen Nationalismusforschung. Daneben folgen die Gliederungspunkte innerhalb der beiden chronologischen Untersuchungsabschnitte aber vor allem quellennah den thematischen Schwerpunkten zeitgenössischer Konnotierungen der Denkmalfiguren.

1. Zeitgenössische öffentliche Denkmaldeutungen beziehen die Nation regelmäßig auf den Krieg. Diesen Zusammenhang unterstellen in der Tat bereits zahlreiche Nationalismustheorien ${ }^{298}$. Ebenso haben historische Darstellungen zur Entwicklung der europäischen Nationen zumindest für die Phase der Nationalstaatsbildung Kriegen eine Katalysatorrolle zugewiesen ${ }^{299}$. Nicht nur für den preußischen ${ }^{300}$, sondern auch für den nichtpreußischen Nationalismus seit den Befreiungskriegen ist ein massives »Kriegerethos« als konstitutiver Faktor unterstellt worden ${ }^{301}$. Eine formative Rolle wird dem Krieg auch bei der Kon-

${ }^{297}$ Vgl. dazu Kirsten BELGUM, Displaying the Nation: A view of nineteenth-century monuments through a popular magazine, in: Central European History (CEH) 26 (1993), S. 457-474.

${ }^{298}$ Vgl. etwa SMTTH, Nationalism, S. 140; Jörg ECHTERNKAMP, Sven Oliver MÜLLER, Perspektiven einer politik- und kulturgeschichtlichen Nationalismusforschung. Einleitung, in: DIES. (Hg.), Die Politik der Nation, S. 1-24, hier S. 1-2.

${ }^{299}$ Vgl. etwa SchUlze, Staat und Nation, S. 126; LANGEWIESCHE, Nation, S. 195; René GIRAULT, Guerres et sentiment national au XIX ${ }^{\mathrm{e}}$ siècle, in: RHMC, supplément 43 (1996) S. 14-21.

${ }^{300}$ Vgl. Dieter LANGEWIESCHE, Reich, Nation und Staat in der deutschen Geschichte, in: HZ 254 (1992) S. 341-381, hier S. 355.

${ }^{301}$ Vgl. Dietmar KLENKE, Zwischen nationalkriegerischem Gemeinschaftsideal und bürgerlich-ziviler Modernität. Zum Vereinsnationalismus der Sänger, Schützen und Turner im Deutschen Kaiserreich, in: GWU 45 (1994) S. 207-223, hier S. 211, 223; Frank BECKER, Bilder von Krieg und Nation. Die Einigungskriege in der bürgerlichen Öffentlichkeit Deutschlands 1864-1913, München 2001 (Ordnungssysteme. Studien zur Ideengeschichte 
stituierung eines britischen, dezidiert insularen und protestantischen nationalen Selbstbildes unter dem umfassenden Eindruck der Kriege gegen Frankreich um die Wende vom 18. zum 19. Jahrhundert bescheinigt (»invention by war $)^{302}$. Der französischen Nationalbewegung ist vor allem für die Phase nach 1871 unterstellt worden, unter der Last der Kriegsniederlage in Richtung eines rigiden Revanchismus und Militarismus mutiert zu $\operatorname{sein}^{303}$.

2. Weiter wird auf die Verbindung geachtet, die die Denkmalprogramme und -inszenierungen zwischen religiösem oder laizistischem Bekenntnis einerund nationaler Loyalität andererseits herstellen. Bezüge zwischen Nationalismus und Religion hat die moderne Forschung in zweierlei Hinsicht offengelegt. Zum einen sieht sie in der quasi-liturgischen und pseudo-sakralen Sinnstiftungsambition nationaler Bewegungen wesentliche Gründe für deren Mobilisierungserfolge ${ }^{304}$. Zum anderen stimmen die Historiographien der drei hier thematisierten Länder in dem Befund einer je spezifischen, phasenweise evidenten und/oder latenten Affinität zwischen einzelnen Konfessionen bzw. dem französischen Laizismus und der nationalen Bewegung überein ${ }^{305}$.

der Neuzeit, 7); Michael JEISMANN, Das Vaterland der Feinde. Studien zum nationalen Feindbegriff und Selbstverständnis in Deutschland und Frankreich 1792-1918, Stuttgart 1992 (Sprache und Geschichte, 19); Christoph JAHR, Uwe MAI, Kathrin ROLLER (Hg.), Feindbilder in der deutschen Geschichte. Studien zur Vorurteilsgeschichte im 19. und 20. Jahrhundert, Berlin 1994 (Zentrum für Antisemitismusforschung der Technischen Universität Berlin, 10).

${ }^{302}$ Vgl. Linda COLLEY, Britons. Forging the Nation 1707-1837, New Haven, London 1992 S. 1-9; DIES., Britishness, S. 280; DIES., The reach of the state, the appeal of the nation. Mass arming and political culture in the Napoleonic Wars, in: Lawrence STONE (Hg.), An imperial state at war. Britain from 1689 to 1815, London 1994, S. 165-184; Keith ROBBINS, An imperial and multinational polity 1832 - 1922, in: GRANT, STRINGER (Hg.), Uniting the Kingdom, S. 244-254, hier S. 248f.; Anne SUMMERS, Militarism in Britain before the Great War, in: History Workshop Journal 2 (1976) S. 104-123; DIES., Edwardian militarism, in: SAMUEL (Hg.), Patriotism I, S. 236-256; Annd BAUERKÄMPER, Die wradikale Rechte« in Großbritannien. Nationalistische, antisemitische und faschistische Bewegungen vom späten 19. Jahrhundert bis 1945, Göttingen 1991 (Kritische Studien zur Geschichtswissenschaft, 93), hier S. 11-22; Paul KENNEDY, The Pre-war Right in Britain and Germany, in: DERS., Anthony NICHOLLS (Hg.), Nationalist and racialist movements in Britain and Germany before 1914, London 1981, S. 1-20; Frans COETZEE, Marilyn Shevin COETZEE, Rethinking the Radical Right in Germany and Britain before 1914, in: JContH 21 (1986) S. 515-537, hier S. 522, 530f.; Michael RAGUSSIS, Figures of conversion. "The Jewish question « \& English national identity, Durham und London 1995, hier u. a. S. $22 \mathrm{f}$.

${ }^{303} \mathrm{Vgl}$. besonders nachdrücklich Raoul GRARDET, Le nationalisme français. Anthologie 1871-1914, Paris 1983, S. 13-15

${ }^{304} \mathrm{Vgl}$. WEHLER, Gesellschaftsgeschichte Bd. 3, S. 943-945.

${ }^{305} \mathrm{Vgl}$. Adolf M. BIRKE, Nation und Konfession. Varianten des politischen Katholizismus im Europa des 19. Jahrhunderts, in: HJb 116 (1996) S. 395-416; Volker SELLIN, Die Politik in der Neuzeit zwischen Konfessionalismus und Ideologisienung, in: Friedhelm $\mathrm{HII}$ TERHAUS, Michael ZOLLER (Hg.), Kirche als Heilsgemeinschaft - Staat als Rechtsgemeinschaft: Welche Bindungen akzeptiert das moderne Bewußtsein?, Köln 1993 
3. Denkmalsetzungen (für Frauen) gehen gelegentlich mit programmatischen Aussagen zu einer geschlechtsspezifischen Emanzipation namens der Nation einher. In der Tat ist bisher vor allem für den deutschen Nationalismus der Nachweis einer dominant männlich geprägten Ausrichtung geführt worden, sofern er erstens mit dem Hinweis auf die erforderliche Außenverteidigung der Nation einen Werte- und Tugendkanon propagierte, der primär auf die diese Abwehrfunktion leistenden Männer zielte, und sofern er zweitens zuerst ihren männlichen Mitgliedern politische Partizipationsversprechen unterbreitete ${ }^{306}$. Andererseits nahm die programmatisch-sprachliche Abdrängung des weiblichen Geschlechts auf einen privaten Separatraum ab, und führte die Aktivität etwa deutscher Frauenvereine und ein religiös-kirchliches Engagement in Frankreich langfristig zur schleichenden Integration der Frauen in den öffentlichen Raum ${ }^{307}$.

4. Bedeutsam ist darüber hinaus im Spiegel der Denkmalinitiativen wie und von wem der Nationsbegriff an bestimmte politische Meinungslager gekoppelt wird. Die Forschung hat diesen Aspekt des nationalen Diskurses immerhin zum Kriterium von Periodisierungsmodellen gemacht. Für Deutschland hat Winkler dargelegt, daß die freiheitlich-emanzipatorische Orientierung der nationalen Bewegung unter dem Eindruck der Reichsgründung »von oben« und unter der folgenden politischen Diskreditierung ihrer ehemaligen, authentischen bürgerlichen und proletarischen Träger zur zwanghaft integralen und zugleich rechtslastig antisemitischen deformiert worden $\mathrm{sei}^{308}$. Für Frankreich hat einerseits Girardet eine Vereinseitigung des französischen Nationalismus nach 1871 im Sinne revanchistisch-aggressiven Denkens veranschlagt, das im Zuge der Boulangerkrise Ende der 1880er Jahre ein eigendynamisches Poten-

(Veröffentlichungen der Hanns-Martin-Schleyer-Stiftung, 38), S. 65-72, und zahlreiche Beiträge in HAUPT, LANGEWIESCHE (Hg.), Nation und Religion. Zugleich darf das Ausmaß konfessionell bedingten binnennationalen Konsenses nicht überschätzt werden. Zur protestantischen Binnenpluralisierung als »kulturelle Versäulung" Gangolf HÜBINGER, Kulturprotestantismus und Politik. Zum Verhältnis von Liberalismus und Protestantismus im wilhelminischen Deutschland, Tübingen 1994, S. 303-313; NIPPERDEY, Deutsche Geschichte, Bd. 1: Arbeitswelt und Bürgergeist, S. 468-507; COLLEY, Britons, S. 367-368; ROBBDN, An imperial and multinational polity, S. 252

${ }^{306}$ Vgl. Ute PLANERT, Zwischen Partizipation und Restriktion. Frauenemanzipation und nationales Paradigma von der Aufklärung bis zum Ersten Weltkrieg, in: Dieter LANGEWIESCHE, Georg SCHMIDT (Hg.), Föderative Nation. Deutschlandkonzepte von der Reformation bis zum Ersten Weltkrieg, München 2000, S. 387-428.

${ }^{307}$ Vgl. ibid. S. 418-428; TACKE, Denkmal im sozialen Raum, S. 107 und vergleichend S. 13If. und 199.

${ }^{308}$ Vgl. Heinrich August WINKLER, Vom linken zum rechten Nationalismus. Der deutsche Liberalismus in der Krise von 1878/79, in: GG 4 (1978) S. 5-28; DERS., Nationalismus, Nationalstaat und nationale Frage in Deutschland seit 1945, in: DERS., Hartmut Kaelble (Hg.), Nationalismus - Nationalitäten -Supranationalität, Stuttgart 1993 (Industrielle Welt, 53), S. 12-33, hier S. 13; Otto DANN, Nationalismus und sozialer Wandel, in: DERS., Nationalismus und sozialer Wandel, Hamburg 1978, S. 77-128, hier S. 116-120. 
tial entfaltete ${ }^{309}$. Andererseits ist der französische als individualistisch-humanistischer, nicht-ethnischer und überwiegend pazifistischer Nationalismus scharf von der deutschen, ausdrücklich bereits vor dem Ersten Weltkrieg für entgleist erachteten Entwicklung abgegrenzt worden ${ }^{310}$. Anhand der Semantik von "patriotism « wird auch dem englischen Nationalismus ab Ende der 1870er Jahre eine Rechtswende von der radikaldemokratischen politischen Oppositionsbewegung zum ebenso royalistisch motivierten wie rassistisch-antisemitisch durchsetzten und militaristisch zelebrierten Konsens mit dem imperialistischen Programm der Disraeli-Regierung bescheinigt ${ }^{311}$. Aus europäischer, allerdings maximal kursorisch vergleichender Perspektive ist die These vom »Inhalts- und Funktionswandel« der Nationalismen von der »Emanzipations«zur illiberalen »Integrationsideologie« als Konsequenz der sozioökonomischen und soziokulturellen Transformationsprozesse v.a. während der letzten beiden Dekaden des 19. Jahrhunderts bestätigt worden ${ }^{312}$. Die Veränderung der Perspektive auf eine gegenteilige, gerade die Kontinuität zwischen frühem und spätem Nationalismus in Deutschland wie in Europa betonende Sicht vertritt gegenüber den Periodisierungsmodellen am nachdrücklichsten Langewiesche, der von einer fundamentalen Gleichzeitigkeit von Partizipationsverheißung und Gewaltpotential der nationalen Idee gesprochen hat ${ }^{313}$. Daß der Nationalismus im Europa des späten 19. Jahrhunderts gleichermaßen in qualitativ neue Formen der Wechselwirkung sowohl mit dem Konservatismus als auch mit dem Populismus tritt, wird aus dieser Perspektive konzediert ${ }^{314}$.

5. Schließlich wird geprüft, ob und in welcher Weise die öffentlichen Denkmalprogrammatiken und -kulte eine Affinität des Nationalismus zum Mythos erkennen lassen. Daß nationale Geschichtserzählungen und Ur-

${ }^{309} \mathrm{Vgl}$. GRARDET, Le nationalisme, S. 12-20, 276. Mit Girardet argumentiert Robert TOMBS, Preface, in: DERS. (Hg.), Nationhood, S. XI-XV; ähnlich STERNHELL, The political culture, S. 30. Vgl. auch Jacques DrOZ, Der Nationalismus der Linken und der Nationalismus der Rechten in Frankreich (1871-1914), S. 1-13, hier S. 5

${ }^{310} \mathrm{Vgl}$. Antoine PROST, The impact of war on French and German political cultures, in: HJ 37 (1994) S. 209-217, hier S. 210-213.

${ }^{311} \mathrm{Vgl}$. Hugh CUNNINGHAM, The language of patriotism, S. 70, 73, 75, 77f.; Eric EVANS, Englishness and Britishness. National identities, c.1790-c.1870, in: GRANT, STRINGER (Hg.), Uniting the Kingdom, S. 223-243, hier S. 225-231

312 Vgl. Hans-Ulrich WEHLER, Zur Funktion und Struktur der nationalen Kampfverbände im Kaiserreich, in: Werner CONZE, Gottfried SCHRAMM, Klaus ZERNACK (Hg.), Modernisierung und nationale Gesellschaft im ausgehenden 18. und im 19. Jahrhundert, Berlin 1979, S. 113-124, hier S. 118. Zum Vergleich europäischer Imperialismen John MACKENZIE, European Imperialism: Comparative Approaches, in: European History Quarterly (EHQ) 22 (1992), 415-429.

${ }^{313}$ Vgl. LANGEWIESCHE, Nationalismus im 19. und 20. Jahrhundert.

${ }^{314}$ Vgl. Barbara VOGEL, Vom linken zum rechten Nationalismus. Bemerkungen zu einer Forschungsthese, in: Bernd Jürgen WENDT (Hg.), Vom schwierigen Zusammenleben der Deutschen: nationale Identität und Nationalismus im 19. und 20. Jahrhundert, Frankfurt a. M. u. a. 1992 , S. $97-110$ 
sprungsmythen ein Phänomen nicht nur des deutschen ${ }^{315}$, sondern ebenso des englischen ${ }^{316}$ wie französischen ${ }^{317}$ Nationalismus darstellen, muß als zentrales Argument gegen eine typologische Differenzierung zwischen »objektiven « und »subjektiven « Nationen gelten ${ }^{318}$. In repetitiven, zirkulären und genealogischen Formen $^{319}$ versichert die mythische Erzählung dem Gehalt nach einer nachweislichen Authentizität und Verwurzelung als nationale Gemeinschaft, bezeugt die lineare Abkunft aus früher oder vergleichsweise naher Vorzeit, erhebt rückwärtsgewandt die ruhm- und/oder entbehrungsreiche Vergangenheit zum Referenzpunkt kollektiven Selbstwertgefühls und stellt zukunftsorientiert ein verheißungsvolles Schicksal in Aussicht ${ }^{320}$.

${ }^{315} \mathrm{Vgl}$. aber HASTINGS, The construction of nationhood, S. 109-112; sonst Ute GERHARD, Jürgen LINK, Zum Anteil der Kollektivsymbolik an den Nationalstereotypen, in: LINK, WULfFING (Hg.), Nationale Mythen, S. 16-52, hier S. 26-42; Edgar WOLFRUM, Geschichte als Waffe. Vom Kaiserreich bis zur Wiedervereinigung, Göttingen 2001, S. 1025; Otto W. JoHnston, Der deutsche Nationalmythos. Ursprung eines politischen Programms, Stuttgart 1990, hier S. 49-64, 195-242; Helga SCHULTZ, Mythos und Aufklänung. Frühformen des Nationalismus in Deutschland, in: HZ 263 (1996) S. 31-67, hier S. 31-34; Arno BORST, Barbarossas Erwachen - zur Geschichte der deutschen Identität, in: Odo MARQUarD, Karlheinz STIERLE (Hg.), Identität, München ${ }^{2} 1996$ (Poetik und Hermeneutik, 8), S. 17-60, hier S. 31-58; Andreas DÖRNER, Politischer Mythos und symbolische Politik. Der Hermannmythos: zur Entstehung des Nationalbewußtseins der Deutschen, Hamburg 1996, hier S. 160-201; Herfried MÚNKLER, Mythos und Nation, in: Vorträge der Bibliothek Warburg 1 (1996) S. 107-143.

${ }^{316}$ Vgl. Raphael SAMUEL, Paul THOMPSON, Introduction, in: DIES. (Hg.), The myths we live by, London 1990 ND 1993 (History Workshop Series), S. 1-22, hier S. 2-5; John M. MACKENZIE, Heroic myths of empire, in: DERS. (Hg.), Popular imperialism, S. 109-137; Billie MELMaN, Claiming the Nation's Past: The Invention of an Anglo-Saxon Tradition, in: JContH 26 (1991) S. 575-595; Asa BRIGGS, Saxons, Normans and Victorians, in: DERS., The collected essays of Asa Briggs, Bd. 2: Images, problems, standpoints, forecasts, Brighton, Sussex 1985, S. 215-235, hier S. 221-229; Christopher HILL, The Norman Yoke, in: DERS., Puritanism and revolution, London 1958, S. 50-122, hier besonders S. 109-122; Keith ROBBINS, Great Britain: identities, institutions, and the idea of Britishness, Harlow 1998, S. 29; Rebecca LANGLANDS, Britishness or Englishness? The historical problem of national identity in Britain, in: Nations and Nationalism 5 (1999) S. 53-69, Maike OERGEL, The redeeming Teuton: nineteenth-century notions of the, Germanic in England and Germany, in: CUBITT (Hg.), Imagining nations, S. 75-91.

${ }^{317}$ Vgl. Raoul GIRARDET, Mythes et mythologies politiques, Paris 1986, hier v.a. S. 9-24 und Eugene WEBER, Gauls versus Franks: conflict and nationalism, in: ToMBS (Hg.), Nationalism, S. 8-21. Vgl. zum Vercingetorix-Mythos TACKE, Denkmal im sozialen Raum, S. 29-44; Claude-Gilbert DuBOIS, Qu'est-ce qu'une nation? Conscience d'identité et respect de l'altérité, in: DERS., L'imaginaire de la Nation; 1792-1992. Colloque européen de Bordeaux, Bordeaux 1991, S. 19-31.

${ }^{318} \mathrm{Vgl}$. Anthony D. SMITH, The Golden Age ${ }^{2}$ and national renewal, in: Geoffrey HosKING, George SCHÖPFLIN (Hg.), Myths and Nationhood, London 1997, S. 36-59.

${ }^{319}$ Vgl. Wolf WÜLING, Karin BRUNS, Rolf PARR, Historische Mythologie der Deutschen: 1789-1918, München 1991, hier S. 1-17.

${ }^{320}$ Vgl. Wolfgang KASCHUBA, Volk und Nation: Ethnozentrismus in Geschichte und Gegenwart, in: WINKLER, KAELBLE (Hg.), Nationalismus, S. 56-81, hier besonders S. 59f. 
In der Hälfte der Fälle stimmen die skizzierten Themenachsen direkt mit den Unterkapiteln überein, weil sich eine entsprechende Prominenz der Themen unmittelbar auch im Denkmalpersonal niedergeschlagen hat. Dazu kommen weiter die Themenkomplexe erstens Nation und Revolution und zweitens Nation und Staatsordnung, die mit einem in beiden Fällen immensen monumentalen Personalaufwand am unmittelbarsten dem Umstand Rechnung tragen, daß revolutionäre Umbrüche oder danach jeweils wieder etablierte politische Ordnungen in einem höchst unterschiedlichen Maße die nationale Selbstbildprägung beeinflussen konnten. $\mathrm{DaB}$ die in je diffizilen Gemengelagen von Sieges- oder Niederlagenerfahrungen geprägten Zäsuren 1814/15, 1830, 1848, 1851/52 und 1871 in der französischen Umbruchsgeschichte die Revolutionsthematik in ungleich höherem Maße prominent machten als in England und Preußen-Deutschland, zeichnet sich hier überdeutlich $\mathrm{ab}$. $\mathrm{Zu}$ sehen ist aber auch auf die unterschiedlichen Konditionen nationaler Identifikationsmuster unter den Bedingungen monarchischer oder republikanischer Ordnungen. In einem weiteren zusätzlichen Themenkomplex Nation und Kultur spiegelt sich unterdessen der Umstand wider, daß die Situierung der Nation im Kulturellen kein Spezifikum deutscher Denkmalsetzungen blieb, sondern auch in Paris und London zu einem zentralen Thema nationaler Identifikation aufrückte, während unter der letzten zusätzlichen Themengruppe Nation und Fortschritt die Nation gleichermaßen als Phänomen und Etikett der Moderne in den Blick gerät.

Die Darstellung entlang der Themenachsen schematisiert also den Vergleich. Allerdings müssen innerhalb der beiden Hauptphasen die Chronologien gelegentlich aufgebrochen werden. Die Reihenfolge, in der die Sachgesichtspunkte zur Sprache kommen, kann nicht immer für alle drei Fälle gleichermaßen genau den Prioritäten entsprechen, die sich chronologisch nachweisbar in den jeweiligen Denkmallandschaften ergaben. Umgekehrt sollte davon abgesehen werden, die Chronologie einer der drei Städte als Richtwert zu veranschlagen und die übrigen Denkmallandschaften an ihr zu orientieren, weil so unfreiwillig eine Art Matrix-Konstruktion entstünde, an der die beiden übrigen Vergleichsfälle ohne guten Grund gemessen würden. Das analytische Vergleichsverfahren in einer systematisch-themenspezifisch gegliederten Kapitelfolge hat schließlich dazu gezwungen, über eine verbindliche Zuordnung von Denkmalpersonal zu einem der Themenkomplexe zu entscheiden, die gelegentlich auch anders hätte ausfallen können. In solchen Fällen sind für die vorgenommene Einordnung die jeweils dominanten zeitgenössischen Sinnzuschreibungen ausschlaggebend. 